\title{
Abstracts for 35th GEER-Spanish Spine Society Meeting 2021
}

\section{ORAL COMMUNICATION 1}

\section{DYNAMIC AND STATIC SAGITTAL LUMBAR APEX: A NEW CONCEPT TO ASSESS LUMBAR LORDOSIS DISTRIBUTION IN SPINAL DEFORMITY}

Authors: Iwai, Chizuo ${ }^{1}$; Pizones Arce, Javier ${ }^{2}$; Boissière, Louis ${ }^{3}$; Jakinapally, Sreenath ${ }^{3}$; Yilgor, Caglar ${ }^{4}$; Larrieu, Daniel ${ }^{3}$; Pellisé Urquiza, Ferran ${ }^{5}$; Vital, Jean Marc ${ }^{3}$; Bourghli, Anouar ${ }^{6}$; Obeid, Ibrahim $^{1}$

Affiliations: ${ }^{1}$ Hospital Universitario de Burdeos, Bordeaux, France; ${ }^{2}$ Hospital Universitario La Paz, Madrid, Spain; ${ }^{3}$ Hospital Universitario Pellegrin, Burdeos, France; ${ }^{4}$ Acibadem Maslak Hospital, Istanbul, Turkey; ${ }^{5}$ Hospital Vall d'Hebron, Barcelona, Spain; ${ }^{6}$ Hospital Kingdom, Riyadh, Saudi Arabia

Background and objectives: Sagittal lumbar apex has shown to be a key parameter in sagittal plane morphology. The aim of this study was to understand its behavior with postural changes, assessing two distinct concepts of the lumbar apex.

Materials and methods: Prospective, observational, single-center study in a cohort of patients with adult spinal deformity and sagittal malalignment. Patients $>30$ years of age, SVA $>40 \mathrm{~mm}$, and/or PT $>20^{\circ}$ were included. Whole spine radiographs were obtained in two different positions using the EOS ${ }^{\circledR}$ system: P1, maintaining a natural posture and $\mathrm{P} 2$, compensatory posture (as upright as possible). Sagittal and spinopelvic alignment parameters and two different methods for assessing the level of lumbar apex in P1 and P2 were analyzed. Student's t-test for paired samples was used to compare the changes between P1 and P2.

Results: Twenty-five patients ( 21 women, four men) were recruited. Mean age was 64.8 years (range $=21-79$ ). In compensatory $(\mathrm{P} 2)$ $(p<0.001)$ posture, increase of femoral obliqueness angle $(\Delta \mathrm{FOA}=-9.5 \pm 8.5)$, of pelvic tilt $(\Delta \mathrm{PT} /$ retroversion $=4.9 \pm 5.7)$ and consequent sacral slope decrease $(\Delta \mathrm{SS}=-6.3 \pm 8.3)$, reciprocal decrease of the lower lumbar arch $(\Delta \mathrm{LLA}=8.1 \pm 6.1)$, and increase of the lower thoracic $\operatorname{arch}(\Delta \mathrm{LTA}=8.6 \pm 6.1)$ (Table) were observed.

When the apex was taken as the most anterior lumbar point touching the vertical line in the lateral radiograph (Roussouly concept), postural compensatory changes shifted their location to a more caudal position. When the apex was calculated as the most distal point to a perpendicular line drawn to the global lumbar lordosis (line from the inflection point to the center of the sacral plate), its position remained stable regardless the compensation.

Conclusions: Postural changes shift the location of the lumbar apex if understood as the most anterior point within the harmonic distribution of the lumbar sagittal plane. This concept is useful as an additional sign to distinguish compensatory mechanisms.

However, when the apex is interpreted as the most distant angular point of global lordosis, its position remains stable regardless of any postural change. When planning a surgery, this concept allows to adequately determine its location for appropriate restoration of lumbar distribution.

Table. Analysis of the sagittal plane comparing P1-natural posture versus $\mathrm{P} 2$-compensatory posture

\begin{tabular}{|c|c|c|c|c|}
\hline Variables & $\mathrm{P} 1$ & P2 & $\begin{array}{l}\text { Difference } \\
(\Delta)\end{array}$ & $p$ value \\
\hline FOA $\left(^{\circ}\right)$ & $6.5 \pm 6.1$ & $16 \pm 8.9$ & $-9.5 \pm 8.5$ & $0.000 *$ \\
\hline PI $\left(^{\circ}\right)$ & $55.4 \pm 10.8$ & $55.2 \pm 11$ & $0.2 \pm 2.4$ & 0.683 \\
\hline PT $\left(^{\circ}\right)$ & $27.1 \pm 8.5$ & $32.1 \pm 9$ & $4.9 \pm 5.7$ & $0.000 *$ \\
\hline $\mathrm{SS}\left({ }^{\circ}\right)$ & $28.2 \pm 10.2$ & $21.9 \pm 10$ & $-6.3 \pm 8.3$ & $0.000 *$ \\
\hline SSA $\left(^{\circ}\right)$ & $107.9 \pm 14.1$ & $107.6 \pm 13.6$ & $-0.3 \pm 5$ & 0.757 \\
\hline GT $\left(^{\circ}\right)$ & $37.5 \pm 15.5$ & $37.6 \pm 15.7$ & $-0.1 \pm 0.3$ & 0.909 \\
\hline $\begin{array}{l}\text { Maximum } \\
\text { kyphosis }\left({ }^{\circ}\right)\end{array}$ & $54.2 \pm 18.7$ & $59.7 \pm 20.8$ & $5.5 \pm 10.6$ & $0.015^{*}$ \\
\hline $\begin{array}{l}\text { Upper } \\
\text { thoracic } \\
\operatorname{arch}\left({ }^{\circ}\right)\end{array}$ & $38.7 \pm 15.9$ & $34.9 \pm 16$ & $-3.8 \pm 9.7$ & 0.061 \\
\hline $\begin{array}{l}\text { Lower } \\
\text { thoracic } \\
\operatorname{arch}\left({ }^{\circ}\right)\end{array}$ & $15.9 \pm 10.8$ & $24.5 \pm 11.9$ & $8.6 \pm 6.1$ & $0.000 *$ \\
\hline $\begin{array}{l}\text { Maximum } \\
\text { lordosis }\left({ }^{\circ}\right)\end{array}$ & $45.8 \pm 4.7$ & $49.5 \pm 16.6$ & $3.6 \pm 5.3$ & $0.002 *$ \\
\hline $\begin{array}{l}\text { Upper lumbar } \\
\operatorname{arch}\left({ }^{\circ}\right)\end{array}$ & $17.5 \pm 11.2$ & $25.5 \pm 13.4$ & $8.1 \pm 6.1$ & $0.000 *$ \\
\hline $\begin{array}{l}\text { Lower lumbar } \\
\text { arch }\left({ }^{\circ}\right)\end{array}$ & $28.6 \pm 9.7$ & $23.3 \pm 9.8$ & $-5.3 \pm 4.5$ & $0.000 *$ \\
\hline
\end{tabular}




\begin{tabular}{|c|c|c|c|c|}
\hline Variables & $\mathrm{P} 1$ & P2 & Difference $(\Delta)$ & $p$ value \\
\hline Apex method 1 & & & $-1.32 \pm 1.51$ & $0.001 *$ \\
\hline Apex method 2 & & & $+0.38 \pm 0.46$ & \\
\hline
\end{tabular}

$P 1$ natural posture, $P 2$ compensatory posture, FOA femoral obliqueness angle, $P I$ pelvic incidence, $P T$ pelvic tilt, $S S$ sacral slope, $S S A$ spino-sacral angle, $G T$ global tilt

*Statistical significance

\section{ORAL COMMUNICATION 2}

\section{RISK FACTORS ASSOCIATED TO INADEQUATE CORRECTION OF PELVIC EXTENSION AS A COMPENSATORY MECHANISM IN ADULT SPINAL SURGERY}

Authors: Lombao Iglesias, Domingo ${ }^{1}$; Fernández González, Manuel ${ }^{2}$; Blanco Hortas, Andrés ${ }^{1}$; Esteban Blanco, Marta $^{2}$; Coto Caramés, Laura $^{1}$; Betegón Nicolás, Jesús ${ }^{2}$; Lozano Muñoz, Ana ${ }^{2}$; Villar Pérez, Julio $^{2}$; Hernández Encinas, José Ángel ${ }^{2}$; Gallego Díez, Leticia ${ }^{2}$

Affiliations: ${ }^{1}$ Hospital Universitario Lucus Augusti, Lugo, Spain;

${ }^{2}$ Complejo Asistencial Universitario de Leon (CAULE), Leon, Spain

Background and objectives: Retroversion or pelvic extension (PT) is the primary compensatory mechanism in cases of anterior unbalance of the trunk. In adult spinal surgery, insufficient correction of this parameter has been associated to worse clinical outcomes and higher incidence of mechanical complications.

The aim of this study was to search for possible factors linked to inadequate correction of PT tp help improve the results of surgery and reduce the incidence of adverse effects.

Materials and methods: Two cohorts were created with adult patients who had undergone spinal deformity surgery and more than 2 years of follow-up, considering postoperative PT correction (Correction Group: PT $\leq 20^{\circ}$; No Correction Group: PT $>21^{\circ}$ ).

A bivariate analysis was performed to compare the Correction Group with the collected demographic variables and reference radiological parameters (Chi-square test). Next, a multivariate model was created using logistic regression. We present the odds-ratios (OR) and confidence intervals $(\mathrm{CI})$.

Results: One hundred and ninety-two patients were included; mean age was 62.3 years $(51 \%>65$ years), $76 \%$ were women, mean of eight instrumented levels, BMI 27.6, and mean follow-up of 29.6 months (Table 1).

Bivariate analysis showed significant association of male patients aged $<65$ years, lower BMI, and better preoperative radiological findings with belonging to the Correction Group after surgery (Table 2).

However, the multivariate analysis indicated that risk factors for insufficient PT correction were being a woman $[\mathrm{OR}=2.56 ;(95 \% \mathrm{CI}$ 1.01-4.28)], worse preoperative PI-LL $[\mathrm{OR}=3.12 ; \quad(95 \%$ CI 1.04-9.75)], and particularly, worse preoperative PT $[\mathrm{OR}=6.16$; (95\% CI 3.04-15.15)].

Conclusions: This study shows that being a woman and having worse lumbopelvic mismatch (PI-LL) and pelvic extension (PT) preoperative radiological values are independent risk factors for inadequate correction of pelvic extension after adult spinal surgery.

Improve weight condition, suggest surgery at younger ages and in less advanced conditions, and careful planning of the surgery are advisable to help improve the outcome.
Table 1 .

\begin{tabular}{lc}
\hline Variable & Patients N $=192$ \\
\hline Sex (M) & $146(76.0)$ \\
Age (years) & $62.3(14.1)$ \\
Age (> 65) & $98(51.0)$ \\
BMI & $27.6(4.9)$ \\
Levels & $8.5(3.6)$ \\
Follow-up (months) & $29.6(16.4)$
\end{tabular}

Values presented as absolute cases and percentages in parenthesis (categorical variables) or means and standard deviations (continuous variables)

Table 2

\begin{tabular}{|c|c|c|c|}
\hline Measurement & Total & Correction Group & $p$ value \\
\hline Sex & & & 0.026 \\
\hline Woman & 146 & 33 (22.6) & \\
\hline Man & 46 & $18(39.1)$ & \\
\hline Age & & & 0.048 \\
\hline$<65$ & 91 & 31 (32.9) & \\
\hline$>65$ & 98 & $20(20.4)$ & \\
\hline BMI & & & 0.005 \\
\hline$<25$ & 60 & $23(38.3)$ & \\
\hline$>25$ & 120 & $23(19.1)$ & \\
\hline Pre-PT & & & $<0.001$ \\
\hline No & 133 & $18(13.5)$ & \\
\hline Yes & 58 & $33(56.9)$ & \\
\hline Pre-SVA & & & 0.045 \\
\hline No & 97 & $20(20.6)$ & \\
\hline Yes & 86 & $29(33.7)$ & \\
\hline Pre-PI-LL & & & $<0.001$ \\
\hline No & 121 & $18(14.8)$ & \\
\hline Yes & 69 & $33(47.8)$ & \\
\hline
\end{tabular}

Values presented as absolute cases and percentages in parenthesis $p$ values were calculated using the McNemar test

\section{ORAL COMMUNICATION 3}

\section{CHARACTERISTICS AND LONG-TERM IMPACT OF UNPLANNED REINTERVENTIONS FOLLOWING ASD SURGERY}

Authors: Capdevila Bayo, Maria ${ }^{1}$; Núñez Pereira, Susana ${ }^{2}$; Vila Casademunt, Alba ${ }^{1}$; Haddad, Sleiman ${ }^{3}$; Ruiz De Villa, Aleix ${ }^{1}$; Pizones Arce, Javier ${ }^{4}$; Kleinstück, Frank ${ }^{5}$; Obeid, Ibrahim ${ }^{6}$; Alanay, Ahmet $^{7}$; Pellisé Urquiza, Ferran ${ }^{3}$; ESSG, European Spine Study Group $^{8}$

Affiliations: ${ }^{1}$ Vall d'Hebron Institut de Recerca, Barcelona, Spain; ${ }^{2}$ Hospital Universitario Donostia, San Sebastián, Spain; ${ }^{3}$ Hospital Universitari Vall Hebron, Barcelona, Spain; ${ }^{4}$ Hospital Universitario La Paz, Madrid, Spain; ${ }^{5}$ Schulthess Klinik, Zurich, Switzerland; 
${ }^{6} \mathrm{CHU}$ Bordeaux, Bordeaux, France; ${ }^{7}$ Acibadem Hospital, Istambul, Turkey; ${ }^{8}$ ESSG. European Spine Study Group, Barcelona, Spain

Background and objectives: Despite the high incidence (17-36\%) of unplanned reinterventions (UR) following adult spine deformity (ASD) surgery, their long-term impact is still poorly understood. The objective of this study was to define the characteristics of reinterventions following ASD surgery as well as to identify their relationship with health-related quality of life (HRQL) measures.

Materials and methods: All patients enrolled in a prospective international multicentre ASD database, operated before March 2015, were included in the study. Linear regression models, controlling for baseline confounding data (demographic, HRQL and radiological) and index surgery characteristics, assessed the relationship between number of UR and their invasiveness on gain of HRQL at 2 and 5-year follow-up.

Results: 361 patients underwent surgery during the study period. 316 $(87.5 \%)$ met the inclusion criteria $(77.5 \%$ women, mean age 52 years, 9.2 fused levels, $36.7 \%$ pelvic fixation, $15.8 \%$ tricolumnar osteotomies); 96 (30.4\%) required at least one revision surgery, $33(10.4 \%)$ two, $17(5.4 \%)$ three, $11(3.5 \%)$ four, $6(1.9 \%)$ five, and $2(0.6 \%)$ six. Mechanical complications $(64.9 \%)$ were the most frequent cause of UR, followed by surgical-site (SS) infection (15.7\%), and neurological complications (6.5\%). UR mean blood loss (475.2 $\mathrm{ml}$ SD 624.8) and surgical time (173.7 min SD 128.7) were lower than in index surgeries (1555.9 SD 1,339.2; 312.3 SD 162.1). No differences were observed for hospital stay between index surgery and UR, except for URs due to SS-infection $(p<0.006)$. UR invasiveness and hospital stay were not associated with HRQL. The number of UR was negatively associated with all HRQL measures, and was constant over the years, independent of the time elapsed since UR $(p<0.05)$ (Table). Conclusions: UR following ASD surgery were associated with significantly lesser gains in HRQL. The association did not diminish over time, and was affected by the number, but not the UR cause. Mechanical complications were the most common cause of UR.

HRQL loss associated to each reintervention by follow-up year

\begin{tabular}{|c|c|c|c|c|c|}
\hline Follow-up year & $\begin{array}{l}\text { Average } \\
\text { gain per } \\
\text { Surgery }\end{array}$ & $\begin{array}{r}\text { HRQL } \\
\text { Index }\end{array}$ & $\begin{array}{l}\text { HRQL } \\
\text { loss per } \\
\text { UR }\end{array}$ & $\begin{array}{l}\text { Relative } \\
\text { impact* }\end{array}$ & $p$ value \\
\hline \multicolumn{6}{|l|}{$\begin{array}{l}\text { Oswestry } \\
\text { Disability } \\
\text { Index (ODI) }\end{array}$} \\
\hline 2 & -10.109 & & 4.879 & 48.3 & 0.001 \\
\hline 5 & -9.428 & & 4.695 & 49.8 & 0.001 \\
\hline \multicolumn{6}{|l|}{ SRS22-Subtotal } \\
\hline 2 & 0.659 & & -0.158 & 24.0 & 0.007 \\
\hline 5 & 0.615 & & -0.186 & 30.2 & 0.002 \\
\hline \multicolumn{6}{|l|}{ SF36-PCS } \\
\hline 2 & 5.778 & & -1.104 & 19.1 & 0.16 \\
\hline 5 & 5.349 & & -1.666 & 31.1 & 0.022 \\
\hline \multicolumn{6}{|l|}{ SF36-MCS } \\
\hline 2 & 3.786 & & -2.226 & 58.8 & 0.016 \\
\hline 5 & 3.504 & & -2.315 & 66.1 & 0.801 \\
\hline
\end{tabular}

*Percentage of health-related quality life (HRQL) loss associated to a unplanned reintervention (UR) relative to the average HRQL gain per Index surgery

\section{ORAL COMMUNICATION 4}

\section{DO THE BENEFITS OF SCOLIOSIS SURGERY IN THE ELDERLY OUTWEIGH ITS RISKS? ANALYSIS OF A SERIES OF PATIENTS OVER 80 YEARS OF AGE}

Authors: Rodríguez Arguisjuela, María $\mathrm{G}^{1}$; Gallego Bustos, Jesús ${ }^{1}$; Coifman Lucena, Ismael ${ }^{1}$; Tomé Bermejo, Félix ${ }^{2}$; Peiró García, Alejandro $^{3}$; Cano García, Sonia ${ }^{2}$; Mengis Palleck, Charles-Louis R. ${ }^{1}$; Álvarez Galovich, Luis ${ }^{1}$

Affiliations: ${ }^{1}$ Fundación Jiménez Díaz. Unidad de Pathology de Columna, Madrid, Spain; ${ }^{2}$ Hospital Universitario Fundación Jiménez Díaz. Hospital General de Villalba, Madrid, Spain; ${ }^{3}$ Hospital Sant Joan de Deu, Barcelona, Spain

Background and objectives: Surgical treatment of adult spinal deformities is complex and with high risk of complications, particularly in elderly patients. We carried out a prospective analysis of a series of consecutive cases that included 31 patients $\geq 80$ years of age with spinal deformity who underwent correction and instrumented fusion and a minimum follow-up of 2 years.

Materials and methods: Retrospective analysis of data collected prospectively from a database of adult spinal deformity, identifying patients $\geq 80$ years who underwent surgery.

Results: Thirty-one patients who had undergone surgery were included. Preoperative data: mean age was $81.9(80-86)$ years and were mostly women (27). The most frequent indication for surgery was post-traumatic kyphosis at the TL junction (45.1\%). Regarding functional parameters, significant improvements were observed in all values. Lumbar VAS scores decreased from 8.1 to 3.7 after 1 year, and 4.3 in the last revision (LR); pre-ODI was 73.1, 32.8 after 1 year, and 50.4 in the LR; COMI went from 7.9 to 3.9 after 1 year and 4.2 in the LR. Only $2 / 23$ patients continued using opioids after 1 year. Regarding spinopelvic parameters, less preoperative SVA unbalance than expected was seen, probably due to its junctional etiology and lumbar compensatory mechanisms. Number of fused levels was $7.2 \pm 3.2$ and mean hospital stay 15 days $\pm 9.2 ; 64.5 \%$ were fixed to sacrum-pelvis and in $90.3 \%$ some type of osteotomy was performed; $22.5 \%$ suffered a major perioperative complication; $29 \%$ required revision surgery; $80.6 \%$ of the patients were satisfied or very satisfied with the outcome of the surgery in their last visit.

Conclusions: Improvements beyond the minimum clinically relevant difference in function and pain are achieved with spinal deformity surgery at 2 years, with adequate correction of sagittal imbalance. Despite the rate of complications and reinterventions, high percentage of patients are satisfied.

\section{ORAL COMMUNICATION 5}

\section{EFFECT OF SURGICAL CORRECTION OF THORACOLUMBAR ROTATIONAL KYPHOSIS IN ADULT SCOLIOSIS ON THE SAGITTAL PLANE}

Authors: Pizones Arce, Javier ${ }^{1}$; Sánchez Pérez-Grueso, F. Javier ${ }^{1}$; Moreno Manzanaro, Lucía ${ }^{1}$; Vila Casademunt, Alba ${ }^{2}$; Sánchez Márquez, José Miguel ${ }^{1}$; Fernández-Baillo Gallego-Sacristana, Nicomedes ${ }^{1}$; Talavera, Gloria ${ }^{1}$; Kleinstück, Frank ${ }^{3}$; Obeid, Ibrahim ${ }^{4}$; Alanay, Ahmet ${ }^{5}$; Pellisé Urquiza, Ferran ${ }^{6}$; ESSG. European Spine Study Group ${ }^{7}$ 
Affiliations: ${ }^{1}$ Hospital Universitario La Paz, Madrid, Spain; ${ }^{2}$ Vall d'Hebron Institut de Recerca, Barcelona, Spain; ${ }^{3}$ Schulthess Klinik, Zurich, Switzerland; ${ }^{4} \mathrm{CHU}$ Bordeaux, Bordeaux, Spain; ${ }^{5}$ Acibadem Hospital, Istanbul, Turkey; ${ }^{6}$ Hospital Vall d'Hebron, Barcelona, Spain; ${ }^{7}$ ESSG. European Spine Study Group, Barcelona, Spain

Background and objectives: Scoliosis frequently associates a thoracolumbar (TL) rotational or transitional kyphosis. We do not understand the effect 3D surgical correction has with respect to the distribution of lordosis, adjustment with the ideal sagittal plane, or mechanical complications.

Materials and methods: Retrospective comparative study of prospectively collected data on adult spinal deformity. Patients treated surgically for TL/lumbar curves $>30^{\circ}$ (including single or double curves), with kyphosis (T10-L2, KTL) $>20^{\circ}$, and at least 2 years of follow-up were included in the study. We assessed age and the following postoperative changes: extent of coronal Cobb, KTL, apical TL translation, lumbar lordosis, and Roussouly's sagittal profile. We examined the consequences of sagittal change of the TL segment with respect to the mismatch with ideal sagittal type and mechanical complications (PJK-PJF, breakage of rods, detachment). Comparison between patients with high values of pelvic incidence (PI $\left.>50^{\circ}\right)$ versus low values of PI $\left(\mathrm{PI}<50^{\circ}\right)$ was done using Chi-square and Student's t-test tests.

Results: We found 574 patients with $\mathrm{TL} / \mathrm{L}>30^{\circ}$ scoliosis, from which 185 met the criteria for KTL $>20^{\circ}(32 \%)$; 2 years of followup had been carried on 171 individuals. Mean age was $57.8 \pm 14.9$ years; mean preoperative and 2 years after surgery Cobb angle were $53.8^{\circ} \pm 16.9$ and $28.8^{\circ} \pm 17.3$, respectively; mean preoperative and 2 years after surgery KTL were $34.4^{\circ} \pm 13$ and $13.2^{\circ} \pm 13.5$, respectively.

No age, PI, Cobb extent, KTL, or apical translation differences were found between the 66 patients with mechanical complications and the 105 with no mechanical complications. Patients with low PI values $(\mathrm{n}=74)$ were younger in comparison to individuals with high PI values $(\mathrm{n}=97)(55 \pm 15$ vs. $60 \pm 13.7$ years; $p=0.028)$. No differences were observed in the rest of comparisons: Cobb correction $\left(23.6^{\circ} \pm 16.9\right.$ vs. $\left.25.7^{\circ} \pm 17.2\right)$, KTL correction $\left(19.7^{\circ} \pm 20.8\right.$ vs $\left.23.1^{\circ} \pm 15.4\right)$, and percentage of mechanical complications $(39.7 \%$ vs. $37.5 \%)$.

It was more difficult to restore the ideal sagittal plane in patients with high PI values (mismatch of $76.2 \%$ ) in comparison to individuals with low PI values (mismatch of $28.4 \%)(p<0.001)$. However, restoration to ideal values did not seem to protect against mechanical complications (35.3\% matched vs. $39.8 \%$ mismatched).

Conclusions: The effect of 3D combined correction of TL scoliosis flattens the TL segment in around $20^{\circ}$, enough to maintain the ideal profile in patients with low PI values, but difficult to achieve in patients with high PI. However, this has little impact on mechanical complications.

\section{ORAL COMMUNICATION 6}

\section{DO PATIENT'S ADVANCED AGE AND FRAILTY REALLY AFFECT IMPLANT-RELATED COMPLICATIONS IN ADULT SPINAL DEFORMITY SURGERY?}

Authors: Esteban Blanco, Marta ${ }^{1}$; Gallego Díez, Leticia ${ }^{1}$; Fernández González, Manuel ${ }^{1}$; Villar Pérez, Julio ${ }^{1}$; Lombao Iglesias, Domingo ${ }^{2}$;
Table 1 Number of complications in each study group

\begin{tabular}{lll}
\hline Complications & Group I & Group II \\
\hline PJK & 3 & 8 \\
Breakage of rods & 1 & 4 \\
Detachment & 4 & 1 \\
Loosening of the material & 3 & 0 \\
\hline
\end{tabular}

Betegón Nicolás, Jesús ${ }^{1}$; Hernández Encinas, José Ángel ${ }^{1}$; Lozano Muñoz, Ana ${ }^{1}$; Blanco Hortas, Andrés ${ }^{2}$; Coto Caramés, Laura ${ }^{2}$

Affiliations: ${ }^{1}$ Complejo Asistencial Universitario de Leon (CAULE). Unidad de Columna-Traumatología, Leon, Spain; ${ }^{2}$ Hospital Universitario Lucus Augusti, Lugo, Spain

Background and objectives: Currently, the causes leading to complications in adult spinal deformity (ASD) surgery are being studied. The aim of this study was to assess if age and frailty are associated with the development of complications and how they affect the quality of life of the patient.

Materials and methods: Prospective analysis of 87 patients with a 2-year follow-up. Participants were divided into two groups, Group I ( $<65$ years) and Group II ( $\geq 65$ years). The following implant-related complications were assessed (Table 1): PJK and pseudoarthrosis (breakage of rods, detachment, and loosening). The VAS, ODI, and SRS22 quality of life (QoL) questionnaires were applied. The modified frailty index was used for the analysis.

Results: Group I included 37 patients and Group II 50 patients (Table 2). Eleven patients from Group I and 13 from Group II suffered complications with no statistically significant differences between them $[\mathrm{OR}=0.830(95 \%$ CI $0.322-2.140]$. The number of PJK and breakage of rods was three times higher in Group II than in Group I [PR $=0.173$ (95\% CI 0.579-1.653] (statistical significance). During the preoperative period patients were less frail, developing frailty during the follow-up period and being greater in Group II, although with no statistically significant difference with Group I $(p=0.462)$.

Regarding QoL, no statistically significant intergroup (Table 3) differences were detected with any of the questionnaires. All study patients who did not develop complications showed statistically significant improvement in comparison to their preoperative condition. In comparison to their preoperative condition, no statistically significant differences were seen in patients from Group I with complications; however, Group II patients with complications showed differences in all questionnaires except in the sub-domain function of the $\operatorname{SRS} 22(p=0.3969)$.

Conclusions: Group II patients have more complications and are frailer. Does this justify indication of surgery in ASD patients $<65$ years of age? Further studies with longer follow-up periods are needed to answer this.

\section{ORAL COMMUNICATION 7}

ANALYSIS OF THE INFLUENCE OF DIFFERENT
INTRAOPERATIVE TECHNICAL ASPECTS
IN THE RESTITUTION OF SEGMENTAL LORDOSIS


Table 2 Baseline characteristics of study groups

\begin{tabular}{llll}
\hline Variable & Group I & Group II & $p$ value \\
\hline BMI & $26.54 \pm 5.20$ & $29.16 \pm 5.01$ & 0.433 \\
Number of levels* & $7(5-8)$ & $8(8-12)$ & 0.135 \\
Duration of surgery & $344.19 \pm 106.54$ & $385.87 \pm 123.23$ & 0.108
\end{tabular}

Values presented as means and standard deviations. $p$ values were calculated using Student's t-test

*Non-normal values: data presented as medians and interquartile ranges. $p$ values were calculated using the Mann-Whitney $\mathrm{U}$ test

Table 3 Quality of life of the two groups of patients assessed during follow-up

\begin{tabular}{|c|c|c|c|c|}
\hline Questionnaire & Period & Group I & Group II & $p$ value \\
\hline \multirow[t]{2}{*}{ VAS Back } & Pre & $7.49 \pm 2.46$ & $8.26 \pm 1.98$ & 0.077 \\
\hline & Post & $4.25 \pm 3.12$ & $4.04 \pm 3.06$ & 0.938 \\
\hline \multirow[t]{2}{*}{ VAS Leg } & Pre & $6.90 \pm 3.01$ & $7.41 \pm 2.93$ & 0.563 \\
\hline & Post & $3.98 \pm 3.20$ & $4.04 \pm 3.61$ & 0.163 \\
\hline \multirow[t]{2}{*}{ ODI } & Pre & $55.26 \pm 20.31$ & $60.84 \pm 17.11$ & 0.132 \\
\hline & Post & $38.47 \pm 21.66$ & $39.82 \pm 19.13$ & 0.454 \\
\hline \multirow[t]{2}{*}{ SRSR22_Function } & Pre & $2.36 \pm 0.62$ & $2.32 \pm 0.53$ & 0.613 \\
\hline & Post & $3.02 \pm 0.87$ & $2.82 \pm 0.77$ & 0.408 \\
\hline \multirow[t]{2}{*}{ SRS22_Pain } & Pre & $1.77 \pm 0.73$ & $1.93 \pm 0.62$ & 0.672 \\
\hline & Post & $3.07 \pm 1.04$ & $2.96 \pm 1.01$ & 0.494 \\
\hline \multirow[t]{2}{*}{ SRS22_Self_Image } & Pre & $2.03 \pm 0.54$ & $1.99 \pm 0.59$ & 0.361 \\
\hline & Post & $3.26 \pm 0.73$ & $3.05 \pm 0.75$ & 0.827 \\
\hline \multirow[t]{2}{*}{ SRS22_MentalHealth } & Pre & $2.35 \pm 0.84$ & $2.37 \pm 0.77$ & 0.189 \\
\hline & Post & $3.49 \pm 0.96$ & $3.47 \pm 0.98$ & 0.189 \\
\hline \multirow[t]{2}{*}{ SRS22_Satisfaction } & Pre & $2.72 \pm 0.89$ & $2.58 \pm 1.06$ & 0.926 \\
\hline & Post & $4.13 \pm 0.82$ & $4.05 \pm 0.86$ & 0.903 \\
\hline \multirow[t]{2}{*}{ SRS22_Total } & Pre & $2.13 \pm 0.48$ & $2.17 \pm 0.46$ & 0.792 \\
\hline & Post & $3.26 \pm 0.77$ & $3.14 \pm 0.74$ & 0.992 \\
\hline
\end{tabular}

Values presented as means and standard deviations. $p$ values were calculated using Student's t-test

\section{AND SAGITTAL PARAMETERS IN CIRCUMFERENTIAL LUMBAR FUSION}

Authors: Garzón Márquez, Francisco M. ${ }^{1}$; Rodríguez Arguisjuela, María G. ${ }^{1}$; Mengis Palleck, Charles-Louis R. ${ }^{1}$; Peiró García, Alejandro $^{2}$; Tomé Bermejo, Félix ${ }^{3}$; Álvarez Galovich, Luis ${ }^{1}$

Affiliations: ${ }^{1}$ Fundación Jiménez Díaz. Unidad de Pathology de Columna, Madrid, Spain; ${ }^{2}$ Hospital Sant Joan de Deu, Barcelona, Spain; ${ }^{3}$ Hospital Universitario Fundación Jiménez Díaz. Hospital General de Villalba, Madrid, Spain

Objectives and background: Restitution of lumbar and spinopelvic parameters improves fusion rates and may reduce the Incidence of adjacent segment disease. The aim of this work was to study the effect of different intraoperative technical gestures during circumferential arthrodesis on different spinopelvic parameters.

Materials and methods: We analyzed a consecutive series of 342 patients who underwent one-level circumferential arthrodesis with minimum follow-up of 1 year. Study individuals were divided into four groups: I-posterolateral arthrodesis; II-circumferential arthrodesis with longitudinal cages; III-circumferential arthrodesis with transversal anterior cage; IV-circumferential arthrodesis without cage. The following radiographic measurements were used: segmental lordosis (SL), regional lordosis (RL), lumbar lordosis (LL), pelvic incidence (PI), pelvic incidence-lumbar discordance (PI-LL), and 
Table 1 Description per groups

\begin{tabular}{|c|c|c|c|c|}
\hline Variable & Group I $(n=93)$ & Group II $(n=40)$ & Group III $(\mathrm{n}=196)$ & Group IV $(n=13)$ \\
\hline Age & $52.8 \pm 11.1$ & $48.1 \pm 8.76$ & $47.9 \pm 10.3$ & $45.4 \pm 12.1$ \\
\hline \multicolumn{5}{|l|}{ Sex } \\
\hline Man & $54(58.1 \%)$ & $17(42.5 \%)$ & $102(52.0 \%)$ & $5(38.5 \%)$ \\
\hline Woman & $39(41.9 \%)$ & $23(57.5 \%)$ & $94(48.0 \%)$ & $8(61.5 \%)$ \\
\hline \multicolumn{5}{|l|}{ Etiology } \\
\hline Lytic listhesis & $1(1.1 \%)$ & $4(10.0 \%)$ & $19(9.7 \%)$ & $0(0.0 \%)$ \\
\hline Listhesis without lysis & $25(26.9 \%)$ & $12(30.0 \%)$ & $51(26.0 \%)$ & $4(30.8 \%)$ \\
\hline Degenerative disc disease & $32(34.4 \%)$ & $19(47.5 \%)$ & $103(52.6 \%)$ & $7(53.8 \%)$ \\
\hline Stenosis & $31(33.3 \%)$ & $2(5.0 \%)$ & $10(5.1 \%)$ & $0(0.0 \%)$ \\
\hline Revision of $\mathrm{DH}$ & $4(4.3 \%)$ & $3(7.5 \%)$ & $13(6.6 \%)$ & $2(15.4 \%)$ \\
\hline \multicolumn{5}{|l|}{ Osteotomy } \\
\hline Flavectomy & $82(88.2 \%)$ & $6(15.0 \%)$ & $50(25.5 \%)$ & $10(76.9 \%)$ \\
\hline Single facetectomy & $0(0.0 \%)$ & $29(72.5 \%)$ & $68(34.7 \%)$ & $2(15.4 \%)$ \\
\hline Facetectomy + partial against & $2(2.2 \%)$ & $0(0.0 \%)$ & $56(28.6 \%)$ & $0(0.0 \%)$ \\
\hline Double facetectomy & $1(1.1 \%)$ & $5(12.5 \%)$ & $22(11.2 \%)$ & $1(7.7 \%)$ \\
\hline Complete lamino without facet & $8(8.6 \%)$ & $0(0.0 \%)$ & $0(0.0 \%)$ & $0(0.0 \%)$ \\
\hline \multicolumn{5}{|l|}{ Level } \\
\hline L5-S1 & $44(47.3 \%)$ & $20(50.0 \%)$ & $94(48.0 \%)$ & $10(76.9 \%)$ \\
\hline L4-5 & $35(37.6 \%)$ & $20(50.0 \%)$ & $98(50.0 \%)$ & $3(23.1 \%)$ \\
\hline L3-4 & $13(14.0 \%)$ & $0(0.0 \%)$ & $4(2.0 \%)$ & $0(0.0 \%)$ \\
\hline $\mathrm{L} 2-3$ & $1(1.1 \%)$ & $0(0.0 \%)$ & $0(0.0 \%)$ & $0(0.0 \%)$ \\
\hline
\end{tabular}

anterior and posterior disc height (DH-A, DH-P). Intergroup comparisons of results and assessment of the influence of different factors were carried out on: preoperative disc height, previous SL, fusion level, implant height, degree of facet osteotomy. Linear multiple regression was used to establish a predictive model for lordosis based on the fusion technique, implant lordosis, air level, and type of performed osteotomy.

Results: The four groups had similar epidemiological characteristics (Table 1). Surgery achieved statistically significant changes on SL. No effect was observed on the remaining parameters (Table 2). The technique that achieved most increase of SL was transversal and anterior interbody cage placement (Table 2). Regarding the remaining assessed parameters, bilateral wide facetectomy was the only effective gesture. Neither the height of the cage, nor its placement had a final effect of the restitution of the other studied parameters.

Conclusions: Placement of a transversal and anterior cage in circumferential arthrodesis allows gaining more SL in comparison to a longitudinal placement. However, this gain in SL does not translate into a global lumbar lordosis. Performing a bilateral wide facetectomy is the more relevant surgical gesture to increase local lordosis.

\section{ORAL COMMUNICATION 8}

\section{NEUROPHYSIOLOGIC ALERTS IN MINIMALLY INVASIVE TRANSPSOAS APPROACH: PROSPECTIVE STUDY}

Authors: Luque Pérez, Rafael; Pérez González, José Luis; Sánchez del Saz, Jaime; Domínguez Esteban, Ignacio

Affiliation: Hospital Clínico San Carlos, Madrid, Spain

Background and objectives: Minimally invasive lateral transpsoas approach (MILTA) allows accessing the intervertebral disc with lower risk of complications than with the posterior approach. For this, intraoperative monitoring is necessary during MILTA surgery, to prevent lesions of the lumbar plexus.

Materials and methods: Prospective study of patients who underwent surgery between January 2017 and December 2018.

During the MILTA surgery, multimodal intraoperative neurological monitoring was performed and alerts recorded; furthermore, assessment of long-term clinical and neurophysiologic impact was evaluated. Surgeries were carried out under propofol intravenous general anesthesia and no stoppage by somatosensory evoked potentials (SSPE) registry; motor evoked potentials (MEP), and free running electromyography (EMG); stimulated EMG. 
Table 2 Changes in spinopelvic parameters

\begin{tabular}{|c|c|c|c|c|}
\hline & Group I $(n=93)$ & Group II $(\mathrm{n}=40)$ & Group III $(\mathrm{n}=196)$ & Group IV $(n=13)$ \\
\hline \multicolumn{5}{|l|}{ Segmental lordosis } \\
\hline Preoperative & $7.88 \pm 4.26$ & $7.60 \pm 4.11$ & $8.44 \pm 4.63$ & $5.62 \pm 2.66$ \\
\hline Postoperative & $8.78 \pm 4.12$ & $8.40 \pm 4.13$ & $12.7 \pm 3.69$ & $6.77 \pm 3.03$ \\
\hline Estimated change & $0.90 \pm 2.00$ & $0.80 \pm 2.50$ & $4.27 \pm 4.00$ & $1.15 \pm 0.90$ \\
\hline Change $95 \%$ CI & $(0.48,1.31)$ & $(0.00,1.60)$ & $(3.70,4.83)$ & $(0.61,1.70)$ \\
\hline$p$ value & $<0.001$ & 0.050 & $<0.001$ & 0.001 \\
\hline \multicolumn{5}{|l|}{ Regional lordosis } \\
\hline Preoperative & $22.1 \pm 7.70$ & $23.5 \pm 8.55$ & $25.8 \pm 8.40$ & $20.4 \pm 5.42$ \\
\hline Postoperative & $22.3 \pm 7.49$ & $23.0 \pm 7.22$ & $28.2 \pm 8.13$ & $20.9 \pm 5.62$ \\
\hline Change estimation & $0.28 \pm 3.46$ & $-0.54 \pm 3.53$ & $2.41 \pm 4.77$ & $0.54 \pm 1.39$ \\
\hline Change 95\% CI & $(-0.43,0.99)$ & $(-1.70,0.59)$ & $(1.74,3.08)$ & $(-0.30,1.38)$ \\
\hline$p$ value & 0.437 & 0.341 & $<0.001$ & 0.188 \\
\hline \multicolumn{5}{|l|}{ Lordosis lumbar } \\
\hline Preoperative & $52.7 \pm 10.5$ & $55.7 \pm 11.1$ & $54.5 \pm 12.2$ & $54.5 \pm 14.0$ \\
\hline Postoperative & $53.3 \pm 10.5$ & $53.8 \pm 11.1$ & $55.1 \pm 11.8$ & $54.2 \pm 11.4$ \\
\hline Change estimation & $0.56 \pm 4.06$ & $-1.85 \pm 2.18$ & $0.62 \pm 4.27$ & $-0.38 \pm 2.93$ \\
\hline Change $95 \% \mathrm{CI}$ & $(-0.28,1.40)$ & $(-2.50,-1.20)$ & $(0.02,1.22)$ & $(-2.20,1.39)$ \\
\hline$p$ value & 0.187 & $<0.001$ & 0.045 & 0.645 \\
\hline \multicolumn{5}{|l|}{ Sacral Slope } \\
\hline Preoperative & $34.2 \pm 9.5$ & $34.5 \pm 12.4$ & $34.4 \pm 10.4$ & $36.8 \pm 9.5$ \\
\hline Postoperative & $35.2 \pm 8.79$ & $35.6 \pm 10.3$ & $34.8 \pm 9.6$ & $37.2 \pm 7.32$ \\
\hline Change estimation & $1.05 \pm 8.03$ & $1.18 \pm 7.68$ & $0.33 \pm 7.86$ & $0.38 \pm 5.92$ \\
\hline Change $95 \% \mathrm{CI}$ & $(-0.60,2.71)$ & $(-1.30,3.63)$ & $(-0.80,1.44)$ & $(-3.20,3.96)$ \\
\hline$p$ value & 0.209 & 0.339 & 0.555 & 0.819 \\
\hline \multicolumn{5}{|l|}{ pelvic tilt } \\
\hline Preoperative & $19.4 \pm 11.1$ & $19.0 \pm 10.8$ & $16.0 \pm 9.35$ & $18.5 \pm 6.83$ \\
\hline Postoperative & $18.1 \pm 11.2$ & $19.3 \pm 7.73$ & $15.3 \pm 9.8$ & $19.5 \pm 6.05$ \\
\hline Change estimation & $-1.34 \pm 11.5$ & $0.30 \pm 10.8$ & $-0.62 \pm 9.13$ & $1.00 \pm 8.14$ \\
\hline Change $95 \% \mathrm{CI}$ & $(-3.70,1.02)$ & $(-3.20,3.75)$ & $(-1.90,0.67)$ & $(-3.90,5.92)$ \\
\hline$p$ value & 0.261 & 0.861 & 0.345 & 0.666 \\
\hline \multicolumn{5}{|l|}{ Pelvic incidence } \\
\hline Preoperative & $54.1 \pm 14.4$ & $54.2 \pm 13.8$ & $50.1 \pm 14.8$ & $55.8 \pm 10.6$ \\
\hline Postoperative & $53.9 \pm 13.7$ & $55.3 \pm 12.2$ & $49.9 \pm 14.7$ & $54.8 \pm 14.8$ \\
\hline Change estimation & $-0.20 \pm 13.2$ & $1.02 \pm 11.6$ & $-0.20 \pm 10.4$ & $-1.00 \pm 12.0$ \\
\hline Change $95 \% \mathrm{CI}$ & $(-2.90,2.51)$ & $(-2.70,4.74)$ & $(-1.70,1.25)$ & $(-8.30,6.27)$ \\
\hline$p$ value & 0.881 & 0.580 & 0.783 & 0.769 \\
\hline
\end{tabular}

Two categories of alerts were established: minor alerts, caused by surgical handling, which may be reverted by correcting valve, dissector, or pin placement, implant size, etc., and major alerts in cases in which registries did not normalize after the procedure.

Results: Forty MILTA surgeries (57 levels) were prospectively evaluated with final follow-up of around 2-3 years. Indication for surgery was degenerative disc disease (20 multilevel surgeries). Left approach was performed in 23 patients (49 levels). L3L4 was the most commonly operated level: 29 (72\% of the patients (P), 50.8\% levels (N)).

Three cases were not assessable due to technical problems or patient's need of anesthesia. No alerts were registered in three of the monitorings $(7.5 \%$ of the $\mathrm{P} ; 5.35 \% \mathrm{~N})$. The most commonly detected minor alert was "changes in SSPE amplitude in the femoral area": $12(30 \%$ of the P; $21 \% \mathrm{~N}$ ) during the placement of the dissector. The most commonly detected structure in the surgical field was the femoral nerve: nine $(22.5 \%$ of the $\mathrm{P} ; 15 \% \mathrm{~N})$. Forty-three minor alerts were registered in 23 patients $(57 \%$ of the $\mathrm{P})$ and 10 major alerts in 10 patients $(25 \%$ of the $\mathrm{P})$. There was neurological impact in eight patients and in six, postoperative EMG showed persistent neurological lesions (15\% of the P; $10 \% \mathrm{~N}$ ).

Conclusions: Registries may be reversed in most occasions by adapting the surgical technique and with neurophysiologic control to prevent tissue injuries. Six lesions in the lumbar plexus were registered. Without neurophysiologic control and its protective effect, the incidence on neurological lesions with MILTA surgery might have reached $62.5 \%$ in patients who underwent surgery. 


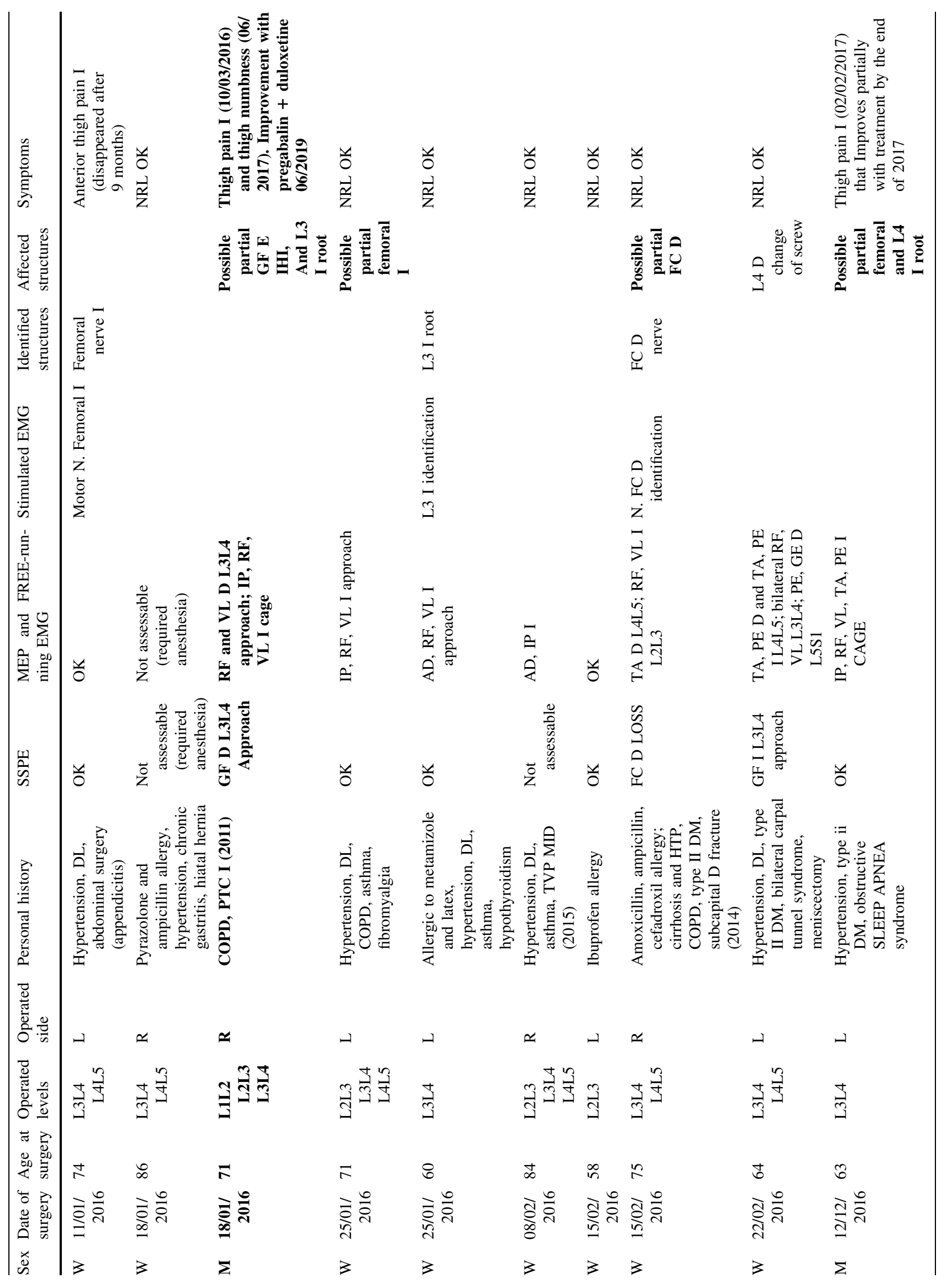




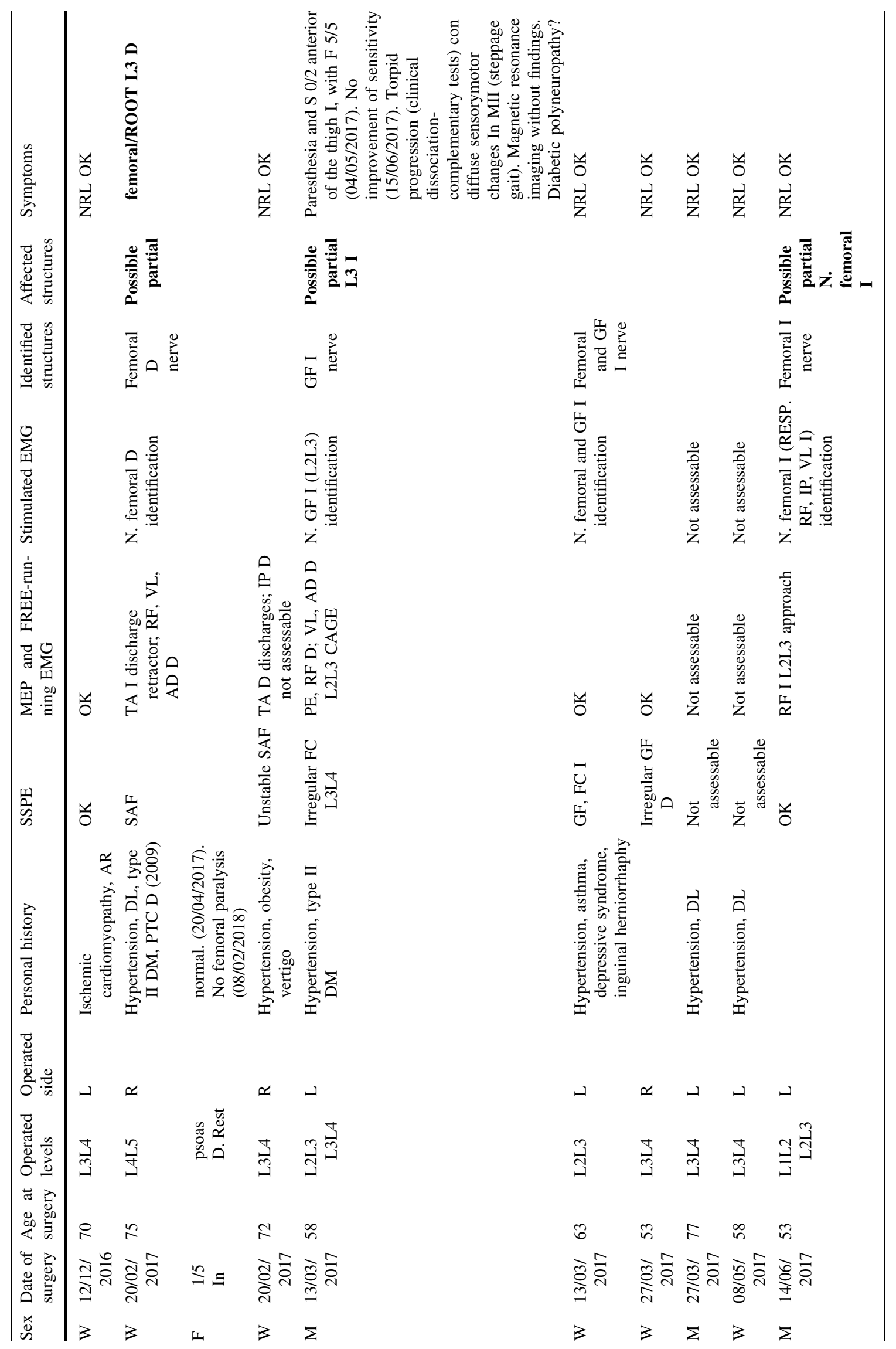




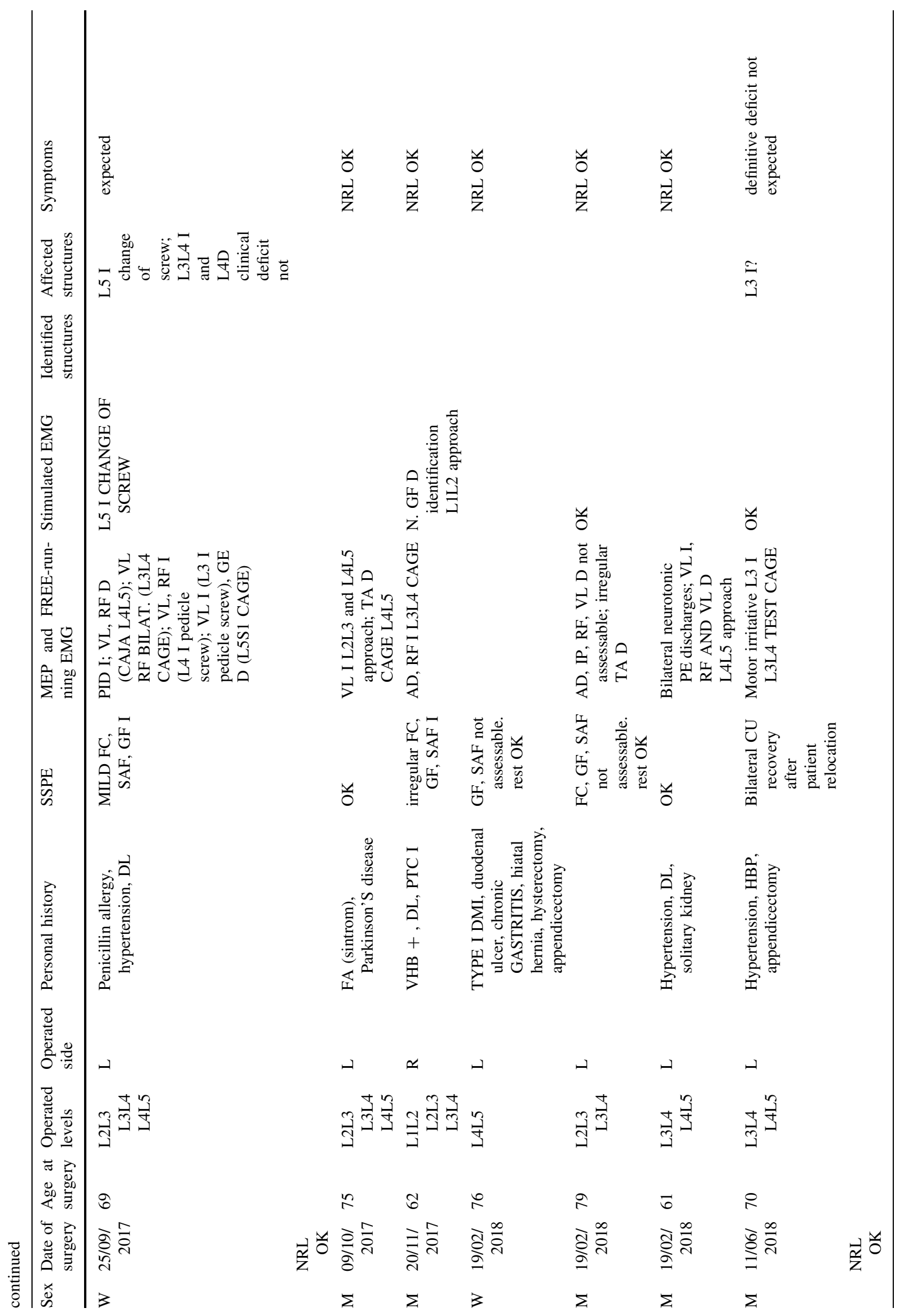




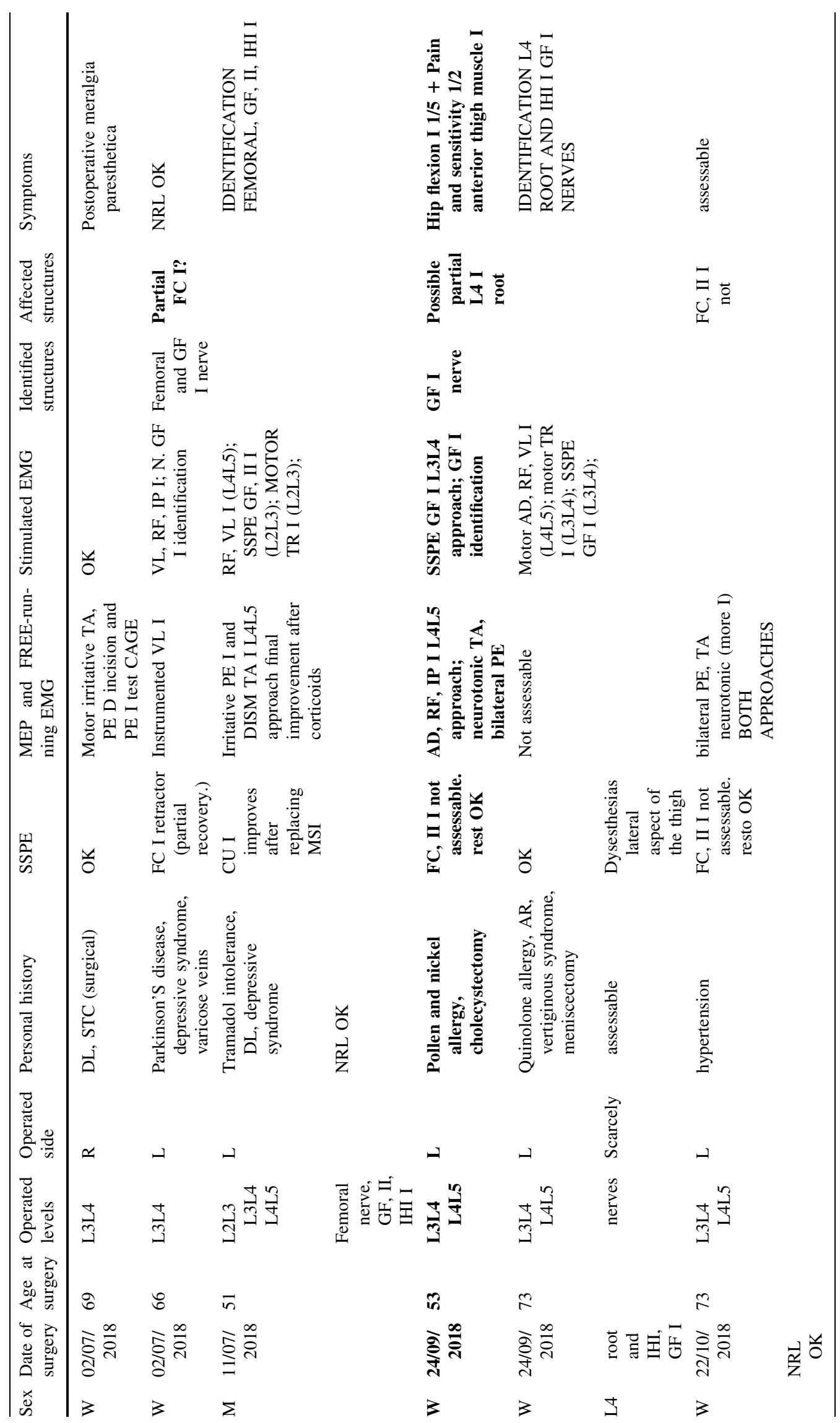




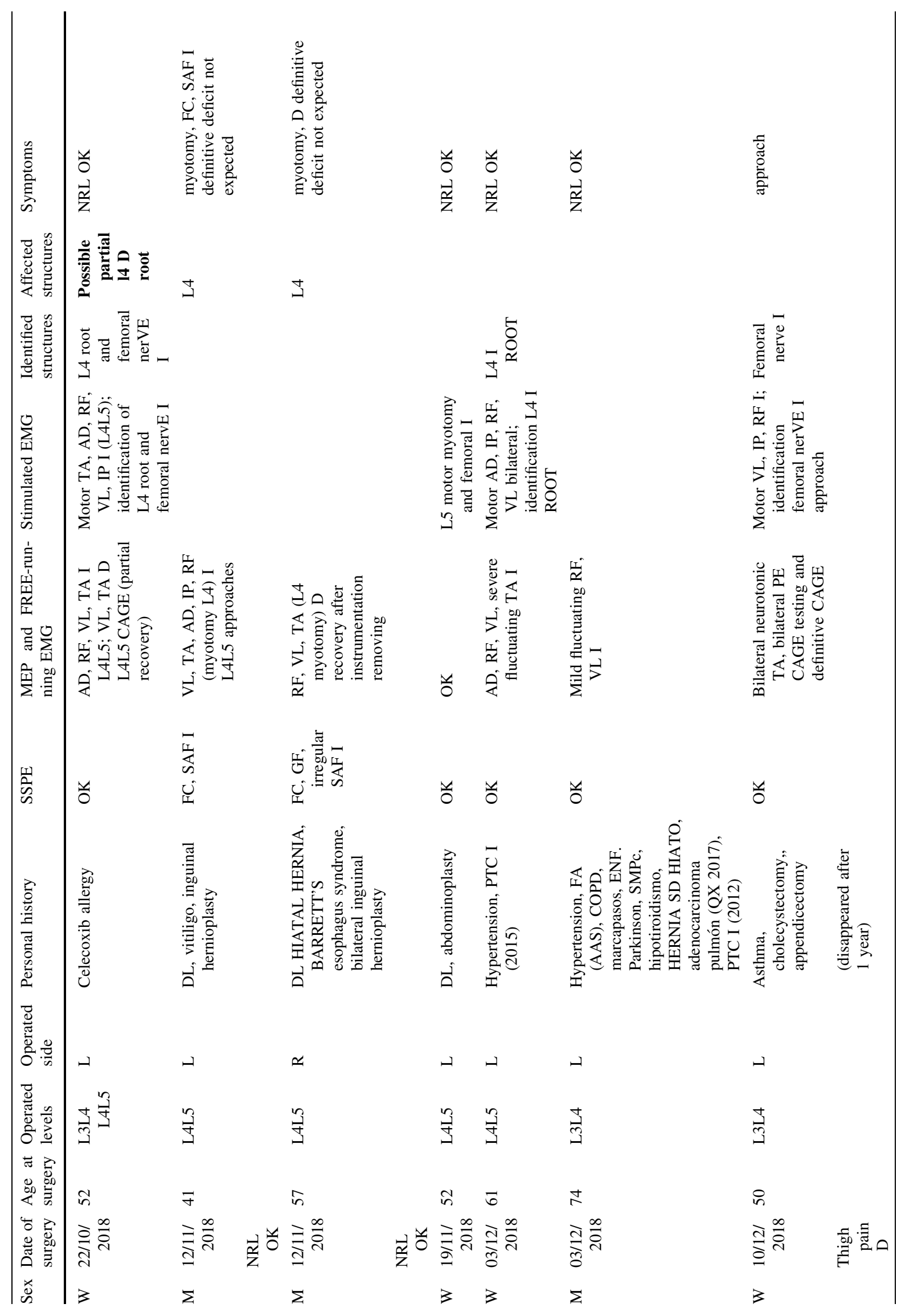




\title{
ORAL COMMUNICATION 9
}

\section{MINIMALLY INVASIVE SURGERY VERSUS OPEN SURGERY FOR THE MANAGEMENT OF LUMBAR SPINE DEGENERATIVE DISC DISEASE: ARE THERE REALLY DIFFERENCES IN CLINICAL AND FUNCTIONAL OUTCOMES?}

Authors: Quevedo Narciso, Tania; Fernández Fernández, Tanya; Igualada Blázquez, Cristina; Vicente Herrera, Edmundo; Fernández Mariño, José Ramón; Esparragoza Cabrera, Luis Alejandro

Affiliation: Hospital General Universitario Gregorio Marañón, Madrid, Spain

Background and objectives: Surgical treatment of low back disease may be done by open surgery or minimally invasive surgery (MIS), an alternative that promises the same results, but with less damage to soft tissue and faster recovery.

There are many studies on the use of MIS in fractures, comparisons on screw positioning, etc. However, few comparative studies have been done against open surgery in degenerative diseases.

The objectives of the present study were to assess perioperative/postoperative results in patients who undergo open arthrodesis in comparison to MIS in low back degenerative diseases (one or two levels).

Materials and Methods: Comparative study that included 83 and 36 patients who underwent open surgery and MIS, respectively. Patients presented one or two level lumbar degenerative disc disease, no previous interventions, without central spine stenosis, and symptoms of lumbago (low back pain)/radiculopathy).

Pre- and postoperative clinical follow-up at 3, 6, 12, and 24 months.

Lumbar/radicular VAS comparisons, functional and labor status, complications, reinterventions, among other items.

Results: VAS scoring improved in both groups, being notably better in the group who underwent open surgery during the first year. During functional recovery: at 3 months, $62 \%$ of the patients who underwent open surgery group recovered their activity versus $45.7 \%$ of individuals in the MIS group; at six months functional recovery was seen in $95 \%$ of the open surgery group versus $70 \%$ of the MIS group. Significant differences were seen for both periods $(p<0.05)$.

The rate of complications was $42.9 \%$ during the first year in the MIS group, mainly over the first 3 months, versus $18 \%$ in the open surgery group; significant difference $(p<0.05)$. Rate of reinterventions was $28.6 \%$ for the MIS group versus $6.9 \%$ for the open surgery group over the whole follow-up.

There were no significant differences in surgery duration, blood loss, or hospital stay.

Conclusions: Open surgery and MIS aim achieving the same results; however, in this study, we observe that functional recovery and improvement of pain is plausibly better in individuals who undergo open surgery.

Stands out the difference in complications between the two groups, as well as the rate of reinterventions, significantly higher in the group of patients treated with MIS.

In short, we conclude that currently MIS does not improve the results obtained by open surgery in patients with degenerative disc disease, and may lead to debate on current indications.

\section{ORAL COMMUNICATION 10}

\author{
NAVIGATION ASSISTED ROBOTIC INTERVENTION \\ IN MINIMALLY INVASIVE SURGERY OF THE LUMBAR \\ SPINE
}


Authors: Domínguez Esteban, Ignacio; Luque Pérez, Rafael; Pérez González, José Luis; Huerta Cebolla, Javier; Collado Gosalvez, Alicia

\section{Affiliation: Hospital Clínico San Carlos, Madrid, Spain}

Objectives: Analysis of preliminary results for the first 10 patients (40 pedicle screws) who underwent minimally invasive transforaminal arthrodesis by navigation assisted robotic surgery.

Background: Minimally invasive surgery (MIS) in lumbar spine diseases, particularly transforaminal arthrodesis, has proven to be clinically effective and cost-effective. However, technological dependency when performing these techniques does not make the learning curve shorter, particularly when it comes to correctly placing pedicle screws using two-dimensional (2-D) fluoroscopy. Introduction of navigation-assisted robots has reduced the percentage of incorrect placements, accuracy reaching $98 \%$.

Materials and methods: Ten patients with lumbar pathology subsidiary to undergo L4-L5 or L5-S1 TLIF-MIS arthrodesis were treated. Three of the patients had dysplastic spondylolisthesis and seven degenerative disc disease. Six were women and four men. Mean age was 48 years. In four cases the fused levels were L5-S1 and in six L4-L5. The Excelsius (Globus) system was used with 2-D fluoroscopy image fusion method and preoperative CT.

Results: Mean duration of surgery was $95 \mathrm{~min}$ and fluoroscopy time, every four screws, was $28.2 \mathrm{~s}$ (7.05 s per screw).

Mean hospital stay was $36 \mathrm{~h}$. None of the patients required transfusion, and no infections were registered. Postoperative pedicle screw positions were determined by CT. Following the Gertzbein-Robbins classification, all screws (40/40) were included in Group A or B: $\mathrm{A}=39(97.5 \%)$ and $\mathrm{B}=1(2.5 \%)$.

Conclusions: Overall, minimally invasive spine surgery, and particularly TLIF-MIS, has shown very good clinical and radiological outcomes and lower rate of complications. Incorrect placement of pedicle screws, as well as radiation, are two relevant problems when using this technique. Navigation assisted robotic surgery achieves an accuracy of around $98 \%$ and very little exposure to radiation.

\section{ORAL COMMUNICATION 11}

\section{RESULTS OF THE USE OF DISCOGEL@ IN PATIENTS WITH RADICULAR PAIN}

Authors: Díaz Morfa, Margarita ${ }^{1}$; Sanz Aguilera, Sylvia ${ }^{1}$; Garzón Márquez, Francisco M. ${ }^{1}$; Tomé Bermejo, Félix² ; Benito Gallo, Marina $^{1}$; Mengis Palleck, Charles-Louis R. ${ }^{1}$; Álvarez Galovich, Luis ${ }^{1}$

Affiliations: ${ }^{1}$ Fundación Jiménez Díaz. Unidad de Pathology de Columna, Madrid, Spain; ${ }^{2}$ Hospital Universitario Fundación Jiménez Díaz. Hospital General de Villalba, Madrid, Spain

Background and objectives: The treatment of radicular pain caused by contained herniated disc in the lower back is complex. Discogel (DiscoGel ${ }^{\circledR}$, Gelscom SAS, France) is a radiopaque gelified ethanol, used as a chemonucleolysis substance for treating contained herniated discs. We carried out a transversal prospective study to assess the effectiveness and safety of Discogel ${ }^{\circledR}$ in the treatment of radicular pain and evaluate predictive parameters of procedural success.

Materials and methods: The 49 patients with low back pain and sciatica included in the study underwent chemonucleolysis with Discogel ${ }^{\circledR}$. Minimum follow-up was 1 year; in $81.6 \%$ of the patients, location was L4-5. Medical history (low back pain/sciatica), radiological findings (Pfirrmann, Modic, posterocentral, foraminal herniated disc), and evolution of pain and function (VAS, ODI, and COMI) were assessed at 3, 6, and 12 months.

Results: Mean age was 53.4 years. VAS score of lower limbs improved from $6.9 \pm 2.1$ to $3.2 \pm 2.5$ at 3 months, to $2.7 \pm 2.2$ at
6 months, and to $2.9 \pm 2.1$ at 1 year $(p<0.001)$. Regarding low back pain, VAS scores went from $5.3 \pm 3.4$ to $4.9 \pm 3.6$ at 3 months and to $4.7 \pm 3.2$ at 1 year. Preoperative ODI was $48 \pm 21$, changing to $23 \pm 14,22 \pm 13$, and $19 \pm 15$ at 3, 6, and 12 months, respectively. Eighty-three per cent of the patients were satisfied or very satisfied. Patients whose primary complaint was pain in the lower extremities, better clinical results were achieved in the group who predominantly had low back pain (88\% versus $59 \%, p<0.05)$. Results were better in patients with soft protruded discs in comparison to those with bulged, dehydrated diffused discs $(p<0.05)$. Two patients had to undergo surgical treatment.

Conclusions: Discogel ${ }^{\circledR}$ is effective and safe for the treatment of radicular pain caused by contained herniated disc. Better results are achieved when symptoms are mainly radicular and with soft disc protrusion.

\section{ORAL COMMUNICATION 12}

\section{ENDOSCOPIC LUMBAR SPINE SURGERY: FUTURE GOLD STANDARD IN THE TREATMENT OF HERNIATED DISCS}

Authors: González Murillo, Manuel ${ }^{1}$; De Uña Gallego, Zoe ${ }^{1}$; García García, Miguel Ángel ${ }^{1}$; Delfino Carrillo, Renato ${ }^{2}$; Sanz Ferrando, Luis $^{1}$

Affiliations: ${ }^{1}$ Hospital Universitario de Torrejón, Torrejón de Ardoz, Spain; ${ }^{2}$ Hospital Universitario de Getafe, Getafe, Spain

Background and objectives: Endoscopic lumbar spine discectomy outcomes are similar to those achieved using conventional techniques (microdiscectomy/open discectomy), accompanied by a series of advantages, e.g., incisions smaller than one centimeter, less damage to tissue, less formation of scar tissue, less postoperative pain, lower number of hospital admissions and surgical complications.

The aim of this study was to describe the learning curve in the 52 cases who underwent surgery between 2019 and 2020 .

Materials and methods: Descriptive study of 52 endoscopic discectomies (full-endoscopy) in 43 patients ( 29 men and 14 women). We assessed the following data: epidemiological, type of approach (interlaminar, posterolateral transforaminal, and extreme lateral), duration of surgery and hospital admission; pre- and postoperative VAS and ODI were performed and recorded.

Results: Mean age was de $42.28 \pm 11.6$ years.

Thirty-one interlaminar, 14 posterolateral transforaminal, and seven extreme-lateral transforaminal approaches were carried out. The most frequently operated level was L5-S1 (30 discectomies), followed by L4-L5 (16), L3-L4 (4), and L2-L3 (2). Seven patients had a double discectomy.

The primary location of herniated discs was within the canal (35), followed by foraminal (17).

Mean duration of the procedure was $62.72 \pm 26.84 \mathrm{~min}$. It is worth noting that progressive decrease of surgery duration was observed with progression of the learning curve.

Regarding complications, the following were identified: two dural lesions, two patients with early disc re-herniation who had to undergo surgery again, and one patient who required arthrodesis in less than 6 months.

The number of endoscopic procedures increased throughout 2020 aiming to reduce the number of hospital admissions due to the COVID-19 pandemic. Achieved mean admission time, considering all study patients, was $21 \mathrm{~h}$.

Conclusions: In conclusion, endoscopic discectomy is a safe, effective surgical alternative to conventional microdiscectomy. In few years, it will be established as the gold standard for the treatment of 
herniated discs and be the standard technique in most spinal surgery units.

\section{ORAL COMMUNICATION 13}

\section{IMPLEMENTATION OF MIXED MODELS IN THE STUDY OF RADIOLOGICAL ADJUSTMENT VARIABLES IN ADULT PATIENTS OPERATED FOR SPINAL DEFORMITY}

Authors: Blanco Hortas, Andrés ${ }^{1}$; Lombao Iglesias, Domingo ${ }^{1}$; Coto Caramés, Laura ${ }^{1}$; Esteban Blanco, Marta ${ }^{2}$; Fernández González, Manuel $^{3}$; Betegón Nicolás, Jesús ${ }^{2}$; Lozano Muñoz, Ana ${ }^{2}$; Hernández Encinas, José Ángel ${ }^{2}$; Villar Pérez, Julio ${ }^{2}$; Gallego Díez, Leticia ${ }^{2}$

Affiliations: ${ }^{1}$ Hospital Universitario Lucus Augusti, Lugo, Spain; ${ }^{2}$ Complejo Asistencial Universitario de Leon (CAULE). Unidad de Columna-Traumatología, Leon, Spain; ${ }^{3}$ Complejo Hospitalario de Leon, Leon, Spain

Background and objectives: Mixed models are a type of statistical analysis that allows examining different response variables and simultaneously study the value of the studied phenomenon and its variability.

The purpose of this study was to apply mixed analysis in the followup study of adult patients who underwent spinal deformity surgery.

Materials and methods: Retrospective follow-up study of a population of patients who underwent spinal deformity (SD) surgery, classified by age, sex, BMI, achieving correction of preoperative parameters PT, SVA, and PI-LL.

Mixed models were used to compare pre- and postoperative changes in achieving optimal PT correction, differences between distinct risk factors, and interaction between both factors.

Results: Ninety-nine patients were included in the study; mean age was 62.2 years, $76 \%$ were women, BMI 27.5, and mean follow-up of 29.6 months (Table 1).

Clear differences were seen between the studied risk factors. No significant changes seem to occur between pre- and postoperative progression, although there is clear association, with very unequal time-related progression, depending on the presence or not of risk factors, particularly regarding preoperative radiological factors, e.g., SVA $(p=0.001)$, PI-LL $(p=0.022)$, and PT $(<0.001)$.

Conclusions: Clear intergroup differences between the studies risk groups are seen in adult patients regarding the achievement of PT correction. These differences are even greater preoperatively, decreasing postoperatively. Thus, distinct intergroup progression over time is observed. These results seem to indicate a correlation between patients with risk factors and changed PT; in these cases, improvement in a significant percentage of individuals is achieved with

Table 1 .

\begin{tabular}{lc}
\hline Variable & Patients N $=99$ \\
\hline Sex $(\mathrm{M})$ & $145(75.9)$ \\
Age $^{*}$ & $62.2(14.2)$ \\
Age $(>65)$ & $98(51.3)$ \\
BMI* & $27.5(4.9)$ \\
BMI $(>25)$ & $119(66.5)$ \\
Follow-up* & $29.6(16.4)$
\end{tabular}

Values presented as absolute cases and percentages in parenthesis (categorical variables) or as means and standard deviations (* continuous variables) surgery. On the contrary, patients without risk factors are in a more favorable position regarding preoperative PT measurement, but with worsening of this parameter postoperatively because other factors are forced due to their better preoperative condition.

\section{ORAL COMMUNICATION 14}

\section{THREE-DIMENSIONAL PLANNING AND GENERATION OF SPECIFIC DRILL GUIDE TEMPLATES BY 3D PRINTING FOR ADULT SPINAL DEFORMITY}

Authors: Mendoza Revilla, Germán Alejandro; Coto Caramés, Laura; Lombao Iglesias, Domingo; Salido Villarón, Alejandro

Affiliation: Hospital Universitario Lucus Augusti, Lugo, Spain

Background: Pedicle screw malpositioning rate in adult spine deformity surgery is around $9.3 \%$ and is associated with neurological complications. This has promoted the development of studies to assess the accuracy of different instrumentation techniques.

Recent advances in 3D printing have allowed the generation of patient-specific guides that can be used intraoperatively.

We present a technical description of the manufacturing (with freeware) of three 3D printed navigational guides that accurately place six pedicle screws in a 3D printed phantom.

Materials and methods: A 3D reconstruction of the T11-L1 vertebral segment of a patient with severe spinal deformity was generated via freeware. Based on the $3 \mathrm{D}$ model, the ideal pedicle screw trajectory of the six pedicles were determined. The phantom and the drill guides were 3D printed with an FDM printer.

We compared two study arms (free hands vs. 3D printed drill guide) and assessed the performance in both arms of two surgeons (senior spine surgeon vs. PGY-3).

We judged the position of the screws within the pedicle according to the modified Neo \& Sakamoto classification; screw angulation in axial plane and screw placement time.

Results: We developed three patient-specific 3D drill guides that matched the posterior surface of the selected spinal segment.

When using the 3D drill guide, the senior surgeon and the resident misplaced on average $1^{\circ}$ and $2^{\circ}$ away from the planned ideal axial angulation, respectively (Table 1). By using the $3 \mathrm{D}$ drill guide, the senior surgeon and the resident managed to reduce screw placement time by $45 \%$ and $50 \%$, respectively (Table 2), and accomplished ideal positioning (Grade 0) in five of six screws (Table 2) according to the modified Neo and Sakamoto classification. Malpositioning, attributed to micromobility and thermolability of the guides, may be prevented by printing in more resistant materials, which was not possible in our study due to budgetary limitations.

Conclusions: Virtual preoperative planning, 3D modeling, and 3D printing allows the generation of patient-specific implants.

By using reverse engineering and 3D printing freeware, we were able to design a drill guide that avoided malpositioning and reduced pedicle screw placement time in a severe spinal adult deformity case.

\section{ORAL COMMUNICATION 15}

\section{ASSESSMENT OF NEW SURGICAL AND PHARMACOLOGICAL STRATEGIES FOR THE PREVENTION OF FIBROSIS IN SPINAL CORD TRAUMA: STUDY IN WILD BOARS}

Authors: Romero Muñoz, Luis María ${ }^{1}$; Barriga Martín, Andrés ${ }^{1}$; Del Cerro de Pablo, Patricia ${ }^{2}$; Rodríguez de Lope Llorca, Ángel ${ }^{3}$; Collazos Castro, Jorge Eduardo ${ }^{2}$ 
Table 1 Angulation measurements of the pedicle screw

\begin{tabular}{lclccccc}
\hline Internal angulation degree & Left T11 & Right T11 & Left T12 & Right T12 & Left L1 & Right L1 & Mean angulation difference \\
\hline Ideal in the axial plane (in the simulation) & 11.69 & 14.06 & 13.05 & 13.52 & 17.53 & 13.27 & \\
Freehand (senior surgeon) & 16.7 & 12.9 & 11.8 & 24.1 & 20.00 & 31.5 & \\
Difference with ideal positioning & 5.01 & 1.16 & 1.25 & 10.58 & 2.47 & 18.23 & 6.45 \\
Freehand (resident)* & 12.95 & 7.12 & 21.48 & 4.3 & 19.75 & 14.52 & \\
Difference with ideal positioning & 12.95 & 21 & 21.48 & 22.74 & 19.75 & 14.52 & 18.74 \\
3D guide (senior surgeon) & 11.65 & 13.21 & 10.00 & 14.4 & 17.96 & 13.97 & 0.7 \\
Difference with ideal positioning & 0.04 & 0.85 & 3.05 & 0.88 & 0.43 & 0.99 \\
3D guide group (resident) & 20.1 & 16.86 & 13.47 & 13.45 & 17.07 & 13.81 & \\
Difference with ideal positioning & 8.41 & 2.8 & 0.42 & 0.07 & 0.46 & 0.54 & 2.11 \\
\hline
\end{tabular}

*Outward angulation

Table 2 Time in minutes for pedicle screw placement

\begin{tabular}{lllllllll}
\hline & Left T11 & Right T11 & Left T12 & Right T12 & Left L1 & Right L1 & Total time & Mean time per screw \\
\hline Freehand (senior surgeon) & $2: 00$ & $1: 30$ & $1: 50$ & $0: 57$ & $2: 13$ & $1: 16$ & $9: 19$ & $1: 37$ \\
Freehand (resident) & $2: 21$ & $2: 27$ & $2: 49$ & $1: 59$ & $2: 23$ & $2: 31$ & $14: 30$ & $2: 26$ \\
3D guide (senior surgeon) & $1: 30$ & $0: 17$ & $0: 30$ & $1: 15$ & $1: 15$ & $0: 28$ & $5: 08$ & $0: 52$ \\
3D guide (resident) & $0: 27$ & $2: 04$ & $0: 38$ & $1: 26$ & $2: 27$ & $0: 19$ & $7: 21$ & $1: 13$ \\
\hline
\end{tabular}

Table 3 Classification of pedicle positioning according to the modified Neo and Sakamoto classification system

\begin{tabular}{|c|c|c|c|c|c|c|}
\hline & Left T11 & Right T11 & Left T12 & Right T12 & Left L1 & Right L1 \\
\hline Virtual planning (ideal position) & Grade 0 & Grade 0 & Grade 0 & Grade 0 & Grade 0 & Grade 0 \\
\hline Freehand (senior surgeon) & Grade 3 & Grade 0 & Grade 3 & Grade 0 & Grade 1 & Grade 0 \\
\hline Freehand (resident) & Grade 3 & Grade 3 & Grade 3 & Grade 3 & Grade 3 & Grade 3 \\
\hline 3D guide (senior surgeon) & Grade 0 & Grade 0 & Grade 0 & Grade 0 & Grade 0 & Grade 1 \\
\hline 3D guide (resident) & Grade 3 & Grade 0 & Grade 0 & Grade 0 & Grade 0 & Grade 0 \\
\hline
\end{tabular}

Affiliations: ${ }^{1}$ Hospital Nacional de Parapléjicos, Toledo, Spain; ${ }^{2}$ Laboratorio de Reparación Neural and Biomateriales. Hospital Nacional de Parapléjicos, Toledo, Spain; ${ }^{3}$ Servicio Neurosurgery. Hospital Virgen de la Salud, Toledo, Spain

Background: Traumatic spinal cord injury and invasive interventions cause extended fibrotic response that prevents neural regeneration. The aim of the study was to apply a surgical method as a repair therapy without an increase of fibrosis, which would lead to therapeutic failure.

Materials and methods: Experimental study. We created a porcine model of spinal cord injury by durotomy and spinal cord hemisection with exeresis of a cervical segment $(1 \mathrm{~cm})$ to assess neural repair strategies. Twelve two-month old female wild boars (Sus scrofa) were used to evaluate the different surgical scenarios: (1) Control injury with dural reparative microsurgery, (2) duroplasty using bovine pericardium, and (3) previous method plus hyaluronic acid as antifibrotic agent on the area of the injury. The animals were sacrificed 1 month post-injury to assess fibrotic response and condition of neural tissue using conventional histological and immunohistochemical methods. The ethics committee of our center approved the experiments.

Results: In the control, dural suture prevents invasion of the injury by extradural connective tissue and development of $1-\mathrm{cm}$ meningeal thickening in the perilesional area. The dura mater undergoes retraction with adhesion on spinal cord surface, reducing the original cavity. The rest of the space is mainly occupied by connective PDGFR $\beta$ + tissue from the meninges, pericytes, and perivascular fibroblasts. Duroplasty using bovine pericardium also blocked the entrance of extradural connective tissue and reduced the tension in the dura mater. However, 1 month post-injury, perigraft inflammation points were seen, restricted to the area of injury with good tissue integration, although the area of the injury was invaded by fibrosis, mainly from the arachnoid and pia mater. This fibrosis was not inhibited by packing the cavity with low- or high-molecular-weight hyaluronic acid. Neither the duroplasty nor the hyaluronic acid caused further neural damage.

Conclusions: Duroplasty prevents the collapse and adherence of the dura mater on spinal cord tissue and the invasion of the injury by extramedullary fibrotic tissue, facilitating the use of biological therapies for spinal cord injuries.

\section{ORAL COMMUNICATION 16}

ACCURACY OF INTRAOPERATIVE RADIOGRAPHS AND COMPUTED AXIAL TOMOGRAPHY IN COMPARISON TO LAMINECTOMY TO ASSESS THE PLACEMENT 


\section{OF THORACIC SCREWS IN ADOLESCENT IDIOPATHIC SCOLIOSIS PATIENTS: EXPERIMENTAL STUDY IN A SIMULATION LAB}

Authors: Peiró García, Alejandro ${ }^{1}$; Rosa-Filezio Marina, Marina Rosa $^{2}$; Teles, Alisson ${ }^{3}$; Parsons, David ${ }^{2}$; Ferri-De-Barros, Fabio ${ }^{2}$

Affiliations: ${ }^{1}$ Hospital Sant Joan de Deu, Barcelona, Spain; ${ }^{2}$ Alberta Children's Hospital, Calgary, Canada; ${ }^{3}$ Mcgill Scoliosis And Spine Group, Montreal, Canada

Background and objectives: Improving the safety and effectiveness of instrumented posterior fusion in adolescent idiopathic scoliosis (AIS) is key to reduce the rate of complications and potential risks associated to deformity surgery. The most common way to verify screw placement is by using intra- or postoperative radiographs or computed axial tomography (CAT).

The purpose of this work was to compare the accuracy of intraoperative radiographs and CAT to assess the placement of thoracic pedicle screws in a simulation lab.

Materials and methods: Prospective experimental study carried out in a simulation lab, in which five surgeons carried out T3 to T7 bilateral instrumentations of 20 scoliosis models using 10 pedicle screws per model an four different techniques: with pedicle awl and motor brocade, both techniques with and without CAT-based navigation.

Following instrumentation, radiographs and CAT were obtained and graded following the Abul-Kasim classification of screw placement (misplacement) by three independent observers. Next, a laminectomy of the models was done by a neurosurgeon and integrity of the pedicle assessed as per the classification, evaluating any type of breach.

Results: Inter-rater reliability regarding measurements was minimum or nil (Kappa - 0.024 and 0.275) (Table 1). The percentage of agreement between the three observers and the laminectomy varied between 60.8 and $97.9 \%$ (Table 2). Forty-eight breaches were seen in the axial plane and four in the sagittal plane in the laminectomy; $100 \%$ of sagittal plane breaches were underdiagnosed by the radiologists and between $47.9 \%$ and $70.8 \%$ of axial plane breaches. Percentage of undiagnosed breaches in AP radiographs varies between $68.8 \%$ and $97.8 \%$ (Table 3 ).

Conclusions: Assessment of pedicle screw placement using radiographs and CAT may underdiagnose the presence of invasion in the pedicle's wall. Although many of these breaches have no clinical repercussion, this study shows the difficulty of assessing thoracic pedicle screw placement in adolescent idiopathic scoliosis.

Statistical analysis: Inter-rater reliability was measured using Fleiss's kappa (Fleiss, 2003), and intraclass correlation coefficient (ICC) (Koo et al. 2016). Percentages of agreement between each rater and direct inspection of the pedicle in the model were also calculated.

Fleiss JL, Levin B, Paik MC. Statistical Methods for Rates and Proportios. Third Edition ed: Willey; 2003.

Koo TK, Li MY. A Guideline of Selecting and Reporting Intraclass Correlation Coefficients for Reliability Research. J Chiropr Med. 2016;15(2):155-163.
Table 2 Agreement between radiologist assessment and direct visualization of the model

\begin{tabular}{llll}
\hline & Rater 1 $(\%)$ & Rater 2 $(\%)$ & Rater 3 $(\%)$ \\
\hline Axial CAT & 62.3 & 73.0 & 60.8 \\
Sagittal CAT & 95.0 & 92.5 & 97.9 \\
AP X-ray & 76.0 & 71.0 & 74.5 \\
Lateral X-ray & 95.0 & 92.5 & 97.9 \\
\hline
\end{tabular}

$C A T$ computed axial tomography, $A P$ anteroposterior

Table 3 Frequency of missed breaches diagnosed by direct inspection

\begin{tabular}{lccc}
\hline & Rater 1 $(\%)$ & Rater 2 $(\%)$ & Rater 3 $(\%)$ \\
\hline Axial CAT $(\mathrm{N}=48)$ & 66.7 & 70.8 & 47.9 \\
Sagittal CAT $(\mathrm{N}=4)$ & 100 & 100 & 100 \\
AP X-ray $(\mathrm{N}=48)$ & 97.9 & 68.8 & 81.3 \\
Lateral X-ray $(\mathrm{N}=4)$ & 100 & 100 & 100
\end{tabular}

$C A T$ computed axial tomography, $A P$ anteroposterior

\section{ORAL COMMUNICATION 17}

\section{ROLE OF MONOMERIC C-REACTIVE PROTEIN IN THE MODULATION OF INFLAMMATORY RESPONSE IN INTERVERTEBRAL DISC CELLS}

Authors: Pino Minguez, Jesús ${ }^{1}$; Ruiz Fernández, Clara² ${ }^{2}$ González Rodríguez, María ${ }^{2}$; Cordero Barreal, Alfonso ${ }^{2}$; Villar Liste, Rosa ${ }^{2}$; Camba, Miguel ${ }^{2}$; Ait Eldjoudi, Djediga ${ }^{2}$; Díez Ulloa, Máximo Alberto $^{3}$; Farrag Abdelhafez, Yousof Ramadan ${ }^{2}$; Conde Aranda, Javier $^{2}$; Gualillo, Oreste ${ }^{2}$

Affiliations: ${ }^{1}$ SERGAS, Xerencia de Xestión Integrada de Santiago XXI Santiago, Laboratorio de Investigación Neirid, IDIS (Instituto de Investigación Sanitaria de Santiago), Santiago de Compostela, Spain; ${ }^{2}$ Laboratorio Neirid. Instituto de Investigación IDIS, Santiago de Compostela, Spain; ${ }^{3}$ COT. CHU Santiago de Compostela, Santiago de Compostela, Spain

Background: C-reactive protein (CRP) is an early indicator of infection and inflammation; knowing its value may help determine the progression of an inflammatory or autoimmune disease and/or effectiveness of a treatment. C-reactive protein mainly circulates as a pentamer, and, to date, its physiopathological function at the level of

Table 1 Inter-rater reliability assessment of 200 pedicle screws among three raters

\begin{tabular}{|c|c|c|c|c|c|c|}
\hline & \multicolumn{3}{|c|}{ Fleiss Kappa } & \multicolumn{3}{|c|}{ Intraclass correlation } \\
\hline & Kappa & $95 \% \mathrm{CI}$ & $p$ value & ICC & $95 \% \mathrm{CI}$ & $p$ value \\
\hline Axial CAT & 0.049 & -0.009 to 0.106 & 0.096 & 0.371 & $0.204-0.508$ & $<0.001$ \\
\hline Sagittal CAT & -0.024 & -0.092 to 0.044 & 0.493 & 0.129 & -0.098 to 0.316 & 0.121 \\
\hline AP X-ray & 0.034 & -0.018 to 0.087 & 0.201 & 0.548 & $0.403-0.658$ & $<0.001$ \\
\hline Lateral X-ray & 0.275 & $0.198-0.351$ & 0.0001 & 0.751 & $0.671-0.811$ & $<0.001$ \\
\hline
\end{tabular}

$C A T$ computed axial tomography, $A P$ anteroposterior 
intervertebral disc cells, both in nucleus pulposus (NP) and fibrous ring, remains unknown. Under certain pathological conditions, pentameric C-reactive protein may dissociate to its monomers, generating monomeric C-reactive protein (mCRP). Although in some cells the role of mCRP has been partially clarified, its activity at the level of intervertebral disc cells has not been yet elucidated. The main objective of this study was to investigate the physiopathological relevance of mCRP in healthy and degenerated intervertebral disc cells. Materials and methods: We examined the in vitro effects of mCPR administration on the expression of multiple mediators of inflammatory response of NP and annulus fibrosus (AF) cells by qRT-PCR and western blot analysis. AF and NP cells were obtained by enzymatic digestion with collagenase and pronase, used in the first passage to prevent the loss of phenotype. mRNAs were obtained by Trizol extraction and subsequent purification on Macherey-Nagel columns. Reverse transcription reaction, e.g., PCR amplification, was carried out with specific primers from Superarray Biosciences (Quiagen) in a real-time thermocycler (Stratagene MX3005P, Agilent). Western blot protein analysis was done with reagents and equipment from BioRad and antibodies from Cell Signaling.

Results: Results indicated that mCRP increased mRNA and protein expression of different inflammatory and degenerative mediators such as NOS2, COX2, MMP13, VCAM1, IL-6, IL-8, and LCN2.

Conclusions: mCRP exerts a powerful catabolic effect on the cells of the intervertebral disc, increasing the expression of inflammatory mediators and proteolytic enzymes, which promote disc tissue degradation and inflammation.

\section{ORAL COMMUNICATION 18}

\section{SURGICAL CORRECTION OF HYPERKYPHOSIS DOES NOT IMPROVE CARDIORESPIRATORY PARAMETERS IN SCHEUERMANN'S DISEASE}

Authors: Palacios Cabezas, Pablo ${ }^{1}$; Palacios Duch, Isabel ${ }^{2}$; Lorente Gómez, Alejandro ${ }^{3}$; Lorente Moreno, Rafael ${ }^{4}$

Affiliations: ${ }^{1}$ Hospital Universitario Madrid Sanchinarro, Madrid, Spain; ${ }^{2}$ Hospital de Henares, Madrid, Spain; ${ }^{3}$ Hospital Universitario Ramón and Cajal, Madrid, Spain; ${ }^{4}$ Hospital Infanta Cristina, Badajoz, Spain

Background and objectives: An inverse correlation between thoracic kyphosis and aerobic capacity in patients with Scheuermman's disease greater than $75^{\circ}$ has been described. It is not known if surgical correction improves these parameters. The purpose of this work was to assess the effect of surgery on cardiorespiratory fitness in patients with Scheuermann's disease.

Materials and methods: Prospective longitudinal study that included a cohort of 23 patients with Scheuermann's disease aged between 13 and 15 years who underwent surgery. Mean thoracic kyphosis was $78.3^{\circ} \pm 5.1^{\circ}$ Cobb. We assessed surgical correction and cardiorespiratory parameters including maximal oxygen uptake (VO2max), expiratory volume (EV), duration of the exercise, and energy cost (metabolic equivalents-MET); these parameters were compared against the magnitude of the curve.

Results: Mean correction was $43 \%$ (Cobb: $44.6^{\circ} \pm 2.9^{\circ}$ ). No improvements were observed for most cardiorespiratory parameters 2 years after surgery. VO2max was similar before and after surgery (preoperative $36.7 \pm 8.5 \mathrm{ml} / \mathrm{kg} / \mathrm{min}$ vs. postoperative $36.9 \pm 8.2$ ). There was no correlation between the percentage of correction and changes in $\mathrm{VO} 2 \mathrm{max}$ or $\mathrm{EV}$.

Conclusions: Patients with Scheuermann's disease have limited tolerance to maximum exercise that does not improve 2 years after surgical correction.

\section{ORAL COMMUNICATION 19}

\section{DECREASE IN THE RATE OF COMPLICATIONS AND HOSPITAL STAY IN PATIENTS WHO UNDERGO ADOLESCENT IDIOPATHIC SCOLIOSIS FOLLOWING THE ENHANCED RECOVERY AFTER SURGERY PROTOCOL}

Authors: Peiró García, Alejandro; Vilalta Vidal, Imma; García Fontecha, César Galo

Affiliation: Hospital Sant Joan de Deu, Barcelona, Spain

Background and objectives: The enhanced recovery after surgery (ERAS) protocol is an evidence-based multidisciplinary approach for perioperative management of major surgeries, aimed at reducing complications and rate of readmission, and improve functional recovery. The purpose of this work was to compare if the implementation of this agreed protocol for the postoperative management in adolescent idiopathic scoliosis (AIS) improves hospital stay and postoperative complications.

Materials and methods: The ERAS protocol was introduced in our center for AIS surgery since June 2019. Data from patients who underwent AIS surgery between June 2018 and June 2020 by posterior instrumented fusion were recorded. Patients were divided into two groups: Group 1 (previous protocol, from June 2018 to June 2019) and Group 2 (the ERAS protocol, from June 2019 to June 2020). The following data were registered: demographic, radiological, postoperative complications, days of hospital stay and ICU, and reinterventions.

Results: Ninety-four patients were registered, 54 in Group 1 and 39 in Group 2. No significant intergroup differences were observed regarding demographic (age, sex, origin) and preoperative radiological data (type of curve and magnitude). Rate of complications was significantly higher in Group $1(p=0.014)$ : 13 complications in Group 1 and two in Group 2 (one pleural effusion due to hydric overcharge in ICU and a prominence of material that did not require surgical revision. Three reinterventions were performed in Group 1 and none in Group 2, with no statistically significant difference $(p=0.191)$, probably due to the low number of cases. Hospital stay was significantly lower in Group 2 (mean of 4.97 vs. mean of 7.64 days in Group 1) $(p=0.000)$. Regarding stay in the ICU, no intergroup differences were determined (1.06 in Group 1 vs. 1.0 in Group 2) $(p=0.083)$.

Table 1 Hospital and ICU stay group statistics

\begin{tabular}{llllll}
\hline & Group & N & Mean & Standard deviation & Mean standard error \\
\hline Hospital stay & Pre-ERAS & 55 & $\underline{\mathbf{7 . 6 4}}$ & 2.895 & 0.390 \\
\multirow{2}{*}{ ICU stay } & ERAS & 39 & $\underline{\mathbf{4 . 9 7}}$ & 1.630 & 0.261 \\
& Pre-ERAS & 54 & $\underline{\mathbf{1 . 0 6}}$ & 0.231 & 0.031 \\
& ERAS & 39 & $\underline{\mathbf{1 . 0 0}}$ & 0.000 & 0.000 \\
\hline
\end{tabular}


Table 2 Complications crosstab count

\begin{tabular}{llrl}
\hline & \multicolumn{2}{l}{ Group } & Total \\
\cline { 2 - 3 } & Pre-ERAS & ERAS & \\
\hline Complications & & 37 & 79 \\
No & 42 & $\mathbf{2}$ & 15 \\
Yes & $\underline{\mathbf{1 3}}$ & 39 & 94 \\
Total & $\mathbf{5 5}$ & & \\
\hline
\end{tabular}

Table 3 Reinterventions crosstab count

\begin{tabular}{lrrr}
\hline & \multicolumn{2}{c}{ Group } & Total \\
\cline { 2 - 3 } & Pre-ERAS & ERAS & \\
\hline Reintervention & 51 & 39 & \\
No & $\underline{\mathbf{3}}$ & $\mathbf{0}$ & 30 \\
Yes & 54 & 39 & 93 \\
Total & & & \\
\hline
\end{tabular}

Conclusions: This study suggests that the ERAS protocol for AIS surgery is associated to a decrease of hospital stay and improvement of postoperative care. (Tables 1, 2 and 3).

\section{ORAL COMMUNICATION 20}

\section{CAN IMAGING TESTS CORRECTLY CAPTURE DEFORMITIES? CORRELATION BETWEEN TAPS, SRS 22, AND SURFACE TOPOGRAPHY IN ADOLESCENT IDIOPATHIC SCOLIOSIS}

Authors: Muñoz Núñez, Laura; Riquelme García, Óscar; García Martín, Azucena

Affiliation: Hospital General Universitario Gregorio Marañón, Madrid, Spain

Background and objectives: Adolescent idiopathic scoliosis (AIS) is characterized by rotation of the vertebral bodies and trunk asymmetry. Quantification of vertebral rotation may be done by clinical and radiological methods.

During consultation, it is common to find discrepancies between radiological deformity (Cobb angle) and aesthetic deformity, hampering decision-making.

Self-image scales together with surface topography are specific instruments used to assess pre- and postoperative asymmetry, showing the relationship between them.

The objectives of this study was to compare subjective deformity scales against objective measurements (surface topography) to assess the agreement in the estimation of symmetry.

Materials and methods: Prospective study (2017-2020) carried out in a pediatric tertiary center that included 18 AIS patients who required surgery.

We analyzed radiological (Cobb), scoliometer, TAPS and SRS22 (self-image domain) scales, and preoperative surface topography study data.

For the surface topography study, the patient was in a standing position to obtain a surface model. A specific software allowed defining the relationship between the distance of the surface of one hemibody and the reflected one. These distances were expressed in a colormap.

Statistical analyses were carried out with the Mann-Whitney U test.

Results: Preoperative Cobb, SRS-22, and TAPS were $59.5^{\circ}$ (44-82), 3.2 , and 3.1, respectively.

Postoperative Cobb, SRS-22, and TAPS were $29^{\circ}$ (17-46), 4.15 and 4.3 , respectively.

The resulting asymmetry showed a mean distance decrease of $49.31 \%$, as well as a decline in preoperative and postoperative data dispersion (median $47.83 \%$ and SD: $52.09 \%$ ). The colormap showed correction of coronal deviation with some asymmetries in the scapulae and shoulders.

No differences in the results between the tests assessing trunk asymmetry were found.

Conclusions: The imaging tests show similar results regarding symmetry estimation; moreover, they suggest clear improvement after surgery.

Imaging tests are non-invasive useful tools to objectively and subjectively compare preoperative existing asymmetries and postoperative improvements.

\section{ORAL COMMUNICATION 21}

\section{SPINAL MUSCULAR ATROPHY AND SCOLIOSIS: IS NUSINERSEN ADMINISTRATION POSSIBLE IN PATIENTS WITH SEVERE OR OPERATED SCOLIOSIS?}

Authors: Vilalta Vidal, Imma; Peiró García, Alejandro; Carrera García, Laura; Natera De Benito, Daniel; Ortez González, Carlos Ignacio; Nascimento Osorio, Andrés; García Fontecha, César Galo

Affiliation: Hospital Sant Joan de Deu, Barcelona, Spain

Background: Spinal muscular atrophy (SMA) is a motor neuron disease caused by the absence of the SMN1 gene and one of the genetic disorders with the highest mortality rate. Treatment with nusinersen is promising for patients affected by this disease, who require repeated intrathecal administration, with the difficulties associated to severe or operated scoliosis.

Objectives: To describe our experience with intrathecal administration of nusinersen in patients with severe or operated scoliosis. Assess if operated scoliosis are a contraindication for this intrathecal therapy. Materials and methods: Prospective, observational study in patients with SMA and severe or prior scoliosis surgery, carried out between March 2018 and November 2019. The following variables were collected: age, sex, Cobb angle, pelvic obliquity (PO), and kyphosis in patients who had not undergone surgery. In operated patients: type of surgery and complications, number of processes, need of CT scan for intrathecal puncture, contraindications for the administration and alternatives.

Results: Sixteen patients, 10 boys/6 girls, aged between nine and 20 years. Four, who had not been operated, had scoliosis with Cobb angle of $80^{\circ}-87^{\circ}$, PO of $14^{\circ}-25^{\circ}$, and kyphosis of $55^{\circ} / 115^{\circ}$. From the 12 patients who had been operated: six had growth rods, five instrumented arthrodesis (one with bone window), one spinal fusion with removal of material. In seven of the patients who had undergone surgery, the technique was dismissed after CT scan due to the riskbenefit balance and complex puncture: in one case (removal of material) it was not possible due to bone fusion, three transforaminal technique achievable, three achievable but with technical difficulties. From the nine patients to whom the technique was applied: four had not been operated, five operated: two growth rods and three arthrodesis, total of 45 interlaminar route processes, eight patients required CT scan-guided puncture. One of the patients with growth 
rods who underwent surgery had cerebrospinal fluid leak. Minor complications: headache and pain at puncture site.

Conclusions: Treatment with nusinersen is possible even in patients with instrumented fusion. No bone fusion differences are seen in CT scans of patients who underwent surgery with growth rods and arthrodesis. Patient with bone window required puncture at another level due to fusion. Is free access for intrathecal administration of the drug during the surgical strategy necessary in these patients?

\section{ORAL COMMUNICATION 22}

\section{RELATIONSHIP OF DISTAL INSTRUMENTATION LEVEL IN LUMBAR MORPHOLOGY AND SPINOPELVIC PARAMETERS}

Authors: Javier Martínez, Elías Enmanuel ${ }^{1}$; Rodríguez Pino, Luis²; Bovea Marco, Miquel ${ }^{2}$; Simón Pérez, Vicent ${ }^{2}$; De Pedro Abascal, $\mathrm{Miguel}^{2}$; Pérez Vergara, Silvia ${ }^{2}$; Morales Valencia, Jorge Mario ${ }^{2}$; Rubio Belmar, Pedro Antonio ${ }^{2}$; Bas Hermida, José Luis²; Bas Hermida, Paloma ${ }^{2}$; Bas Hermida, Teresa ${ }^{2}$

Affiliations: ${ }^{1}$ Clínica Santa María de la Asunción, Tolosa, Spain; ${ }^{2}$ Hospital Politécnico and Universitario La Fe, Valencia, Spain

Background and objectives: Adolescent idiopathic scoliosis surgery aims the greatest correction of all spatial planes, establishing a balance between the fused and non-fused segments to maintain the highest trunk movement with the fewest possible mechanical complications.

The purpose of this work was to identify morphological changes and spinopelvic parameters associated to the selection of distal instrumentation level following posterior instrumented arthrodesis in patients with Lenke types I and II adolescent idiopathic scoliosis.

Materials and Methods: Retrospective analysis of data collected prospectively in a cohort of patients with adolescent idiopathic scoliosis who had undergone treatment.

Twenty-two patients who underwent surgery in one center between January 2008 and January 2018 were selected. Preoperative and at 2 years spinopelvic and morphological parameters were analyzed.

A preoperative planning software was used to calculate pelvic incidence, pelvic tilt, sacral slope, lumbar lordosis, thoracic kyphosis, T1-pelvic angle, inflexion point of thoracic curve to lumbar curve.

Presence of mechanical complications were identified in patient's medical record: adding-on and DJK.

Statistical relationship between variables determined using R; $p$ values $<0.05$ were considered significant.

Results: No statistically significant differences were found between spinopelvic parameters and distal level of instrumentation in patients with idiopathic scoliosis.

Regarding morphological variables, significant statistical relationships were seen between the translation of the lumbar apex and postoperative lumbar lordosis ( $p=0.016$ ), as well as of the T1-pelvic angle with the translation of the thoracolumbar inflexion point $(p=0.012)$.

Conclusions: Translation of the lumbar apex could modify the extent of lumbar lordosis and translation of the inflexion point can change T1-pelvic angle. Both of these morphological parameters should be taken into consideration perioperatively due to their relationship with quality of life.

\section{ORAL COMMUNICATION 23}

\section{PARS REPAIR SURGICAL TREATMENT OF SPONDYLOLYSIS IN SPORTS PATIENTS: PROSPECTIVE STUDY}

Authors: González Menocal, Alfonso'; Egea Gámez, Rosa María² Galán Olleros, María ${ }^{3}$; González Díaz, Rafael ${ }^{4}$

Affiliations: ${ }^{1}$ Hospital Universitario Infanta Elena, Madrid, Spain; ${ }^{2}$ Hospital Universitario Niño Jesús, Madrid, Spain; ${ }^{3}$ Hospital Clínico San Carlos, Madrid, Spain; ${ }^{4}$ Hospital Universitario Niño Jesús. Hospital Nuestra Señora Del Rosario. Hospital Sanitas La Moraleja, Madrid, Spain

Background and objectives: Spondylolysis is the most common identifiable cause of low back pain in children and adolescents. Surgical treatment is reserved for symptomatic cases, despite being a conservative therapy. The aim of this study was to analyze the results of pars repair surgery in athletes with L2 to L4 injuries.

Materials and methods: Prospective multicenter study that included all sports patients who underwent surgery for traumatic spondylolysis (positive scanning and MR without disc degeneration) by pars repair; debridement + iliac crest autograft and sublaminar fixation with a pedicle screw-hook system, except in patients with unilateral lesion who were treated with screw and wire. Pre- and postoperative clinical (Oswestry Disability Index (ODI) and visual analogue scale for pain (VAS)) and radiological data were collected, as well as complications. Patients with L5 spondylolysis (different biomechanical behavior), multiple-level spondylolysis, or other type of spinal deformity were excluded from the study.

Results: Data of 18 middle- and high-class sports patients were analyzed; mean age was 17.3 (12-22) years. All had bilateral spondylolysis except one with unilateral. Rate post-surgery consolidation was $100 \%$, confirmed by CAT $4-6$ months post-intervention. No relevant clinical or radiological complications were identified during follow-up. Mean VAS score changed from 7.6 to 0.8 and ODI from 70 to 2 after surgery. All patients recovered their regular activities and there were no recurrence of symptoms. There was no need to remove instrumentation in any of the cases.

Conclusions: Pars repair in sports patients with traumatic spondylolysis is an effective procedure, with very high fusion rates and satisfactory results as per the assessment scales, as well as a return to regular activities and associated to low percentage of complications (Table 1).

\section{ORAL COMMUNICATION 24}

\section{PREDICTION MODEL FOR PROGNOSIS AND SEQUELAE OF CERVICAL SPRAIN IN TRAFFIC ACCIDENTS}

Authors: Bastida Mera, José; Pescador Hernández, David; Crespo Cullell, Íñigo; Blanco Blanco, Juan Francisco; Díaz Álvarez, Agustín; De Haro López, José Miguel; Gómez Ruiz, Victoria; Ollero Malagón, Lourdes; Martin Moreno, Víctor

Affiliation: Hospital Universitario de Salamanca, Salamanca, Spain

Objectives and background: Cervical sprain (CS) is a high incidence injury in traffic accidents and a therapeutic challenge; psychosocial factors seem to be more relevant than physical factors in the prognosis. Bad prognosis factors regarding outcome and sequelae are diverse, and although they have been defined in multiple countries, this has not clearly be done in Spain.

The main objectives of this study were to establish a prediction model of the degree of impairment 6 months after the Injury, assess 
Table 1 Published articles over the past 10 years on pars repair in spondylolysis patients $<30$ years*

\begin{tabular}{|c|c|c|c|c|c|c|c|c|c|}
\hline Study & $\mathrm{n}$ & $\begin{array}{l}\text { Age, years } \\
\text { (range) }\end{array}$ & Level & $\begin{array}{l}\text { Unilateral } \\
\text { or } \\
\text { bilateral }\end{array}$ & Repair technique & $\begin{array}{l}\text { Preoperative } \\
\text { functional } \\
\text { result }\end{array}$ & $\begin{array}{l}\text { Postoperative } \\
\text { functional } \\
\text { result }\end{array}$ & $\begin{array}{l}\% \text { of } \\
\text { consolidation }\end{array}$ & $\begin{array}{l}\text { Follow-up } \\
\text { (months) }\end{array}$ \\
\hline $\begin{array}{l}\text { Altaf et al. } \\
\quad(2011)^{\dagger}\end{array}$ & 20 & $13.9(9-21)$ & L5 (20) & 20-bilateral & $\begin{array}{l}\text { Pedicle screw by } U \\
\text { rod }+ \text { iliac crest } \\
\text { autograft } \\
\\
(27.6-87.6)\end{array}$ & $\begin{array}{l}\text { ODI } 54 \\
\quad(42-78) \\
\text { VAS } 8.1 \\
(6.5-10)\end{array}$ & $\begin{array}{l}\text { ODI } 8(8-42)) \\
\text { VAS } 1.6 \\
(0-8.2)\end{array}$ & 80 & 48 \\
\hline \multirow[t]{2}{*}{$\begin{array}{l}\text { Giudici et al. } \\
\quad(2011)^{\dagger} \\
\quad(24-180)\end{array}$} & 7 & $18(10-26)$ & $\begin{array}{l}\text { L4 (3), L5 } \\
\quad(59)\end{array}$ & 7-bilateral & $\begin{array}{l}\text { Buck repair }+ \text { iliac crest } \\
\text { autograft }\end{array}$ & NR & Good $28.5 \%$ & 42.85 & 78 \\
\hline & $\begin{array}{r}8 \\
37\end{array}$ & & & $\begin{array}{l}\text { 8-bilateral } \\
\text { 37-bilateral }\end{array}$ & $\begin{array}{l}\text { Scott repair + graft } \\
\text { Pedicle } \\
\text { screw }+ \text { wire }+ \text { iliac } \\
\text { crest autograft }\end{array}$ & $\begin{array}{l}\mathrm{NR} \\
\mathrm{NR}\end{array}$ & $\begin{array}{l}\text { Good } 62.5 \% \\
\text { Good } 83.5 \%\end{array}$ & $\begin{array}{l}87.5 \\
97.29\end{array}$ & \\
\hline $\begin{array}{l}\text { Rajasekaran } \\
\text { et al. } \\
\quad(2011)^{\dagger}\end{array}$ & 9 & $24(15-31)$ & $\begin{array}{l}\mathrm{L} 2 \text { (1), L3 } \\
\quad(1), \mathrm{L} 4 \\
\quad(1), \mathrm{L} 5 \\
\quad(8)\end{array}$ & $\begin{array}{l}\text { 2-unilateral } \\
\text { 7-bilateral }\end{array}$ & $\begin{array}{l}\text { Buck repair }+ \text { iliac crest } \\
\text { autograft }\end{array}$ & NR & $\begin{array}{l}\text { Satisfactory in } \\
\quad 78 \%\end{array}$ & 100 & $45(9-108)$ \\
\hline $\begin{array}{l}\text { Kim et al. } \\
\quad(2012) \\
\quad(36-123)\end{array}$ & 25 & $21(15-29)$ & $\begin{array}{l}\text { L4 (1), L5 } \\
\quad(24)\end{array}$ & $\begin{array}{l}\text { 2-unilateral } \\
\text { 23-bilateral }\end{array}$ & $\begin{array}{l}\text { Buck repair }+ \text { iliac crest } \\
\text { autograft }\end{array}$ & NR & $\begin{array}{l}\text { Good or } \\
\text { excellent } \\
88 \%\end{array}$ & 72 & 71 \\
\hline $\begin{array}{l}\text { Hioki et al. } \\
\quad(2012)\end{array}$ & 44 & $24.2 \pm 5.4$ & $\begin{array}{l}\text { L4 (2), L5 } \\
\quad(44)\end{array}$ & 44-bilateral & $\begin{array}{l}\text { Scott repair }+ \text { iliac crest } \\
\text { autograft }\end{array}$ & $\begin{array}{l}\text { JOA score } \\
20.3 \pm 3.7\end{array}$ & $\begin{array}{l}\text { JOA score } \\
25.4 \pm 2.1\end{array}$ & 67.4 & $85 \pm 17$ \\
\hline \multirow[t]{2}{*}{$\begin{array}{l}\text { Clegg et al. } \\
\quad(2013)^{\dagger}\end{array}$} & 49 & $17.7(10-22)$ & $\begin{array}{l}\mathrm{L} 3 \text { (2), L4 } \\
\quad \text { (3), L5 } \\
\quad \text { (42), L6 } \\
\quad \text { (2) }\end{array}$ & $\begin{array}{l}\text { 8-unilateral } \\
\text { 41-bilateral }\end{array}$ & $\begin{array}{l}\text { Scott repair }+ \text { iliac crest } \\
\text { autograft }\end{array}$ & NR & $\begin{array}{l}\text { ODI } \\
\qquad 10.2 \pm 15.9\end{array}$ & NR. $14.3 \%$ & \\
\hline & & & & & reintervention & $21.7 \pm 5.5$ & & & \\
\hline $\begin{array}{l}\text { De Bodman } \\
\text { et al. } \\
\quad(2014)^{\dagger}\end{array}$ & 35 & $13.7(7-19)$ & L5 (35) & 35-bilateral & $\begin{array}{l}\text { Modified Buck } \\
\text { repair + iliac crest } \\
\text { autograft }\end{array}$ & NR & ODI 12.6 & & \\
\hline$(0-57.7)$ & 91.4 & $112(24-288)$ & & & & & & & \\
\hline \multirow[t]{2}{*}{$\begin{array}{l}\text { Synder et al. } \\
\text { (2014) }\end{array}$} & 16 & $16(11-30)$ & $\begin{array}{l}\mathrm{L} 3(2), \mathrm{L} 4 \\
\quad(3), \mathrm{L} 5 \\
\quad(11)\end{array}$ & $\begin{array}{l}\text { 3-unilateral } \\
\text { 13-bilateral }\end{array}$ & $\begin{array}{l}\text { Buck repair + Autograft or } \\
\text { allograft }+ \text { BMP }\end{array}$ & NR & $88 \%$ & & \\
\hline & & & & & asymptomatic & 89.6 & $14.06(12-26)$ & & \\
\hline $\begin{array}{l}\text { Menga et al. } \\
(2014)^{\dagger}\end{array}$ & 31 & $16(10-37)$ & $\begin{array}{l}\mathrm{L} 3 \text { (2), L4 } \\
\quad \text { (3), L5 } \\
\quad \text { (26), L6 } \\
\quad(1)\end{array}$ & $\begin{array}{l}\text { 4-unilateral } \\
\text { 27-bilateral }\end{array}$ & $\begin{array}{l}\text { Buck repair }+ \text { iliac crest } \\
\text { autograft }\end{array}$ & VAS $7(1-10)$ & VAS $2(0-10)$ & 93.54 & 60 \\
\hline $\begin{array}{l}\text { Gillis et al. } \\
\text { (2015) }\end{array}$ & 7 & $16-23$ & $\begin{array}{l}\mathrm{L} 3(2), \mathrm{L} 5 \\
\quad(5)\end{array}$ & 7-bilateral & $\begin{array}{l}\text { Pedicle } \\
\text { screw }+ \text { wire }+ \text { bone } \\
\text { grafting }+ \text { BMP, MIS }\end{array}$ & NR & $\begin{array}{l}-29 \text { with } \\
\text { respect to } \\
\text { previous } \\
\text { values }\end{array}$ & 85.7 & $12-54$ \\
\hline $\begin{array}{l}\text { Lee et al. } \\
\text { (2015) }\end{array}$ & 47 & $22.7 \pm 6.8$ & $\begin{array}{l}\text { L3 (1), L4 } \\
\quad(13), \text { L5 } \\
\quad(33)\end{array}$ & $\begin{array}{l}\text { 3-unilateral } \\
\text { 44-bilateral }\end{array}$ & $\begin{array}{l}\text { Buck repair }+ \text { iliac crest } \\
\text { autograft }\end{array}$ & $\begin{array}{l}\text { VAS } 8.4 \pm 2 \\
\text { ODI } \\
25.3 \pm 6.2\end{array}$ & $\begin{array}{l}\text { VAS } 3.7 \pm 1.2 \\
\text { ODI } 4.7 \pm 7.1\end{array}$ & $55 \%$ & $14.4 \pm 3.7$ \\
\hline \multirow[t]{3}{*}{$\begin{array}{l}\text { Karatas et al. } \\
\qquad(2016)^{\dagger}\end{array}$} & 9 & $15.8(13-17)$ & $\begin{array}{l}\mathrm{L} 2 \text { (1), L4 } \\
\quad \text { (3), L5 } \\
\quad(6)\end{array}$ & 3-unilateral & 6-bilateral & Buck & & & \\
\hline & & & & & $\begin{array}{l}\text { repair }+ \text { iliac crest } \\
\text { autograft }+ \text { BMP, MIS }\end{array}$ & NR & Good $88.8 \%$ & 100 & $21 \pm 8.5$ \\
\hline & 7 & $16.4(14-18)$ & $\begin{array}{l}\mathrm{L} 3(1), \mathrm{L} 4 \\
\quad(1), \mathrm{L} 5 \\
\quad(6)\end{array}$ & $\begin{array}{l}\text { 2-unilateral } \\
\text { 5-bilateral }\end{array}$ & $\begin{array}{l}\text { Sublaminar pedicle screw- } \\
\text { hook system }+ \text { iliac crest } \\
\text { autograft } \pm \text { BMP }(2)\end{array}$ & NR & Good $85.7 \%$ & 100 & $24 \pm 13.5$ \\
\hline
\end{tabular}


Table 1 continued

\begin{tabular}{|c|c|c|c|c|c|c|c|c|c|}
\hline Study & $\mathrm{n}$ & $\begin{array}{l}\text { Age, years } \\
\text { (range) }\end{array}$ & Level & $\begin{array}{l}\text { Unilateral } \\
\text { or } \\
\text { bilateral }\end{array}$ & Repair technique & $\begin{array}{l}\text { Preoperative } \\
\text { functional } \\
\text { result }\end{array}$ & $\begin{array}{l}\text { Postoperative } \\
\text { functional } \\
\text { result }\end{array}$ & $\begin{array}{l}\% \quad \text { of } \\
\text { consolidation }\end{array}$ & $\begin{array}{l}\text { Follow-up } \\
\text { (months) }\end{array}$ \\
\hline $\begin{array}{l}\text { Jia et al. } \\
\text { (2016) }\end{array}$ & 8 & $28.4 \pm 6.3$ & $\begin{array}{l}\text { L4 (2), L5 } \\
\quad(6)\end{array}$ & 8-bilateral & $\begin{array}{l}\text { Navigated Buck repair, } \\
\text { MIS + iliac crest } \\
\text { autograft }\end{array}$ & VAS 6.8 & VAS 1.4 & 81.3 & $\begin{array}{l}27.4 \\
\quad(20-33)\end{array}$ \\
\hline $\begin{array}{l}\text { Brandon } \\
\text { et al. } \\
2017)^{\dagger}\end{array}$ & 9 & 15.4. (13-17) & $\begin{array}{l}\text { L4 (2), L5 } \\
\quad(7)\end{array}$ & $\begin{array}{l}\text { 1-unilateral } \\
\text { 8-bilateral }\end{array}$ & $\begin{array}{l}\text { Sublaminar pedicle screw- } \\
\text { hook system }+ \text { autograft } \\
\text { local }\end{array}$ & $\begin{array}{l}\text { VAS } 5.6 \\
\quad(2-8)\end{array}$ & VAS $1.2(0-3)$ & 77.8 & $11.9(6-24)$ \\
\hline $\begin{array}{l}\text { Ghobrial } \\
\text { et al. } \\
\text { ( } 2017\end{array}$ & 9 & $17.7(14-20)$ & $\begin{array}{l}\text { L4 (4), L5 } \\
\quad(5)\end{array}$ & 9-bilateral & Buck repair + BMP, MIS & $\begin{array}{l}\text { VAS } \\
\quad 7.33 \pm 2.35\end{array}$ & $\begin{array}{l}\text { VAS } \\
\quad 0.11 \pm 0.33\end{array}$ & 66.7 & $30.8(3-59)$ \\
\hline $\begin{array}{l}\text { Debnath } \\
\text { et al. } \\
\text { (2018) }\end{array}$ & 52 & $19(8-30)$ & $\begin{array}{l}\text { L3 (4), L4 } \\
\quad \text { (3), L5 } \\
\quad(43)\end{array}$ & $\begin{array}{l}\text { 9-unilateral } \\
\text { 43-bilateral }\end{array}$ & $\begin{array}{l}\text { Buck repair }(44) / \text { Scott } \\
\text { repair }(3) / \text { Other } \\
(2)+\text { iliac crest } \\
\text { autograft }\end{array}$ & $\begin{array}{l}\text { VAS } \\
\quad 6.6 \pm 0.97 \\
\text { ODI } \\
37 \pm 10.5\end{array}$ & $\begin{array}{l}\text { VAS } 0.8 \pm 1.2 \\
\text { ODI } \\
\quad 9.2 \pm 13.4\end{array}$ & NR & NR \\
\hline \multirow[t]{2}{*}{$\begin{array}{l}\text { Ishida et al. } \\
\text { (2018) }\end{array}$} & 5 & $16(11-20)$ & $\begin{array}{l}\mathrm{L} 3 \text { (1), L4 } \\
\quad(3), \mathrm{L} 5 \\
\quad(15)\end{array}$ & 5-bilateral & $\begin{array}{l}\text { Hook system }+ \text { iliac crest } \\
\text { autograft }\end{array}$ & VAS $8 \pm 0$ & VAS $4 \pm 0$ & 40 & $22(9-39)$ \\
\hline & 13 & & & 13-bilateral & $\begin{array}{l}\text { Sublaminar pedicle screw- } \\
\text { hook system + iliac crest } \\
\text { autograft }\end{array}$ & $\begin{array}{l}\text { VAS } \\
\quad 5.8 \pm 2.6\end{array}$ & VAS $2.5 \pm 2.3$ & 71 & \\
\hline $\begin{array}{l}\text { Linhares } \\
\text { et al. } \\
(2019)^{\dagger}\end{array}$ & 22 & $28.28 \pm 11.4$ & $\begin{array}{l}\text { L4 (1), L5 } \\
\quad(22)\end{array}$ & 22-bilateral & $\begin{array}{l}\text { Pedicle screw by } \mathrm{U} \text { rod }+ \\
\text { iliac crest autograft }\end{array}$ & VAS & $\begin{array}{l}\quad 8.06 \pm 1.09 \\
\text { ODI } \\
43.5 \pm 21.0\end{array}$ & $\begin{array}{l}\text { VAS } \\
\quad 3.1 \pm 2.9 \\
\text { ODI } \\
20.9 \pm 22.1\end{array}$ & 95.5 \\
\hline \multicolumn{10}{|l|}{$171.9 \pm 15$} \\
\hline $\begin{array}{l}\text { Ücer et al. } \\
\quad(2020)^{\dagger}\end{array}$ & 18 & $23.7(18-32)$ & $\begin{array}{l}\text { L4 (4), L5 } \\
\quad(14)\end{array}$ & 18-bilateral & Buck repair, MIS & VAS & $\begin{array}{l}\quad 6.93 \pm 2.35 \\
\text { ODI } \\
64.8 \pm 12.4\end{array}$ & $\begin{array}{l}\text { VAS } \\
1.1 \pm 0.31 \\
\text { ODI } \\
1.44 \pm 0.5\end{array}$ & 77 \\
\hline $\begin{array}{l}16.04 \\
\quad(12-28)\end{array}$ & & & & & & & & & \\
\hline
\end{tabular}

$O D I$ Oswestry disability index, VAS visual analogue scale for pain, $M I S$ minimally invasive surgery, $B M P$ bone morphogenetic protein, $J O A$ score, Japanese orthopedic association score for back pain, Buck repair intralaminar compression screw + graft, Scott repair circular repair with wire

*All studies between 2010 and 2020 with patients aged $<30$ years are included. Among the studies with individuals with age range $>30$, those in which mean age of patients was below 30 years, were included. Studies that included patients with other associated spinal deformities were excluded

† Study that includes patients with spondylolisthesis $<10-15 \%$ or Grade I;

demographic, own patient, and clinical bad prognosis, and role of physiotherapy in the management of CS.

Materials and methods: Prospective analytical study of 200 patients who suffered a traffic accident with $\mathrm{CD}$ diagnosis. Results were collected and codified in Excel by staff other than the physicians who attended the patients; analyses were carried out using the IBM SPSS package. A multivariate analysis of variance (MANOVA) was carried out and generation of a predictive model.

Results: Following MANOVA, three predictive models were obtained to know the value of the VAS, WDQ, and NSDI scales 6 months after discharge.

VAS. $-1.01+(-0.77$ smoker $)+(0.37$ seat $)+(0.07$ car of the injured individual $)+(0.03$ WDQ at discharge $)+(0.70$ headache at discharge $)+(-0.91$ depression $)+(0.59$ VAS at discharge $)$ WDQ. $-11.67+(-6.51$ smoker $)+(3.74$ seat $)+(1.02$ car of the injured individual $)+(0.81 \mathrm{WDQ}$ at discharge $)+(8.40$ headache at discharge)
NDI. $-7.58+(-4.28$ rectification in X-ray $)+(1.53$ number of occupants $)+(0.67$ initial VAS $)+(0.10$ WDQ at discharge $)+(0.87 \mathrm{NDI}$ at discharge $)+(-2.25$ (initial BA $)$.

Conclusions: CS is a relevant public health problem due to the high cost it has and the multiple factors that influence prognosis.

Despite the follow-up difficulties of these patients, three predictive formulae on injury prognosis have been obtained.

\section{ORAL COMMUNICATION 25}

COMPARATIVE STUDY OF TWO COHORTS OF PATIENTS WHO UNDERWENT ANTERIOR CERVICAL INTERBODY FUSION WITH PREFORMED ALLOGRAFT AND TANTALUM CAGES 
Authors: Mengis, Charles Louis $\mathrm{R}^{1}$; Gallego Bustos, Jesús ${ }^{1}$; Tomé Bermejo, Félix ${ }^{2}$; Benito Gallo, Marina ${ }^{1}$; Hevia García-Bobia, Ignacio $^{3}$; Peiró García, Alejandro ${ }^{4}$; Piñera Parrilla, Ángel R. ${ }^{5}$; Garzón Márquez, Francisco M. ${ }^{1}$; Rodríguez Arguisjuela, María G. ${ }^{1}$; Álvarez Galovich, Luis ${ }^{1}$

Affiliations: ${ }^{1}$ Fundación Jiménez Díaz. Unidad de Pathology de Columna, Madrid, Spain; ${ }^{2}$ Hospital Universitario Fundación Jiménez Díaz. Hospital General de Villalba, Madrid, Spain; ${ }^{3}$ Hospital General de Segovia, Segovia, Spain; ${ }^{4}$ Hospital Sant Joan de Deu, Barcelona, Spain; ${ }^{5}$ Hospital Universitario de Cabueñes, Gijón, Spain

Background and objectives: Theoretically, the use of allograft cages for anterior cervical interbody fusion (ACIF) has its advantages, as they can be cut out and display less magnetic susceptibility artifacts. However, there are no clinical studies assessing their incorporation capacity and stability over time. We carried out a radiological analysis of a cohort of patients with ACIF with allograft and compared it against a cohort ACIF with tantalum cages.

Materials and methods: We included 31 consecutive patients between 2016 and 2019 with degenerative cervical pathology in whom conservative treatment failed and who underwent 1- to 2-level ACIF, with minimum follow-up of 1 year. We collected demographic and radiological data (C1-C7 cervical lordosis, segmental lordosis, anterior and posterior vertebral height of the operated levels) in preoperative, immediate postoperative, and end of follow-up radiographs. A more than three-centimeter collapse of the cage was considered subsidence. Postoperative complications were analyzed. Results were compared against a cohort of patients who underwent cervical arthrodesis with tantalum cage.

Results: Thirty-one patients were included in the study (20 women). Mean age was 46 years (30-74) and 45 operated levels. Mean increase of regional lordosis in the immediate postoperative period was $7.7^{\circ}$ and $1.8^{\circ}$ loss at the end of follow-up. Regarding C1-C7 lordosis, $0.35^{\circ}$ were lost in the immediate postoperative period, with $4.1^{\circ}$ improvement at the end of follow-up. These trends were also observed for the tantalum cohort. Cage subsidence was diagnosed in four cases, observed more frequently in the tantalum group (11 cases). There was one case of chronic dysphagia, one wound dehiscence, and three implant breakages.

Conclusions: Lordotic allograft cages are useful for correcting segmental and cervical lordosis in patients with degenerative cervical pathology; values are comparable to those obtained with tantalum cages, but with higher rates of complications. Thus, we do not recommend their use (Tables 1 and 2).

\section{ORAL COMMUNICATION 26}

\section{RESULTS AFTER 5 YEARS OF A SECOND-GENERATION CERVICAL SPINE ARTHROPLASTY}

Table 1 Radiological follow-up of patients who underwent anterior cervical interbody fusion with tantalum cage

\begin{tabular}{lccc}
\hline & Preoperative* & Postoperative* & At the end of follow-up \\
\hline C1-C7 Cobb (cervical lordosis) & $44.2(13.5)$ & $42.6(13.8)$ & $54.3(12.7)$ \\
Segmental Cobb & $1.5(5.7)$ & $8.5(4.2)$ & $7.1(4.4)$ \\
\hline
\end{tabular}

Table 2 Radiological follow-up of patients who underwent anterior cervical interbody fusion with allograft cages

\begin{tabular}{lccc}
\hline & Preoperative* & Postoperative* & At the end of follow-up \\
\hline C1-C7 Cobb (cervical lordosis) & $36.97(13.6)$ & $36.6(12.4)$ & $40.7(9.3)$ \\
Segmental Cobb & $1.7(6.1)$ & $9.4(7)$ & $7.6(4.8)$ \\
\hline
\end{tabular}

Authors: Bosch García, David ${ }^{1}$; Luna Gutiérrez, Rodrigo ${ }^{1}$; García Cardona, Carlos ${ }^{1}$; Alonzo González, Francisco² ${ }^{2}$ Núñez Camarena, Jorge H. ${ }^{1}$; Escudero Cisneros, Berta ${ }^{1}$

Affiliations: ${ }^{1}$ Hospital Universitari Mutua de Terrassa, Barcelona, Spain; ${ }^{2}$ Hospital Ceibal de Accidentes del Instituto Guatemalteco de Seguridad Social, Ciudad de Guatemala, Guatemala

Background and objectives: "Second-generation" cervical arthroplasties are non-articulating disc prostheses (elastomeric deformable core), i.e., they do not rely on a mechanical interface with a specific friction couple. To the best of our knowledge, there are no published data on 5 years results on this type of arthroplasties. The purpose of this study was to determine the results after 5 years of second-generation cervical arthroplasty in the treatment of patients with cervical disc diseases with or without herniated discs, in our center.

Materials and methods: We assessed a historic cohort of all patients who underwent programmed cervical spine arthroplasty in our institution with use of a second-generation cervical prosthesis (M6-C artificial cervical disc). Inclusion criteria were patients with primary cervical surgery and minimum follow-up of 5 years. We assessed demographic, clinical, and radiological data.

Results: Thirty-seven patients; 59.5\% male. Mean age was 47.1 years (range 30-66). Mean follow-up was 75.1 months (range 62.5-92.2). One level and two levels were replaced in 27 and 10 patients, respectively. The most frequently replaced levels were C5-C6 in 17 patients and C6-C7 in 20 patients. Statistically significant improvement was observed at the end of follow-up for the Cervical Disability index, and cervical and radicular pain $(p<0,001)$. Regarding patient satisfaction, $89.1 \%$ communicated being satisfied or very satisfied. During the follow-up period, three patients required reintervention. Radiological results identified seven patients with adjacent syndrome, two of which underwent surgery again. Mean extension and flexion mobility at 5 years was 8.1 (SD 5.91).

Conclusions: In our center, second-generation cervical prostheses lead to good results 5 years after surgery (follow-up at 5 years), with improvement in functional and pain scales. Similarly, patient satisfaction is good with preservation of mobility. In this study, adjacent syndrome is seen in $18.9 \%$ of study patients and $8.1 \%$ underwent reintervention (Table 1).

\section{ORAL COMMUNICATION 27}

\section{MANAGEMENT OF DEGENERATIVE CERVICAL MYELOPATHY IN THE ELDERLY}

Authors: Álvarez, Ana Sofía; Ferrer Pomares, Pierre; Lara Almunia, Mónica; Tejada Solis, Sonia

Affiliation: Hospital Universitario Fundacion Jiménez Díaz, Madrid, Spain 
Table 1 Preoperative and at end of follow-up clinical data of study patients

\begin{tabular}{lccc}
\hline & Preoperative data (SD) & Follow-up at 5 yearrs (SD) & $p$ value \\
\hline Cervical disability index & 62.1 (SD 6.4) & 16.4 (SD 4.1) & $p<0.001$ \\
Visual analogue scale for pain at cervical level & 6.7 (SD 1.6) & 2.3 (SD 0.9) & $p<0.001$ \\
Visual analogue scale for pain at radicular level & 7.1 (SD 1.2) & 2.1 (SD 0.7) & $p<0.001$ \\
\hline
\end{tabular}

$S D$ standard deviation

Background and objectives: Management of cervical myelopathy secondary to spondyloarthritis in the elderly is controversial, with no clear recommendations in the literature in favor of surgery regarding prevention of spinal cord injury with severe neurological deterioration. The purpose of this study was to study cervical myelopathy after mild trauma in patients $>60$ years with previously asymptomatic degenerative cervical spinal stenosis.

Materials and methods: Retrospective study with patients $>60$ years diagnosed with cervical myelopathy between 2018 and 2019 and underwent surgery in our center. Pre- and postoperative clinical and radiological data were collected. Existence of a medical history of associated mild trauma was checked. Furthermore, we carried out a search in PubMed on the treatment of patients with degenerative cervical myelopathy over the past 10 years.

Results: Between 2018 and 2019, 91 patients diagnosed with cervical myelopathy underwent surgery, $47(51.6 \%)$ of which were $>60$ years (62-93 years). Thirty-three patients underwent microdiscectomy and cervical arthrodesis and 14 decompressive laminectomy. Fourteen (29.7\%) patients had medical history of associated mild trauma associated to the symptoms. Two patients required urgent surgery and three were admitted for early interventions due to sudden neurological worsening after trivial falls. Postoperative improvement was observed in 38 patients. Eight remained stable, one worsened, and one died 1 month after surgery. There were no postoperative acute complications. Eighty-seven articles were reviewed, obtained with the search phrase "surgical cervical myelopathy asymptomatic patients".

Conclusions: Cervical spondyloarthritis in the elderly is a risk factor for spinal cord injury after minor trauma that may affect $30 \%$ of at risk population. Programmed surgery in these patients has low risk and may prevent disabling neurological deterioration; thus, it should be considered when evaluating the risk-benefit of the intervention.

\section{ORAL COMMUNICATION 28}

\section{GRISEL'S SYNDROME: PROGRESSION OF NON- TRAUMATIC TORTICOLLIS IN PEDIATRIC POPULATION}

Authors: Martínez González, Carmen ${ }^{1}$; Quesada García, Belén ${ }^{2}$; Egea Gámez, Rosa María ${ }^{1}$; González Díaz, Rafael ${ }^{1}$

Affiliations: ${ }^{1}$ Hospital Infantil Niño Jesús, Madrid, Spain; ${ }^{2}$ Hospital Virgen del Prado, Talavera de la Reina, Spain

Background: Non-traumatic rotatory subluxation of the atlantoaxial joint (Grisel's syndrome) is associated to infections or otolaryngology surgeries in pediatric age. It is an uncommon pathology requiring high degree of clinical suspicion.

The aim of this study was to provide clinical and radiological descriptions, as well as treatment and progression of patients diagnosed with Grisel's syndrome.

Materials and methods: Retrospective, observational study of patients treated in our center between 2009 and 2019. Patients diagnosed with Grisel's syndrome and minimum follow-up of 1 year, were included in the study. The following parameters were assessed: clinical, analytical, and radiological, as well as prescribed treatments.
Results: Nineteen patients met the inclusion criteria (15 girls). Mean age was 6.9 years (1-15 years). Most common symptoms were cervicalgia associated to torticollis and limited range of cervical movement. Eight patients had medical history of ear, head, and neck surgery. Diagnostic delay was seven days (0.5-30). In $69 \%$ of the patients, increased CRP was detected in diagnostic analytical tests. According to the classification by Fielding and Hawkins, 10 patients were Type II (displacement as per CT scan of 3-5 mm), six Type III (displacement $>5 \mathrm{~mm}$ ), and two Type I (displacement $<3 \mathrm{~mm}$ ). Thirteen patients were admitted to hospital for cervical traction, with mean hospital stay of 9.2 days (1-23 days). Mean subsequent use of collar was 25 days (7-35). Two patients came back to consultation due to relapse.

Conclusions: Grisel's syndrome is a diagnosis to be considered in pediatric patients with torticollis and history of infections or otolaryngology surgeries. Increased values of CRP in analytical tests, as well as of the atlantoaxial distance by CT scan will confirm the diagnosis. Most patients do not need surgical treatment and the condition can be resolved with anti-inflammatory drugs or orthopedic measures.

\section{ORAL COMMUNICATION 29}

\section{RELATIONSHIP OF KINESIOPHOBIA WITH PAIN AND QUALITY OF LIFE IN PATIENTS WITH IDIOPATHIC SCOLIOSIS}

Authors: Figueras San Román, Clara ${ }^{1}$; Bago Granell, Juan ${ }^{1}$; Matamalas Adrover, Antonia ${ }^{1}$; Pizones Arce, Javier ${ }^{2}$; Pellisé Urquiza, Ferran $^{1}$; Betegón Nicolás, Jesús ${ }^{3}$; Sánchez Márquez, José Miguel ${ }^{2}$; Esteban Blanco, Marta ${ }^{3}$; Moreno Manzanares, Lucía ${ }^{2}$

Affiliations: ${ }^{1}$ Hospital Vall d'Hebrón, Barcelona, Spain; ${ }^{2}$ Hospital Universitario La Paz, Madrid, Spain; ${ }^{3}$ Complejo Asistencial Universitario de Leon (CAULE), Leon, Spain

Background: Fear of movement (kinesiophobia) is characteristic in individuals with non-specific back pain and has not been assessed in patients with idiopathic scoliosis (IS) due to the lack of formal validation of the appropriate instrument (Tampa Scale of Kinesiophobia (TSK).

Objectives: To analyze the validity of the TSK in a cohort of patients with IS.

Materials and methods: Prospective, transversal, multicenter study. Patients with IS $\geq 30^{\circ}$ without previous surgery, aged between 12 and 40 years, were included in the study. Patients completed the following questionnaires: TSK-11, SRS-22r, a numeric pain rating scale (NRS), the Hospital Anxiety and Depression scale (HADS), and item 7 of the COMI to assess work/school absenteeism. For statistical analyses, the study sample was divided into two groups: adolescents (12-18 years) and young adults (19-40 years). Cronbach's alpha was calculated to assess internal consistency. Discriminative and concurrent validity were obtained by calculating Pearson's correlation coefficients between the TSK-11 and the rest of instruments.

Results: Two hundred and seventy-five patients were included; 198 adolescents (mean age 14.6 years) and 77 young adults (mean age 
Table 1 Concurrent validity analysis. Bivariate correlations between TSK-11 scores and the rest of scales in both study groups

\begin{tabular}{lcc}
\hline & \multicolumn{2}{l}{ TSK-11 } \\
\cline { 2 - 3 } & Adolescents & Young adults \\
\hline Last month NRS & 0.130 & $\mathbf{0 . 3 6 1} * *$ \\
Item 7 of COMI (work absenteeism) & -0.031 & $\mathbf{0 . 3 2 7} * *$ \\
HAD (anxiety) & 0.067 & 0.212 \\
HAD (depression) & $\mathbf{0 . 1 9 6 * *}$ & $\mathbf{0 . 3 0 1} * *$ \\
SRS-22r (function) & $-\mathbf{0 . 1 4 3} *$ & $-\mathbf{0 . 3 7 8} * *$ \\
SRS-22r (pain) & $-\mathbf{0 . 1 6 3} *$ & $-\mathbf{0 . 3 4 1} * *$ \\
SRS-22r (image) & $-\mathbf{0 . 1 5 5} *$ & $-\mathbf{0 . 3 4 4} * *$ \\
SRS-22r (mental health) & -0.131 & $-\mathbf{0 . 3 2 6} * *$ \\
SRS-22r (subtotal) & $-\mathbf{0 . 1 6 7} *$ & $-\mathbf{0 . 4 3 3 * *}$ \\
\hline
\end{tabular}

$* p<0.05 ; * * p<0.001$

26.9 years). Mean Cobb angle was $44.9^{\circ}$ and $48.9^{\circ}$, respectively. Mean TSK $( \pm$ SD) was $21.5( \pm 5.93)$ for the adolescent group and $24.2( \pm 6.63)$ for the young adults $(p<0.05)$ (possible TSK range 11-44 points).

The questionnaire presented adequate internal consistency (Cronbach's alpha of 0.76 in adolescents and 0.79 in young adults). No correlation was seen between TSK scoring and extent of the curve in either group. Kinesiophobia was correlated with depression and quality of life in both groups, and in the group of young adults, with pain intensity and work/school absenteeism (Table 1).

Conclusions: The Spanish version of the TSK-11 is a reliable valid instrument to assess kinesiophobia in IS. However, in the group of adolescents there is weak correlation between kinesiophobia and pain intensity, disability, and emotional condition, suggesting the need to analyze other psychosocial parameters in this age group.

\section{ORAL COMMUNICATION 30}

\section{IMMEDIATE STANDING X-RAYS PREDICT THE COLLAPSE OF CONSOLIDATION IN AGED PATIENTS WITH THORACOLUMBAR BURST FRACTURES}

Authors: Pazos Mohri, Alba; Puente Sánchez, Luis; Díez Ulloa, Máximo Alberto

Affiliation: Servicio de COT. CHU Santiago de Compostela, Santiago de Compostela, Spain

Vertebral fractures in aged individuals are a growing problem. Most can be treated without surgery, but in certain cases they evolve to early painful collapse and/or posttraumatic deformity.

The challenge is to be able to predict which patients will evolve poorly. Many classifications have been developed for this population group (e.g., Sugita, DGW, etc.), because the natural evolution differs from that of younger patients (Farcy, McCormack, Magerl, TLICS, AOSpine classifications, among others).

Recently, it has been suggested that immediate standing X-rays (mechanical stress test), with the orthosis, may predict THE final collapse of this fracture.

Hypothesis: admission and after $24-48 \mathrm{~h}$ (with orthosis) standing $\mathrm{X}$-rays in aged patients with traumatic thoracolumbar fracture, allow predicting future vertebral alignment after consolidation.

Materials and methods: Prospective study of a cohort, approved by the Ethics Committee in Clinical Research.
Inclusion criteria: age $>65$ years, acute fracture of thoracolumbar subaxial C-spine caused by a fall, hospital admission, treatment with a corset.

Exclusion criteria: fractures at several levels, suspicious for malignancy, not immediate fracture.

Variables: Farcy index $(\mathrm{F})$, regional kyphosis $(\mathrm{C}$ : Cobb from cranial vertebra to caudal to the broken one) -both measured at admission (F0 and $\mathrm{C} 0$ ), at 24-48 $\mathrm{h}$ in standing position with corset (F1 and $\mathrm{C} 1)$, and at 3 months, without corset (F2 and $\mathrm{C} 2$ )-, collapse (increase from $\mathrm{F} 0$ to $\mathrm{F} 1$-F0F1- and from $\mathrm{F} 1$ to $\mathrm{F} 2-\mathrm{F} 1 \mathrm{~F} 2-$; as well as from $\mathrm{C} 0$ to $\mathrm{C} 1$ $\mathrm{C} 0 \mathrm{C} 1$ - and from $\mathrm{C} 1$ to $\mathrm{C} 2-\mathrm{C} 1 \mathrm{C} 2-)$, spinopelvic parameters, age, and sex.

Statistical analyses: IBM SPSS Statistics (on-line subscription, December 2020) and $\mathrm{R}$ package.

Results: $\mathrm{n}=35$ (four required surgery: three reinforcements and one fusion); age 75 years (66-87), nine men and 24 women.

No correlation was observed between sex or age and any other variable.

$\mathrm{F} 0=8^{\circ} \pm 7^{\circ} ; \mathrm{F} 1=12^{\circ} \pm 7^{\circ} ; \mathrm{F} 2=15^{\circ} \pm 8^{\circ}$

$\mathrm{C} 0=8^{\circ} \pm 13^{\circ} ; \mathrm{C} 1=11.5^{\circ} \pm 14^{\circ} ; \mathrm{C} 2=13^{\circ} \pm 13^{\circ}$

F2 correlated with F0 and F1 $(p<0.001)$; with F0F1 $(p=0.038)$, and with $\mathrm{F} 1 \mathrm{~F} 2(p=0.007)$.

Particularly F2 with F1 (Pearson's $=0.89 ; 95 \%$ CI $=0.78-0.94$ ).

Linear regression: $\mathrm{F} 2=2.61288+\mathrm{F} 1 \times 1.01237 . \mathrm{R} 2=0.79(\mathrm{~F} 1$ explains $79 \%$ of $\mathrm{F} 2$ ).

$\mathrm{C} 2$ correlated with $\mathrm{C} 0$ and $\mathrm{C} 1(p<0.001)$.

Particularly C2 with C1 (Pearson's $=0.94$ ).

Linear regression: $\mathrm{C} 2=2.23371+\mathrm{C} 1 \times 0.93758 . \mathrm{R} 2=0.927$.

Conclusions: Immediate standing collapse predicts alignment to consolidation (3 months).

It is thus advisable to include this type of X-ray in the follow-up protocol.

\section{ORAL COMMUNICATION 31}

\section{BENEFITS OF ANTERIOR INTERBODY FUSION: A PROPENSITY SCORE-BASED ANALYSIS}

Authors: Vila Casademunt, $\mathrm{Alba}^{1}$; Capdevila Bayo, Maria ${ }^{1}$; Haddad, Sleiman $^{2}$; Núñez Pereira, Susana ${ }^{3}$; Ruiz De Villa, Aleix ${ }^{1}$; Kleinstück, Frank $^{4}$; Alanay, Ahmet ${ }^{5}$; Obeid, Ibrahim ${ }^{6}$; Pellisé Urquiza, Ferran ${ }^{2}$; ESSG. European Spine Study Group ${ }^{7}$

Affiliations: ${ }^{1}$ Vall d'Hebron Institut de Recerca, Barcelona, Spain; ${ }^{2}$ Hospital Universitari Vall d'Hebron, Barcelona, Spain; ${ }^{3}$ Hospital Universitario Donostia, San Sebastián, Spain; ${ }^{4}$ Schulthess Klinik, Zurich, Switzerland; ${ }^{5}$ Acibadem Hospital, Istambul, Turkey; ${ }^{6} \mathrm{CHU}$ Bordeaux, Bordeaux, France; ${ }^{7}$ ESSG. European Spine Study Group, Barcelona, Spain

Background and objectives: Interbody fusion (IF) is a key tool in Adult Spinal Deformity (ASD) surgery to promote fusion and restore sagittal balance. Recent technological advances and deficiencies of posterior-only approaches have boosted the use of combined approaches over the past years. The objective of this study was to compare surgical outcomes in ASD patients treated with anterior IF (Ant-IF) versus posterior IF (Post-IF).

Materials and methods: We analyzed all patients included in a prospective multicentre ASD database receiving IF treatment and having 2-year postoperative data. A propensity score (PS)-based analysis was performed to adjust Ant-IF and Post-IF patient characteristics making the populations comparable. The PS was built using 21 confounding variables defined by a multicentre team of surgeons. To guarantee a high overlap of treatment distributions, we selected patients from the $0-0.5$ area of the PS. Comparisons of radiographic 
outcomes, heath-related quality of life (HRQL), incidence of complications and reinterventions between both groups were performed. Differences among groups were assessed with average treatment effects (ATEs).

Results: 431 patients underwent treatment with IF before December 2018. 369 patients $(93.3 \%)$ had data 2-years after surgery and were included in this study (79.4\% women, mean age 62.9 , coronal Cobb $33.7^{\circ}$, sagittal imbalance $\left.60.8 \mathrm{~mm}\right) ; 47(12.7 \%)$ were treated with Ant-IF and 322 (87.3\%) with Post-IF. Before PS-adjustment, Ant-IF patients were younger (58.6 vs. 63.6y, $p<0.05$ ), had a higher rate of pelvic fusion ( $80.9 \%$ vs. $51.2 \%, p<0.05)$, and higher number of IF per patient $(2.8$ vs. $1.6, p<0.50)$. ATEs in radiographic outcomes showed that Ant-IF was associated with greater sagittal correction $(p<0.05)$. No significant differences were found for HRQL. A trend towards fewer mechanical complications was associated to Ant-IF, not reaching statistical significance (Table).

Conclusions: Ant-IF has no effect on postoperative clinical outcomes, although it is associated to an improvement in the restauration of the sagittal balance. This may be related to a possible protective effect against mechanical complications and reinterventions.

\begin{tabular}{lcr}
\hline & $\begin{array}{l}\text { Observed } \\
\text { preoperative } \\
\text { 2-years }\end{array}$ & $\begin{array}{r}\text { differences } \\
\text { versus }\end{array}$ \\
\hline $\begin{array}{l}\text { Average } \\
\text { treatment } \\
\text { effects (ATEs) }\end{array}$ & & \\
HRQL & & \\
ODI & 2.936 & 1.13 (SD 7.78) \\
$\begin{array}{l}\text { SRS22 } \\
\text { (subtotal) }\end{array}$ & 0.059 & 0.50 (SD 0.37) \\
SF36 PCS & -1.592 & -0.413 (SD 2.16) \\
SF36 MCS & 0.324 & 4.59 (SD 9.84) \\
\hline
\end{tabular}

\begin{tabular}{lcc}
\hline & $\begin{array}{l}\text { Observed differences pre- ATEs } \\
\text { operative versus 6-weeks }\end{array}$ \\
\hline $\begin{array}{l}\text { Average } \\
\text { treatment } \\
\text { effects (ATEs) }\end{array}$ & & \\
Radiographic & & \\
$\quad$ parameters & & \\
Coronal Cobb & 1.867 & -6.26 (SD 4.52) \\
Sagittal & -8.982 & $-\mathbf{5 4 . 4 6}$ (SD 15.86) \\
$\quad$ imbalance & & -8.90 (SD 5.87) \\
L1-S1 lordosis & -3.333 & -6.47 (SD 3.85) \\
Pelvic tilt & -4.452 & -6.94 (SD 4.84) \\
Lordosis gap & -4.195 & -13.49 (SD 4.90) \\
Global tilt & -5.812 & $-\mathbf{6 . 8 2}$ (SD 1.30) \\
T1 sagittal tilt & -0.932 & \\
\hline
\end{tabular}

\begin{tabular}{|c|c|c|}
\hline & $\begin{array}{l}\text { Observed differences pre- } \\
\text { operative versus } 2 \text {-years }\end{array}$ & ATEs \\
\hline \multicolumn{3}{|l|}{$\begin{array}{l}\text { Average treatment } \\
\text { effects (ATEs) }\end{array}$} \\
\hline \multicolumn{3}{|l|}{$\begin{array}{r}\text { Radiographic } \\
\text { parameters }\end{array}$} \\
\hline Coronal Cobb & 1.849 & $-3.51(\mathrm{SD} 5.352)$ \\
\hline $\begin{array}{l}\text { Sagittal } \\
\text { imbalance }\end{array}$ & -14.719 & $-54.36($ SD 10.89) \\
\hline L1-S1 lordosis & -2.919 & $-10.19(\mathrm{SD} 5.39)$ \\
\hline Pelvic tilt & -1.502 & - 6.59 (SD 2.80) \\
\hline Lordosis gap & -3.781 & -11.05 (SD 4.86) \\
\hline Global tilt & -2.237 & - 13.61 (SD 2.92) \\
\hline T1 sagittal tilt & -0.997 & - 6.01 (SD 1.55) \\
\hline \multicolumn{3}{|l|}{$\begin{array}{l}\text { Complications and } \\
\text { reinterventions }\end{array}$} \\
\hline $\begin{array}{l}\text { Major } \\
\text { complications } \\
\text { (MCs) }\end{array}$ & 0.114 & 0.155 (SD 0.122) \\
\hline $\begin{array}{l}\text { Neurological } \\
\text { MCs }\end{array}$ & 0.011 & $0.030(\mathrm{SD} 0.039)$ \\
\hline Medical MCs & 0.091 & 0.186 (SD 0.118) \\
\hline $\begin{array}{l}\text { Infection-related } \\
\text { MCs }\end{array}$ & 0.011 & $0.037(\mathrm{SD} 0.030)$ \\
\hline Mechanical MCs & 0.012 & $-0.105(\mathrm{SD} 0.076)$ \\
\hline Reinterventions & 0.039 & $-0.120(\mathrm{SD} 0.244)$ \\
\hline
\end{tabular}

\section{ORAL COMMUNICATION 32}

\section{DISC PATHOLOGY EXHIBITS DIVERSE BIOCHEMICAL PHENOTYPES DEFINED BY THEIR ETIOPATHOGENY: THERE ARE DISTINCT PROCESSES}

Authors: Díez Ulloa, Máximo Alberto ${ }^{1}$; Caeiro Rey, José Ramón ${ }^{1}$; Sánchez Temprano, Agustín ${ }^{2}$; Varela Eirin, Marta ${ }^{2}$; Mayan Santos, María $^{2}$

Affiliations: ${ }^{1}$ COT. CHU Santiago de Compostela, Santiago de Compostela, Spain; ${ }^{2}$ Cellcom-Inibic-Sergas, A Coruña, Spain

Disc degeneration, the beginning of the spinal degenerative cascade, is one of the most prolific research fields. There are differential factors: degenerative discs (DDD) cause pain showing inflammatory response (Kepler, 2013; Monchaux, 2017; Wangler, 2021 -global secretome-). There is an ongoig wolrdwide research of therapeutic targets (molecules, cells, exosomes...), despite of the fact that the process is not fully defined nor understood. On the other hand, herniated disc (HD) (acute pathology) tissue shows a biochemical pattern different from that of DDD (chronic pathology) (Díez, 2005).

Obviously, there is an homeostasis imbalance (Wangler, 2021) and, in this tissue homeostasis, intercellular communication plays an essential role.

Hypothesis: disc degeneration causes distinct biochemical environments, defined by etiopathogeny.

Materials and methods: 68 disc tissue samples (51 patients) classified as follows: 
Healthy controls $(\mathrm{H})$ : H1, young $(7-25$ years, $(n=3)$ from three patients - one deformity, other traumatism with intact disc, and one tumor-) or else $\mathrm{H} 2$, adult ( $\mathrm{n}=4$ discs from one donor).

Cases $(C)$ : $C 1$, herniated disc $(n=9)$; $C 2$, simple degeneration (DDD) $(\mathrm{n}=30)$; and C3 accelerated degeneration -aggressive biomechanical environment, defined as adjacent level to a fusion $>2$ levels- $(\mathrm{n}=5)$.

We measured normalized expression levels of: a) intercellular communication (Conexins: Cx43), b) cellular senescence (P16, P21 and beta-galactosidase), and c) tissue response (inflammation: IL1, IL6, Snail 1 and 2, and Twist 1).

Statistics: the Mann-Whitney U test (non-parametric).

\section{Results:}

(1) Intercellular communication

$\mathrm{C} \times 43$ increased with age, decreased after the age of 60 years, and decreased even more after the age of 70 .

(2) Senescence

Increased P16 in $\mathrm{HD}(\mathrm{C} 1)$ versus $\mathrm{HC}$ and DDD (C2).

P21 especially high in HD (C1) versus HC1 (H1), DDD (C2), and adjacent levels (C3), low levels.

(3) Tissue response (inflammation).

IL1 especially high in HD (C1) versus DDD (C2, similar to adjacent level $\mathrm{C} 3$ ) and both versus healthy individuals (HC1-2). IL6 especially high in HD (C1) and particularly DDD (C2) versus healthy; very low in adjacent level (C3).

High Snail1 and Snail 2 similar in the three cases groups $(\mathrm{C} 1-3)$ versus healthy individuals.

Twist1 especially high in HD (C1) and adjacent level (C3) versus healthy and DDD (C2).

(4) Age in simple degenerative process:

DDD group (C2) the most frequent, all increased in $>55$ years, except for Snail 2.

\section{Conclusions:}

(1) Disc pathology $(\mathrm{C} 1-3)$ causes tissue stress, triggering a response that fades down ( $\mathrm{Cx} 43$ and beta-galactosidase)
(2) HD (C1) a more acute pattern (IL,s; Twist1) in comparison to DDD (C2) and adjacent level (C3).

(3) Adjacent level (C3) little inflammation, more fibrosis (Twist1).

\section{ORAL COMMUNICATION 33}

\section{RESULTS AT 7 YEARS POST CERVICAL ARTHROPLASTY VERSUS ANTERIOR CERVICAL ARTHRODESIS: SYSTEMATIC REVIEW AND META-ANALYSIS OF RANDOMIZED CLINICAL TRIALS}

Authors: Núñez Camarena, Jorge H. ${ }^{1}$; Escudero Cisneros, Berta ${ }^{1}$; Omiste Moreno, Irene ${ }^{1}$; Martínez Peñas, Judit ${ }^{1}$; Alonzo González, Francisco $^{2}$; Bosch García, David ${ }^{1}$

Affiliations: ${ }^{1}$ Hospital Universitario Mutua de Terrassa, Terrassa, Spain; ${ }^{2}$ Hospital Ceibal de Accidentes del Instituto Guatemalteco de Safety Social, Ciudad de Guatemala, Guatemala

Background and objectives: If outcomes with cervical arthroplasty (CA) are superior to those of anterior cervical arthrodesis (ACA) remains controversial, particularly when it comes to long-term results. The aim of this meta-analysis was to compare the outcomes of randomized CA against ACA with plaques clinical trials, with 7-year follow-up.

Materials and methods: We carried out a systematic search. Seventeen randomized clinical trials were selected. Review Manager was used for the statistical analyses. We assessed measurements of functional outcomes, adverse events, adjacent segment (AS) degeneration, and secondary surgery. For the meta-analysis a randomeffects model was used. The odds ratio and mean differences with a $95 \%$ confidence interval $(\mathrm{CI})$ were used to evaluate discontinuous and continuous variables, respectively. The level of significance was fixed at $p<0.05$ (Tables 1, 2 and 3).

Results: Four thousand seven hundred twenty-nine $(4,729)$ patients were included in the study. Grouped results showed that overall

Table 1 Risk differences in the randomized clinical trials included in the study assessing overall success 84 months after surgery

\begin{tabular}{|c|c|c|c|c|c|c|}
\hline \multirow[t]{2}{*}{ Study or subgroup (Year) } & \multicolumn{2}{|l|}{$\mathrm{CA}$} & \multicolumn{2}{|l|}{$\mathrm{ACA}$} & \multirow[t]{2}{*}{ Weight $(\%)$} & \multirow[t]{2}{*}{ Odds ratio $95 \% \mathrm{CI}$} \\
\hline & Events & Total & Events & Total & & \\
\hline Burkus et al. (2014) & 207 & 276 & 167 & 265 & 14.55 & 1.76 [1.217-2.547] \\
\hline Janssen et al. (2015) & 86 & 103 & 85 & 106 & 4.26 & $1.25[0.617-2.533]$ \\
\hline Lei et al. (2015) & 27 & 31 & 29 & 35 & 1.16 & $1.40[0.355-5.493]$ \\
\hline Gornet et al. (2016) & 208 & 280 & 167 & 265 & 14.79 & $1.70[1.176-2.445]$ \\
\hline Lanman et al. (2017) & 164 & 209 & 118 & 188 & 10.40 & $2.16[1.388-3.367]$ \\
\hline Radcliff et al. (2017) & 91 & 164 & 41 & 81 & 7.32 & $1.22[0.713-2.073]$ \\
\hline Radcliff et al. (2017) & 137 & 225 & 36 & 105 & 8.81 & $2.98[1.839-4.841]$ \\
\hline Ghobrial et al. (2018) & 195 & 242 & 154 & 221 & 11.06 & $1.81[1.176-2.771]$ \\
\hline Lavelle et al. (2018) & 197 & 242 & 147 & 221 & 11.11 & $2.20[1.437-3.380]$ \\
\hline Vaccaro et al. (2018) & 130 & 151 & 98 & 140 & 6.12 & $2.65[1.477-4.766]$ \\
\hline Gornet et al. (2019) & 164 & 209 & 117 & 188 & 10.43 & $2.21[1.421-3.442]$ \\
\hline Total $(95 \% \mathrm{CI})$ & 1606 & 2132 & 1159 & 1815 & $100.0 \%$ & $1.94[1.67-2.24]$ \\
\hline \multicolumn{7}{|l|}{$p=0.001$} \\
\hline $\mathrm{I}^{2}=5.6 \%, p=0.39$ & & & & & & \\
\hline
\end{tabular}


Table 2 Risk differences in the randomized clinical trials included in the study, assessed at 84 months after surgery: a. Cervical Disability Index, b. Cervical pain, c. Radicular pain, d. Physical domain of the SF-3, e. Mental domain of the SF-36

\begin{tabular}{|c|c|c|c|c|c|c|}
\hline \multirow[t]{2}{*}{ Study or subgroup (year) } & \multicolumn{2}{|l|}{$\mathrm{CA}$} & \multicolumn{2}{|c|}{ ACA } & \multirow[t]{2}{*}{ Weight (\%) } & \multirow[t]{2}{*}{ Mean differences $95 \% \mathrm{Cl}$} \\
\hline & $\mathrm{N}$ & Mean (SD) & $\mathrm{N}$ & Mean (SD) & & \\
\hline \multicolumn{7}{|l|}{ a. Cervical disability index } \\
\hline Burkus et al. (2014) & 276 & $18.1(20.0)$ & 265 & $18.1(20.0)$ & 22.7 & $-0.27[-0.44,-0.10]$ \\
\hline Janssen et al. (2015) & 103 & $22.0(8.9)$ & 106 & $22.0(9.2)$ & 18.7 & $0.00[-0.27,0.27]$ \\
\hline Lei et al. (2015) & 31 & $11.3(6.4)$ & 35 & $17.4(5.9)$ & 10.7 & $-0.99[-1.51,-0.48]$ \\
\hline Loumeau et al. (2016) & 22 & $15.4(19.5)$ & 22 & $25.6(23.9)$ & 8.8 & $-0.46[-1.06,0.14]$ \\
\hline Radcliff et al. (2017) & 164 & $17.9(19.7)$ & 81 & $18.2(17.6)$ & 18.9 & $-0.02[-0.28,0.25]$ \\
\hline Radcliff et al. (2017) & 225 & $18.0(19.1)$ & 105 & $26.2(22.4)$ & 20.2 & $-0.41[-0.64,-0.17]$ \\
\hline Total $(95 \% \mathrm{CI})$ & 821 & & 614 & & $100.0 \%$ & $-0.29[-0.51,-0.08]$ \\
\hline \multicolumn{7}{|l|}{$p=0.013$} \\
\hline \multicolumn{7}{|l|}{$\mathrm{I} 2=69.9 \%, p=0.005$} \\
\hline \multicolumn{7}{|l|}{ b. Cervical pain } \\
\hline Burkus et al. (2014) & 276 & $13.1(23.3)$ & 265 & $19.4(24.8)$ & 18.0 & $-0.26[-0.43,-0.09]$ \\
\hline Janssen et al. (2015) & 103 & $27.3(13.0)$ & 106 & $22.8(13.7)$ & 15.4 & $0.34[0.07,0.61]$ \\
\hline Lei et al. (2015) & 31 & $23.0(16.0)$ & 35 & $38.0(17.0)$ & 9.8 & $-0.91[-1.42,-0.40]$ \\
\hline Loumeau et al. (2016) & 22 & $11.7(18.8)$ & 22 & $27.9(34.7)$ & 8.1 & $-0.58[-1.19,0.02]$ \\
\hline Radcliff et al. (2017) & 164 & $19.0(26.9)$ & 81 & $21.1(24.4)$ & 15.6 & $-0.08[-0.35,0.19]$ \\
\hline Radcliff et al. (2017) & 225 & $19.0(27.1)$ & 105 & $28.7(30.4)$ & 16.5 & $-0.34[-0.58,-0.11]$ \\
\hline Vaccaro et al. (2018) & 151 & $13.3(23.6)$ & 140 & $19.4(25.1)$ & 16.5 & $-0.25[-0.48,-0.02]$ \\
\hline Total $(95 \% \mathrm{CI})$ & 972 & & 754 & & $100.0 \%$ & $-0.24[-0.46,-0.02]$ \\
\hline \multicolumn{7}{|l|}{$p=0.091$} \\
\hline \multicolumn{7}{|l|}{$\mathrm{I}^{2}=77.6 \%, p=0.000$} \\
\hline \multicolumn{7}{|l|}{ c. Radicular pain } \\
\hline Burkus et al. (2014) & 276 & $12.7(24.1)$ & 265 & $15.0(24.9)$ & 21.6 & $-0.09[-0.26,0.07]$ \\
\hline Janssen et al. (2015) & 103 & $22.9(12.5)$ & 106 & $22.2(13.7)$ & 15.3 & $0.05[-0.22,0.33]$ \\
\hline Lei et al. (2015) & 31 & $21.0(15.0)$ & 35 & $33.0(16.0)$ & 7.1 & $-0.77[-1.27,-0.27]$ \\
\hline Loumeau et al. (2016) & 22 & $12.5(23.4)$ & 22 & $27.3(35.7)$ & 5.4 & $-0.49[-1.09,-0.11]$ \\
\hline Radcliff et al. (2017) & 164 & $12.8(23.3)$ & 81 & $20.9(27.1)$ & 15.5 & $-0.33[-0.60,-0.06]$ \\
\hline Radcliff et al. (2017) & 225 & $15.9(25.7)$ & 105 & $18.4(27.0)$ & 17.6 & $-0.10[-0.33,0.14]$ \\
\hline Vaccaro et al. (2018) & 151 & $6.6(17.5)$ & 140 & $12.9(24.3)$ & 17.6 & $-0.30[-0.53,-0.07]$ \\
\hline Total $(95 \% \mathrm{CI})$ & 972 & & 754 & & $100.0 \%$ & $-0.21[-0.37,-0.06]$ \\
\hline \multicolumn{7}{|l|}{$p=0.058$} \\
\hline \multicolumn{7}{|l|}{$\mathrm{I}^{2}=53.6 \%, p=0.044$} \\
\hline \multicolumn{7}{|c|}{ d. Physical domain of the SF-36 } \\
\hline Burkus et al. (2014) & 276 & $45.1(12.0)$ & 265 & $43.2(12.1)$ & 34.6 & $0.16[-0.01,0.33]$ \\
\hline Janssen et al. (2015) & 103 & $46.7(4.5)$ & 106 & $47.3(4.8)$ & 13.7 & $-0.12[-0.39,0.15]$ \\
\hline Radcliff et al. (2017) & 164 & $47.8(11.2)$ & 81 & $46.1(10.1)$ & 14.2 & $0.16[-0.11,0.42]$ \\
\hline Radcliff et al. (2017) & 225 & $46.3(11.1)$ & 105 & $43.7(11.9)$ & 18.6 & $0.23[-0.00,0.46]$ \\
\hline Vaccaro et al. (2018) & 151 & $46.4(12.1)$ & 140 & $44.7(10.1)$ & 18.9 & $0.15[-0.08,0.38]$ \\
\hline Total $(95 \% \mathrm{CI})$ & 919 & & 697 & & $100.0 \%$ & $0.13[0.03,0.23]$ \\
\hline \multicolumn{7}{|l|}{$p=0.223$} \\
\hline \multicolumn{7}{|l|}{$\mathrm{I} 2=2.0 \%, p=0.395$} \\
\hline \multicolumn{7}{|c|}{ e. Mental domain of the $S F-36$} \\
\hline Janssen et al. (2015) & 103 & $49.5(5.3)$ & 106 & $46.8(5.6)$ & 23.5 & $0.49[0.22,0.77]$ \\
\hline Radcliff et al. (2017) & 164 & $50.4(10.6)$ & 81 & $51.3(10.6)$ & 24.1 & $-0.08[-0.35,0.18]$ \\
\hline Radcliff et al. (2017) & 225 & $52.0(10.1)$ & 105 & $49.1(12.7)$ & 26.1 & $0.26[0.03,0.50]$ \\
\hline Vaccaro et al. (2018) & 151 & $52.1(10.5)$ & 140 & $51.0(11.3)$ & 26.3 & $0.10[-0.13,0.33]$ \\
\hline
\end{tabular}


Table 2 continued

\begin{tabular}{|c|c|c|c|c|c|c|}
\hline \multirow[t]{2}{*}{ Study or subgroup (year) } & \multicolumn{2}{|l|}{$\mathrm{CA}$} & \multicolumn{2}{|c|}{ ACA } & \multirow[t]{2}{*}{ Weight (\%) } & \multirow[t]{2}{*}{ Mean differences $95 \% \mathrm{CI}$} \\
\hline & $\mathrm{N}$ & Mean (SD) & $\mathrm{N}$ & Mean (SD) & & \\
\hline $\begin{array}{l}\text { Total }(95 \% \mathrm{CI}) \\
p=0.081 \\
I^{2}=68.9 \% \quad n=0.022\end{array}$ & 643 & & 432 & & $100.0 \%$ & $0.19[-0.03,0.42]$ \\
\hline
\end{tabular}

Table 3 Risk differences in the randomized clinical trials included in the study, assessed at 84 months after surgery: a. Adjacent syndrome, b. Adverse events, c. Reinterventions

\begin{tabular}{|c|c|c|c|c|c|c|}
\hline \multirow[t]{2}{*}{ Study or subgroup (year) } & \multicolumn{2}{|l|}{$\mathrm{CA}$} & \multicolumn{2}{|l|}{ ACA } & \multirow[t]{2}{*}{ Weight (\%) } & \multirow[t]{2}{*}{ Odds Ratio $95 \% \mathrm{Cl}$} \\
\hline & Events & Total & Events & Total & & \\
\hline \multicolumn{7}{|l|}{ a. Adjacent syndrome } \\
\hline Lei et al. (2015) & 9 & 31 & 21 & 35 & 13.8 & $0.27[0.10-0.76]$ \\
\hline Donk et al. (2017) & 0 & 50 & 5 & 47 & 3.2 & $0.07[0.00-1.42]$ \\
\hline Radcliff et al. (2017) & 66 & 164 & 53 & 81 & 20.6 & $0.36[0.20-0.62]$ \\
\hline Radcliff et al. (2017) & 80 & 225 & 85 & 105 & 20.5 & $0.14[0.08-0.26]$ \\
\hline Ghobrial al. (2018) & 23 & 242 & 35 & 221 & 20.5 & $0.56[0.32-0.98]$ \\
\hline Vaccaro et al. (2018) & 94 & 151 & 102 & 140 & 21.4 & $0.61[0.37-1.01]$ \\
\hline Total $(95 \% \mathrm{CI})$ & 821 & & 614 & & $100.0 \%$ & $0.33[0.19-0.58]$ \\
\hline \multicolumn{7}{|l|}{$p<0.001$} \\
\hline \multicolumn{7}{|l|}{$\mathrm{I}^{2}=73.9 \%, p=0.002$} \\
\hline \multicolumn{7}{|l|}{ b. Adverse events } \\
\hline Burkus et al. (2014) & 270 & 276 & 250 & 265 & 8.4 & $2.70[1.03-7.07]$ \\
\hline Janssen et al. (2015) & 28 & 103 & 30 & 106 & 14.8 & $0.95[0.52-1.73]$ \\
\hline Gornet et al. (2016) & 49 & 280 & 44 & 265 & 19.2 & $1.07[0.68-1.67]$ \\
\hline Donk et al. (2017) & 2 & 50 & 6 & 47 & 3.5 & $0.28[0.05-1.49]$ \\
\hline Lanman et al. (2017) & 7 & 209 & 14 & 188 & 8.8 & $0.43[0.17-1.09]$ \\
\hline Radcliff et al. (2017) & 10 & 164 & 3 & 81 & 5.1 & $1.69[0.45-6.31]$ \\
\hline Radcliff et al. (2017) & 12 & 225 & 9 & 105 & 9.2 & $0.60[0.25-1.47]$ \\
\hline Lavalle et al. (2018) & 10 & 242 & 11 & 221 & 9.5 & $0.82[0.34-1.98]$ \\
\hline Vaccaro et al. (2018) & 131 & 151 & 126 & 140 & 12.1 & $0.73[0.35-1.50]$ \\
\hline Gornet et al. (2019) & 8 & 209 & 15 & 188 & 9.4 & $0.46[0.19-1.11]$ \\
\hline Total $(95 \% \mathrm{CI})$ & 527 & 1909 & 508 & 1606 & $100.0 \%$ & $0.83[0.60-1.16]$ \\
\hline \multicolumn{7}{|l|}{$p=0.278$} \\
\hline \multicolumn{7}{|l|}{$\mathrm{I}^{2}=35.8 \%, p=0.121$} \\
\hline \multicolumn{7}{|l|}{ c. Reinterventions } \\
\hline Burkus et al. (2014) & 13 & 276 & 36 & 265 & 14.3 & $0.31[0.16-0.61]$ \\
\hline Janssen et al. (2015 & 7 & 103 & 19 & 106 & 7.4 & $0.33[0.13-0.83]$ \\
\hline Lei et al. (2015) & 0 & 31 & 4 & 35 & 0.71 & $0.11[0.01-2.15]$ \\
\hline Gornet et al. (2016) & 18 & 280 & 29 & 265 & 16.5 & $0.56[0.30-1.03]$ \\
\hline Loumeau et al. (2016) & 0 & 22 & 6 & 22 & 0.7 & $0.06[0.00-1.07]$ \\
\hline Lanman et al. (2017) & 9 & 209 & 28 & 188 & 10.2 & $0.26[0.12-0.56]$ \\
\hline Radcliff et al. (2017) & 5 & 164 & 10 & 81 & 5.1 & $0.22[0.07-0.68]$ \\
\hline Radcliff et al. (2017) & 10 & 225 & 17 & 105 & 9.3 & $0.24[0.11-0.55]$ \\
\hline Sasso et al. (2017) & 2 & 22 & 8 & 25 & 2.2 & $0.21[0.04-1.14]$ \\
\hline Ghobrial al. 2018) & 17 & 242 & 26 & 221 & 15.1 & $0.57[0.30-1.08]$ \\
\hline Vaccaro et al. (2018) & 6 & 151 & 21 & 140 & 7.0 & $0.23[0.09-0.60]$ \\
\hline Gornet et al. (2019) & 10 & 209 & 33 & 188 & 11.4 & $0.24[0.11-0.49]$ \\
\hline Total $(95 \% \mathrm{CI})$ & 97 & 1934 & 237 & 1641 & $100.0 \%$ & $0.33[0.26-0.42]$ \\
\hline \multicolumn{7}{|l|}{$p<0.001$} \\
\hline $\mathrm{I}^{2}=0.0 \%, p=0.487$ & & & & & & \\
\hline
\end{tabular}


success rate was significantly higher in the CA group in comparison to the ACA group (OR $=1.93,95 \%$ CI: $1.66-2.24, p<0.001$ ) with low heterogeneity ( $\mathrm{I} 2=5.6 \%, p=0.39$ ). Significant differences were seen in the improvement of the neck disability index (NDI) in favor of CA $(p=0.013)$. No intergroup differences were detected in the cervical pain scale $(p=0.091)$, radicular pain scale $(p=0.058)$, SF-36 health survey (physical domain) $(p=0.223)$ and SF-36 (mental domain) $(p=0.081)$. Similarly, grouped results indicated less AS in the CA group $(\mathrm{OR}=0.33,95 \% \mathrm{CI} 0.19-0.58, p<0.001)$ and lower percentage of reinterventions ( $\mathrm{OR}=0.32,95 \%$ CI $0.25-0.42$, $p<0.001)$. No differences regardless adverse events were observed (OR $=0.83$, 95\% CI $0.60-1.15, p=0.27$ ).

Conclusions: In long-term follow-up, CA has higher rate of success, improvement of the NDI, less ASs, and lower rate of reinterventions in comparison to ACA. No differences in adverse events, pain scales, nor SF-36 scales.

\section{ORAL COMMUNICATION 34}

\section{CLINICAL AND PSYCHOSOCIAL FACTORS IN PATIENTS WITH IDIOPATHIC SCOLIOSIS. DIFFERENCES BASED ON THE INTENSITY OF BACK PAIN}

Authors: Figueras San Román, Clara ${ }^{1}$; Bago Granell, Juan ${ }^{1}$; Matamalas Adrover, Antonia ${ }^{1}$; Pizones Arce, Javier ${ }^{2}$; Pellisé Urquiza, Ferran $^{1}$; Betegón Nicolás, Jesús ${ }^{3}$; Sánchez Márquez, José Miguel²; Moreno Manzanares, Lucia $^{2}$; Esteban Blanco, Marta ${ }^{3}$

Affiliations: ${ }^{1}$ Hospital Vall d'Hebrón, Barcelona, Spain; ${ }^{2}$ Hospital Universitario La Paz, Madrid, Spain; ${ }^{3}$ Complejo Asistencial Universitario de Leon (CAULE), Leon, Spain

Background: A pain intensity $>3$ in the Numerical Rating Scale (NRS) is a reliable cut-off point to distinguish between idiopathic scoliosis (IS) suffering unacceptable pain from those who do not.

Objectives: To analyze psychosocial, family, a quality of life (QoL) differences in IS patients based on pain intensity.

Materials and methods: Prospective, transversal, multicenter study. Inclusion criteria: patients with IS $\geq 30^{\circ}$ without previous surgery, aged between 12 and 40 years. Patients communicated the intensity of pain using a NRS, and completed the TSK-11 and SRS-22r questionnaires, the Hospital Anxiety and Depression Scale (HADS), item 7 of the Core Outcome Measures Index (COMI) (work/school absenteeism), and the family APGAR. We performed a covariance analysis to compare intergroup means controlling the effects of age and magnitude of the curve.

Results: We included 272 patients divided in two groups:

PAIN Group (NRS > 3): 101 patients, 83.4\% women, mean NRS 5.3.

NO PAIN Group (NRS $\leq 3$ ): 171 patients, $83.4 \%$ women, mean NRS 1.1.

Cobb angle was greater in the PAIN Group (48.6 $6^{\circ}$ vs. $44.6^{\circ}$, $p=0.025)$ and were older (20.9 vs. 16.5 years, $p=0.0001)$ in comparison to the NO PAIN Group.

Intergroup comparisons showed that the PAIN Group had lower SRS-22 pain, mental health, and subtotal value, with no intergroup differences in function or body image. The PAIN Group showed higher levels of kinesiophobia, anxiety, depression, work/school absenteeism, and impact of social/family surroundings. On the contrary, family functioning was similar between the two groups (Tables 1 and 2).

Conclusions: Intensity of pain in IS patients is partially related to age and magnitude of the curve. Regardless of these two variables, patients in the PAIN group show greater degree of anxiety, depression, fear of movement, and maladaptation to family/social life, although family support seems to be adequate. This leads to
Table 1 Intergroup differences in mean scoring of the different measurement modalities

\begin{tabular}{lccl}
\hline & PAIN & NO PAIN & $p$ value \\
\hline SRS-22 (subtotal) & 3.28 & 3.56 & 0.02 \\
SRS-22 (function) & 3.64 & 3.83 & 0.1 \\
SRS-22 (pain) & 3.13 & 3.58 & 0.002 \\
SRS-22 (image) & 3.11 & 3.23 & 0.3 \\
SRS-22 (mental health) & 3.24 & 3.62 & 0.0001 \\
TSK & 23.6 & 21.7 & 0.023 \\
HAD (anxiety) & 7.2 & 4.9 & 0.0001 \\
HAD (depression) & 3.3 & 1.9 & 0.0001 \\
COMI\#7 & 1.34 & 1.08 & 0.001 \\
Family APGAR & 8.58 & 8.80 & 0.38 \\
\hline
\end{tabular}

significantly worse QoL for the PAIN Group in comparison to the NO PAIN Group.

\section{ORAL COMMUNICATION 35}

\section{CIRCUMFERENTIAL ARTHRODESIS USING CORTICAL BONE TRAJECTORY VERSUS PEDICLE SCREWS: COMPARATIVE STUDY OF TWO SIMILAR PAIRED COHORTS}

Authors: Álvarez Galovich, Luis ${ }^{1}$; Mengis Palleck, Charles-Louis R. ${ }^{1}$; Gallego Bustos, Jesús ${ }^{1}$; Benito Gallo, Marina ${ }^{1}$; Peiró García, Alejandro ${ }^{2}$; Tomé Bermejo, Félix ${ }^{3}$; Cano García, Sonia ${ }^{1}$; Garzón Márquez, Francisco M. ${ }^{1}$; Sanz Aguilera, Sylvia ${ }^{1}$; Díaz Morfa, Margarita $^{1}$

Affiliations: ${ }^{1}$ Fundación Jiménez Díaz. Unidad de Pathology de Columna, Madrid; ${ }^{2}$ Hospital Sant Joan de Deu, Barcelona, Spain; ${ }^{3}$ Hospital Universitario Fundación Jiménez Díaz. Hospital General de Villalba, Madrid, Spain

Background and objectives: different biomechanical studies have shown that cortical trajectory (CT) screws have better fixation capacity in comparison to pedicle trajectory (PT). Similarly, CT screws seem to be more effective regarding clinical improvement. However, no study has focused on the possible differences in the capacity to correct sagittal parameters. The purpose of this study was to compare clinical and radiological outcomes between both procedures.

Materials and methods: Fifty-two consecutive patients who underwent circumferential arthrodesis with CT and minimum follow-up of 1 year were analyzed and compared against a cohort of 52 paired control patients from a historical data set in whom PT was used (Table 1). The following parameters were assessed: epidemiological, perioperative, functional improvement (VAS, Oswestry, and COMI scales), and spinopelvic radiological changes. We also evaluated the need of additional surgery and surgery-related complications.

Results: Significant improvements were obtained for both groups in the parameters pain and function at three and 12 months. Hospital stay of CT patients was significantly shorter (2.8 versus 4.9 days for PT, $p<0.001)$. Mean duration of surgery was shorter in PT patients (144 versus $210 \mathrm{~min}$ for CT, $p<0.001$ ). Mean scoring for functional parameters significantly improved in both groups (Table 2). 
Table 2 Percentage of patients showing different clinical characteristics

\begin{tabular}{|c|c|c|c|c|}
\hline & Pain $(\%)$ & No pain $(\%)$ & $p$ value & OR \\
\hline \multicolumn{5}{|l|}{ Sex } \\
\hline Women & 89.1 & 80.1 & 0.06 & $0.49(0.23-1.02)$ \\
\hline \multicolumn{5}{|l|}{ Treatment } \\
\hline Corset & 17.8 & 36.8 & 0.001 & $0.37(0.2-0.67)$ \\
\hline \multicolumn{5}{|l|}{ Daily activity } \\
\hline Not active & 6.9 & 1.8 & 0.04 & $4.17(1.05-16.5)$ \\
\hline Current comorbidities & 23.8 & 10.6 & 0.005 & $0.38(0.19-0.74)$ \\
\hline Past comorbidities & 17.8 & 6.5 & 0.004 & $0.31(0.14-0.7)$ \\
\hline Family history of scoliosis & 41.6 & 33.5 & 0.1 & $0.7(0.42-1.17)$ \\
\hline Family history of spinal pathologies different from scoliosis & 24 & 13.6 & 0.04 & $0.49(0.26-0.94)$ \\
\hline Other serious conditions In the family & 18.2 & 20 & 0.7 & $1.12(0.59-2.12)$ \\
\hline \multicolumn{5}{|l|}{ Communicated having problems with } \\
\hline Teachers/bosses & 11 & 2.4 & 0.005 & $5.09(1.57-16.4)$ \\
\hline School/Work environment & 31 & 13.6 & 0.001 & $2.85(1.54-5.25)$ \\
\hline Relationships with schoolmates/colleagues & 17 & 7.7 & 0.02 & $2.45(1.13-5.3)$ \\
\hline Lack of free time & 30 & 10.7 & 0.0001 & $3.59(1.87-6.88)$ \\
\hline Family relationships & 16 & 4 & 0.001 & $4.4(1.74-11.1)$ \\
\hline
\end{tabular}

Table 1 .

\begin{tabular}{llll}
\hline & Pedicle trajectory $(\mathrm{N}=52)$ & Cortical trajectory $(\mathrm{N}=52)$ & $p$ value \\
\hline Mean age \pm SD & $55 \pm 11.1$ & $54 \pm 10.8$ \\
No patients (women, \%) & $24(46.15)$ & $25(48.07)$ & 0.837 \\
ASA & 2 & 3 \\
1 & 43 & 42 \\
2 & 7 & 7 \\
3 & 0 & 0.851 \\
4 & $28.1 \pm 4.89$ & $28.3 \pm 5.83$ \\
BMI & & \\
Arthrodesis level & 45 & 47 \\
$4-5$ & 7 & 5 \\
$5-1$ & & 0.954 \\
\hline
\end{tabular}

Table 2 .

\begin{tabular}{llll}
\hline & Pedicle trajectory $(\mathrm{N}=52)$ & Cortical trajectory $(\mathrm{N}=52)$ & $p$ value \\
\hline Preoperative ODI & $22.8 \pm 8.4$ & $23.9 \pm 7.3$ & $6.9 \pm 2.5$ \\
Preoperative lumbar VAS & $6.6 \pm 2.4$ & $6.6 \pm 2.9$ & 0.477 \\
Preoperative lower limb VAS & $6.9 \pm 1.9$ & $-13.9 \pm 9.4$ & 0.589 \\
Change in ODI at 3 months & $-10.4 \pm 9.4$ & $-14.6 \pm 6.6$ & $-3.5 \pm 3$ \\
Change in ODI at 12 months & $-11.5 \pm 9.3$ & $-4.1 \pm 3.1$ & 0.163 \\
Change of lumbar VAS at 3 months & $-3.3 \pm 2.8$ & $-4.3 \pm 2.7$ \\
Change of lumbar VAS at 12 months & $-3.7 \pm 3$ & $-4.4 \pm 3.7$ & 0.678 \\
Change of lower limb VAS at 3 months & $-4.9 \pm 3.1$ & $87 \%$ & 0.494 \\
Change of lower limb VAS at 12 months & $-4.9 \pm 3.2$ & 0.535 \\
Satisfaction with the treatment at 3 months & $91 \%$ & 0.494 \\
\hline
\end{tabular}


Regarding radiological parameters, no significant intergroup differences were seen. Rate of complications was similar In both groups. One patient in the PT group developed infection, one case of screw breakage with collapse of the cage in the CT group, and one case in each group of revision of trajectory of one screw.

Conclusions: CT use in circumferential arthrodesis leads to a comparable improvement of clinical symptoms and correction capacity of local lordosis in comparison to traditional PT. However, with CT, hospital stay is shorter and patient's perception with the received treatment is more positive.

\section{ORAL COMMUNICATION 36}

\section{INFLUENCE OF THE DEGREE OF LUMBAR FUSION IN THE DEVELOPMENT OF PROXIMAL JUNCTIONAL KYPHOSIS IN LUMBAR DEGENERATIVE DISEASE}

Authors: Coto Caramés, Laura ${ }^{1}$; Lombao Iglesias, Domingo ${ }^{1}$; Blanco Hortas, Andrés ${ }^{1}$; Salido Villarón, Alejandro ${ }^{1}$; García Choliz, Teresa ${ }^{1}$; Fernández-Billón Castrillo, Inés ${ }^{1}$; Mendoza Revilla, Germán Alejandro $^{1}$; Fernández González, Manuel ${ }^{2}$; Esteban Blanco, Marta ${ }^{2}$; Betegón Nicolás, Jesús ${ }^{2}$; Lozano Muñoz, $\mathrm{Ana}^{2}$; Villar Pérez, Julioº; Hernández Encinas, José Ángel ${ }^{2}$

Affiliations: ${ }^{1}$ Hospital Universitario Lucus Augusti, Lugo, Spain; ${ }^{2}$ Complejo Asistencial Universitario de Leon (CAULE), Leon, Spain

Background and objectives: Proximal junctional kyphosis (PJK) is a common postoperative radiographic finding in lumbar degenerative disease and a frequent cause for revision surgery.

Mechanical risk factors for developing PJK are well defined, but biological risk factors are not.

The aim of this study was to assess the relationship between the degree of lumbar fusion and possible development of PJK.

Table 1 Descriptive

\begin{tabular}{lc}
\hline Variable & Patients $\mathrm{N}=122$ \\
\hline Sex (M) & $75(61.6)$ \\
Age (years)* & $68.1(11.5)$ \\
Age $(>65)$ & $74(60.6)$ \\
Fusion (good) & $34(27.9)$ \\
Vit D (<20) & $80(65.5)$ \\
PJK (Yes) & $25(20.5)$
\end{tabular}

Values are presented as absolute cases and percentages in parenthesis (categorical variables) or means and standard deviations (continuous variables*)
Table 2 Bivariate analysis

\begin{tabular}{llrl}
\hline Variable & Total & PJK Yes & $p$ value \\
\hline Sex & & & 0.032 \\
Man & 47 & $20(26.6)$ & \\
Woman & 75 & & 0.701 \\
Age & & $9(18.7)$ & \\
$<65$ & 48 & $16(21.6)$ & \\
$>65$ & 74 & $4(11.7)$ & 0.137 \\
Fusion & & $21(23.8)$ & \\
Good & 34 & & 0.888 \\
Bad & 88 & $19(20.2)$ & \\
Osteolysis & & $6(21.4)$ & \\
No & 94 & $9(21.4)$ & \\
Yes & 28 & $16(20.0)$ & \\
Vitamin D & & & \\
$>20$ & 82 & & \\
$<20$ & 80 & & \\
\hline
\end{tabular}

Values are presented as absolute cases and percentages in parenthesis$p$ values were calculated using the Chi-square test

Materials and methods: Retrospective study of a cohort of patients who underwent surgery for lumbar degenerative disease by posterolateral instrumentation between 2015 and 2018. Two groups were established based on the development of postoperative PJK. Preoperative levels of vitamin $\mathrm{D}$, degree of bone fusion 1 year after surgery following the criteria described by Lenke, and occurrence of osteolysis (observed in radiographs) were determined. The Chi-square test and logistic regression were used to determine possible factors associated with the results (Tables 1 and 2).

Results: One hundred and twenty-two patients were included in the study; mean age was 68.1 years; 25 patients $(2.05 \%)$ developed PJK 1 year after surgery. Statistically significant sex-related differences were found (woman $>$ man; $p=0.032$ ). No significant differences were seen for the remaining studied variables: age, degree of fusion, occurrence of osteolysis, and preoperative serum levels of vitamin D. Lower percentages of PJK development were seen for solid fusion $(11.7 \%)$ in comparison to deficient fusions $(23.8 \%)$, with no statistically significant differences $(p=0.137)$.

Conclusions: This study does not show a statistically significant relationship between the degree of bone fusion and development of PJK after degenerative lumbar disease surgery. Greater bone fusion seems to relate to lower risk of developing PJK. Further prospective studies with larger series of patients are necessary to confirm these associations. 


\section{ORAL COMMUNICATION 37}

ISOLATED INTERBODY LUMBAR FUSION BY LATERAL APPROACH FOR THE TREATMENT OF SYMPTOMATIC TRANSITIONAL SYNDROME IN PATIENTS WITH PREVIOUS LUMBAR ARTHRODESIS

Authors: Rodríguez Álvarez, Ángel; Vicente Herrera, Edmundo; Igualada Blázquez, Cristina; Riquelme García, Óscar; Esparragoza Cabrera, Luis Alejandro

Affiliation: Hospital General Universitario Gregorio Marañón, Madrid, Spain

Background and objectives: Revision surgery of Transitional Adjacent Segment Syndrome (TASS) by laminectomy and increase of posterolateral-instrumented arthrodesis on an already operated area is a major challenge due to the complexity of the technique and associated morbidity and complications.

Lateral lumbar interbody fusion (LLIF) is a minimally invasive alternative for revision surgeries that reduces the risk of suffering many of these complications.

Objectives: Assess postoperative outcomes (clinical and radiological) of LLIF in the treatment of TASS.

Materials and methods: Series of retrospective cases. Patients with previous lumbar arthrodesis were included, who, when diagnosed with symptomatic TASS, underwent LLIF when conservative treatment failed. Minimum postoperative follow-up was 24 months.

Clinical (ODI, VAS, SF-12) and radiological pre-, immediate post-, and most recent postoperative revision data were collected, as well as intraoperative data.

Results: Fifteen patients met the inclusion criteria (nine women and six men); mean age was $62.5 \pm 9.2$ years, mean follow-up $29.3 \pm 3.6$ months.

One level was operated in 12 patients $(80 \%)$ (nine L2-L3 and three L3-L4); two levels were operated in three patients (20\%) (L2$\mathrm{L} 3+\mathrm{L} 3-\mathrm{L} 4)$

Statistically significant improvements of lumbar and radicular pain $(p<0.001)$, disability index $(p<0.001)$, and SF-12 (CSF $p<0.001$; CSM $p=0.002)$ were observed.

Statistically significant improvements of intervertebral space height $(p<0.001)$, segmental and total lumbar lordosis $(p<0.001$ and $p=0.031$ ), respectively), and pelvic incidence-lumbar lordosis lumbar relation $(p=0.036)$, were seen.

Improvement of segmental and total coronal deformity were observed, without statistical significance.

There were no serious neurological nor infectious complications in any of the patients, although there was occurrence of mild complications in seven cases (paresthesia in the front aspect of the thigh).

One patient had to undergo surgery again because of the collapse of the cage and symptomatic worsening (posterior release and instrumentation).
Conclusions: Treatment of TASS in patients with previous lumbar arthrodesis by LLIF may be an effective and safe alternative, associated to a low number of complications.

\section{ORAL COMMUNICATION 38}

\section{LUMBOSACRAL SAGITTAL BALANCE IN POSTERIOR INTERBODY FUSION}

Authors: Benedetto, Abel Norberto; Rizzi, Pablo Ezequiel; Bruzzone, Mauro Adrian

Affiliation: Hospital Español de Buenos Aires, Caba, Argentina

Background and objectives: Sagittal contour and balance, the result of adaptation to erect stance, depends largely of lumbar lordosis. More than $90 \%$ of disc lesions occur in the ltwo most caudad discs (L4L5 and L5S1). The L5S1 segment contributes with $15^{\circ} \pm 5^{\circ}$ of the total lumbar lordosis. In the case of a degenerative lesion, the decrease in lordosis occurs due to anterior disc collapse and posterior facet degeneration, leading to loss of local lordosis. The aim of this work was to evaluate the changes of lordosis of the L5S1 segment in posterior interbody fusions, comparing cases with cages to others without them.

Materials and methods: Pre- and postoperative measurements of segmental lordosis L5S1 were performed on lateral lumbosacral spine radiographs of 60 patients who underwent posterior lumbar interbody fusion (PLIF) of L5S1 with and without cages. Achieved corrections on the sagittal plane were calculated and compared.

Results: L5S1 segmental lordoses were measured and compared on 60 radiographs of patients with short lumbosacral fusion (L4S1 and L5S1). In Group 1, radiographs of 28 patients who underwent PLIF without interbody cage were assessed. Mean preoperative and postoperative lordosis were $12.3^{\circ}$ and $9.9^{\circ}$, respectively. In 11 cases (39\%), improvement of preoperative lordosis was observed after surgery $(p=0.033)$. In Group 2, radiographs of 32 patients who underwent PLIF with interbody cage were assessed. In this group, mean preoperative and postoperative lordosis were $9.3^{\circ}$ and $16.2^{\circ}$, respectively. In 29 cases (91\%) improvement of preoperative lordosis was observed after surgery $(p<0.001)$. Postoperative results between Group 1 and Group 2 were significantly different $(p<0.001)$ with an increase in lordosis in favor of Group 2.

Conclusions: The use of interbody cages in lumbosacral fusions leads to an increase of the L5S1 segmental lordosis. 


\section{ORAL COMMUNICATION 39}

\section{ANALYSIS OF LONG-TERM RESULTS OF LUMBAR DISCECTOMY WITH AND WITHOUT INTERSPINOUS DEVICE}

Authors: Plasencia Arriba, Miguel Ángel; Maestre García, Carmen; Martín Gorroño, Fernando

Affiliation: Hospital Universitario Principe de Asturias, Alcalá de Henares, Spain

Background: Discectomy is the surgical treatment of choice for a herniated disc. However, it may lead to disc degeneration and spinal instability over time. Interspinous devices (ISD), together with surgery, are a minimally invasive alternative aiming to prevent these complications. The objective of this work was to compare long-term clinical and functional outcomes in patients who underwent conventional discectomy versus surgery during which an ISD was implanted. Materials and methods: Analytical, descriptive, retrospective, transversal study in which 114 patients who had undergone surgery for lumbar herniated discs (55 with ISD) between 2008 and 2011 were analyzed. Minimum follow-up from surgery was 8 years (mean 10 years). We assessed the outcomes with the aid of the Visual Analogue Scale (VAS) and the Oswestry Disability Index; furthermore, we collected data on analgesic use, work status, degree of satisfaction, complications, and reinterventions during the follow-up period.

Results: Overall, improvement of five points (71\%) in the VAS and 36 points $(77 \%)$ in the ODI were observed at the end of follow-up; degree of satisfaction with disc surgery was $76 \%$. Intergroup analysis showed better VAS and ODI in the ISD group, with pre-/postoperative differences of $73 \%$ and $79 \%$ with respect to $66 \%$ and $77 \%$ in the control group, respectively, although with no statistical significance. Current analgesic use and degree of satisfaction were also better in the ISD group. The number of reinterventions at the end of follow-up was lower for the ISD group ( $15.5 \%$ versus $7 \%$ ), with no statistical significance, although differences in estimated survival (Kaplan-Meier). Conclusions: Discectomy is a safe technique for the treatment of disc herniation, with outcomes maintained over time. Adding an ISD to the discectomy achieves better results, although with no statistical significance. The lower number of reinterventions and more extended periods before the patient requires another surgery may be due to a protective effect of the ISD on the operated intervertebral disc.

\section{ORAL COMMUNICATION 40}

\section{CAN INFILTRATION WITH PLATELET RICH CONCENTRATES BE AN OPTION FOR THE CONSERVATIVE TREATMENT OF LUMBAR DEGENERATIVE DISEASE?}

Authors: Luque Pérez, Rafael; Urda Martínez-Aedo, Antonio; Pérez González, José Luis; Domínguez Esteban, Ignacio

Affiliation: Hospital Clínico San Carlos, Madrid, Spain

Background and objectives: Lumbar pain (LP) is one of the most common causes for medical visits and the main reason of sick leave worldwide. Degenerative disc (DD) disease is a cause of LP with the highest clinical impact; regular management of this condition consists of medical treatment and physical measures (rehabilitation). Currently, interventionist therapies have been developed that may help improve patient's symptoms and prognosis.

Here, we aim to analyze clinical and radiological outcomes in patients treated with intradiscal, intraforaminal, and intrafacet joint infiltration with platelet-rich plasma (PRP) of patients with LP symptoms and radiological changes in DD magnetic resonance imaging results.

Materials and methods: Prospective study that included 41 operated patients with mean follow-up of 18 months (12-24). Mean age was 49 years (21-69); 68\% of the patients were women.

Clinical (VAS and ODI) and radiological (MR) outcomes, complications (major and minor), and quality of life (EQ5D) were analyzed. Results: The most frequently infiltrated segment was L4-L5 (72\%); intraforaminal infiltration was right in $86 \%$ of the cases. Regarding complications, three patients developed adverse effects that required admission for medical treatment and observation. All patients recovered with no consequences. There were no cases of infection, nor neurological or vascular lesions. Lumbar VAS improved from 7.5 to 5.1 (improvement of 2.5). Leg VAS decreased from 3.2 to 2.3 (improvement of 1). The ODI improved from 45 to 23 and the EQ5D went from 0.68 to 0.85 . Most patients $(75 \%)$ communicated being satisfied with the outcome of the intervention and $77 \%$ would repeat the therapy. Radiologically, improvement of intervertebral height was seen in $19 \%$ of the cases and percentage of canal invasion by the disc decreased in $21 \%$. One patient required surgery due to worsening of the pathology.

Conclusions: PRP infiltration may be considered for the treatment of LP in patients with degenerative pathology, providing good clinical and radiological results without relevant complications, as shown in this study. 
534

Eur Spine J (2022) 31:500-549

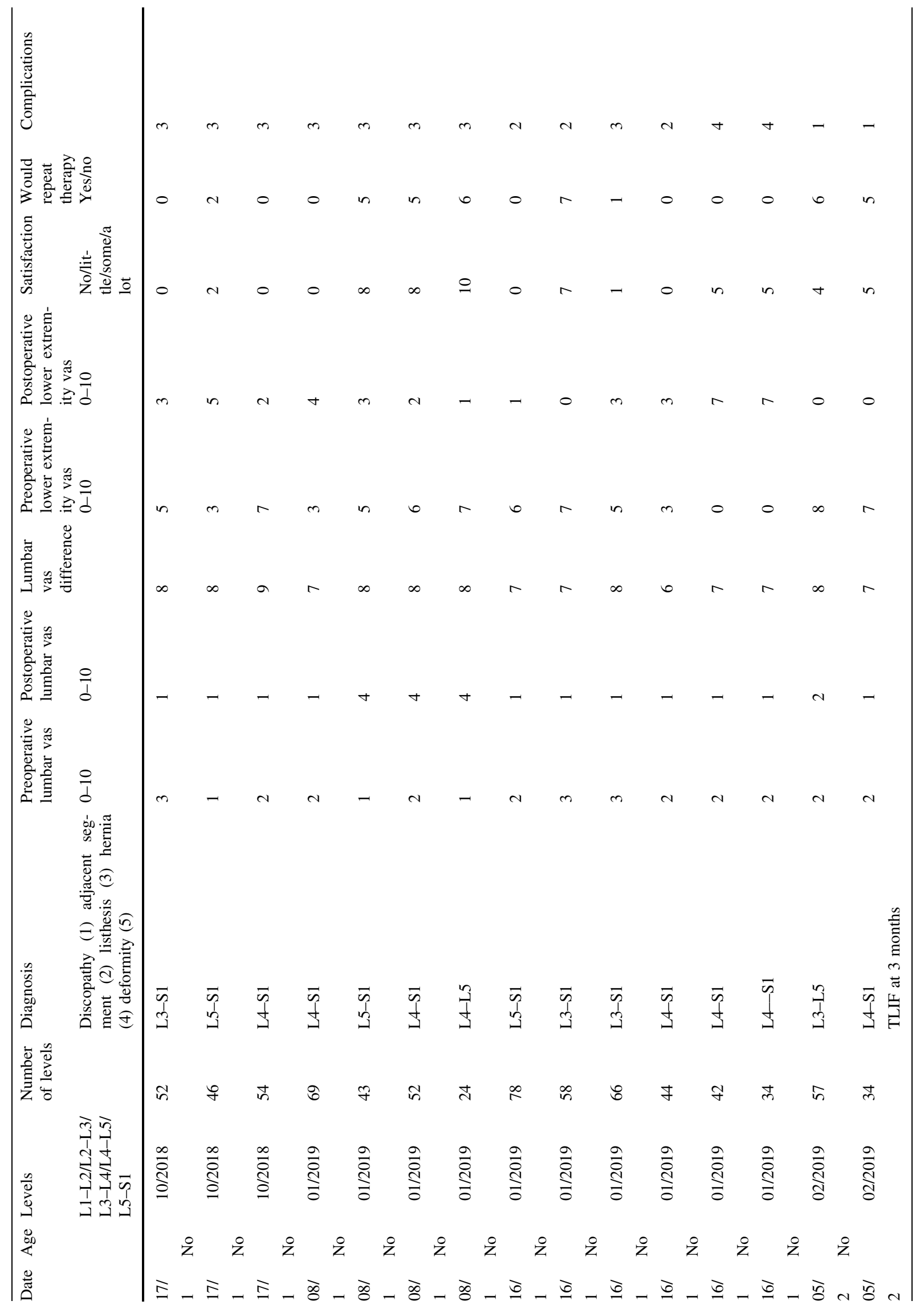

Springer 












\section{ORAL COMMUNICATION 41}

\section{COMPENSATORY MECHANISMS RECRUITED AGAINST PROXIMAL JUNCTIONAL KYPHOSIS BY PATIENTS INSTRUMENTED FROM THE THORACOLUMBAR JUNCTION TO THE PELVIS}

Authors: Pizones Arce, Javier ${ }^{1}$; Sánchez Pérez-Grueso, F. Javier ${ }^{1}$; Moreno Manzanaro, Lucía ${ }^{1}$; Escámez Fernández, Fernando ${ }^{1}$; Yilgor, Caglar $^{2}$; Vila Casademunt, Alba ${ }^{3}$; Fernández-Baillo GallegoSacristana, Nicomedes ${ }^{1}$; Sánchez Márquez, José Miguel ${ }^{1}$; Obeid, Ibrahim $^{4}$; Kleinstück, Frank ${ }^{5}$; Alanay, Ahmet ${ }^{2}$; Pellisé Urquiza, Ferran $^{6}$; ESSG. European Spine Study Group ${ }^{7}$

Affiliations: ${ }^{1}$ Hospital Universitario La Paz, Madrid, Spain; ${ }^{2}$ Acibadem Maslak Hospital, Estambul, Turkey; ${ }^{3}$ Vall d'Hebron Institut de Recerca, Barcelona, Spain; ${ }^{4} \mathrm{CHU}$ Bordeaux, Bordeaux, France; ${ }^{5}$ Schulthess Klinik, Zurich, Switzerland; ${ }^{6}$ Hospital Vall d'Hebron, Barcelona, Spain; ${ }^{7}$ ESSG. European Spine Study Group, Barcelona, Spain

Background and objectives: We understand the compensatory mechanisms in non-instrumented patients against anterior unbalance; however, there is no information on the behavior in patients instrumented to the pelvis.

Materials and methods: Retrospective, observational study of a multicenter prospective database of adult spinal deformity cases. Patients who suffered proximal junctional kyphosis (PJK/PJF) after instrumentation from thoracolumbar transition (T8-L2) erase to the pelvis, with a minimum 2-year follow-up, were included in the study. We measured quantitative global and segmental sagittal spinopelvic, and qualitative sagittal distribution parameters in the immediate postoperative period (6w), and at the time of PJK/PJF appearance. Analyses of changes suffered with the occurrence of PJK/PJF were done to define the compensatory biomechanical sequence of the response.
Results: From the 69 patients for whom complete data were available, we could define two patterns of behavior towards PJK/PJF: 36 activated compensatory (defined as an increase in pelvic retroversion $\left.-\Delta \mathrm{RPV} \rightarrow 5^{\circ}\right)$ and 33 for whom compensatory mechanisms were not activated $\left(\triangle \mathrm{RPV}<5^{\circ}\right)$.

The difference of behavior relied on the amount of pelvic rotation already expended at surgery (not surgically restored at 6w (PTx100/ $\mathrm{PI}=33.9 \%$ vs. $47.8 \% ; p<0.001)$, this trend being greater in Roussouly 1- \& 2-types. The rest of potential factors did not seem to have relevant roles: frailty, Pelvic incidence, hip joint-FOA mobility, or PJK/PJF characteristics (Table 1).

Compensatory individuals showed better postoperative restoration of relative pelvic version- $\mathrm{RPV}=-5.4^{\circ} \pm 6.1$ and lower lumbar $\operatorname{arch}-\mathrm{LLA}=36.3^{\circ} \pm 8.9$; better sagittal alignment $-\mathrm{RSA}=12.4^{\circ}$ \pm 8.8 and GAP-score-4.2. Occurrence of PJK/PJF seemed to be hardly affected by malalignment, compensators' response was based on pelvic retroversion, lower lumbar arc decrease, lumbar apex caudal migration, and upper lumbar arc posterior inclination. Despite compensation, PJK/PJF gradually occurred, by a thoracic kyphosis increase of both upper and lower arches.

Non-compensatory individuals showed worse immediate restoration $(p<0.001)$ of relative pelvic version-RPV $=-12.4^{\circ} \pm 6.5$. and of LLA $=28.4^{\circ} \pm 10.5$; worse sagittal alignment $\left(\mathrm{RSA}=17.1^{\circ}\right.$ \pm 9.4 and GAP-score $=6.8$ ). PJK/PJF seemed secondary to this malalignment, leaving them without compensatory pelvic or spinal reservoir, which forced them into kyphosis beginning at the lumbar apex and extending cranially, mainly throughout the upper thoracic arc.

Conclusions: The TL-pelvis instrumented segment acts as a seesaw interposed between two axes of movement (PJA-RPV) that counteract each other. Depending on which end the unbalance starts, the opposite end acts in response. 
Table 1 Risk factors for compensation after PJK

Adjust $\Delta \mathrm{RPV}>5^{\circ}$ Do not adjust $\Delta \mathrm{RPV}<5^{\circ} \quad p$ value

Demographic

Age (years)

Sex

$6.3+8.7$

$66.3 \pm 8.7$

$69.2 \pm 7.8$

0.142

Man

Woman

Frailty index

Frailty score

Not frail

Frail

Serious frailty

Anatomical capacity towards adjustment

PI $\left({ }^{\circ}\right)$

$40 \%$

$55.6 \%$

$0.45 \pm 0.1$

$28.6 \%$

$56.7 \%$

$60 \%$

$56 \pm 11.1$

$33.3 \%$

$57.1 \%$

$54.5 \%$

Type 4

Immediate postoperative (ImmPost) alignment and sagittal and pelvic distribution PT*100/PI

ImmPost LLA $\left(^{\circ}\right)$

ImmPost FOA $\left(^{\circ}\right)$

ImmPost RPV $\left(^{\circ}\right)$

ImmPost RLL $\left({ }^{\circ}\right)$

ImmPost LDI P (\%)

ImmPost RSA $\left(^{\circ}\right)$

ImmPost GAP-score

ImmPost Roussouly maladjustment

Adjusted

Maladjusted

Characteristics of proximal junctional kyphosis PJK/PJF

ImmPost PJA Magnitude

$\left({ }^{\circ}\right)$

Type of kyphosis

PJK

PJF

Days to kyphosis

Time to junctional kyphosis

Early ( $<90$ days)

Sub-acute (90 days-6 months)

Late ( $>6$ months)

Surgical characteristics

Instrumented upper level

T8-T9

T10-T12

L1-L2

PSO

Yes

No

Biomechanical response towards PJK/PJF ( $\Delta$ = Increase $)$
$33.9 \% \pm 11.6$

$36.3 \pm 8.9$

$5.8 \pm 4.5$

$-5.4 \pm 6.1$

$-8.5 \pm 12.1$

$71.8 \% \pm 18.8$

$12.4 \pm 8.8$

$4.2 \pm 2.9$

$63.3 \%$

$43.6 \%$

$15.5 \pm 8.4$

$51.1 \%$

$54.5 \%$

$460 \pm 461$

$42.9 \%$

$46.2 \%$

$60 \%$

$70 \%$

$52.1 \%$

$36.4 \% \%$

$66.7 \%$

$41.7 \%$
$60 \%$

$44.4 \%$

$0.40 \pm 0.1$

0.144

$71.4 \%$

$43.3 \%$

$40 \%$

$55 \pm 11.3$

0.697

$66.7 \%$

0.349

$42.9 \%$

$45.5 \%$

$47.9 \% \pm 11.7$

$0.000^{*}$

$28.4 \pm 10.5$

$0.001 *$

$4.5 \pm 5$

5.9

$-12.4 \pm 6.5$

0.000 *

$-13.6 \pm 15.1$

0.122

$74.7 \% \pm 22.1$

0.570

$17.1 \pm 9.4$

$0.042 *$

0.001 *

$6.8 \pm 3.5$

0.104

$36.7 \%$

$56.4 \%$

$15.9 \pm 9.8$

0.842

$48.9 \%$

0.787

$45.5 \%$

$388 \pm 552$

0.556

$57.1 \%$

$53.8 \%$

$40 \%$

$30 \%$

0.305

$47.9 \%$

$63.6 \%$

$33.3 \%$

0.407 
Table 1 continued

\begin{tabular}{|c|c|c|c|}
\hline & Adjust $\triangle \mathrm{RPV}>5^{\circ}$ & Do not adjust $\Delta \mathrm{RPV}<5^{\circ}$ & $p$ value \\
\hline$\Delta \mathrm{FOA}\left({ }^{\circ}\right)$ & $2.4 \pm 4.2$ & $2.2 \pm 4$ & 0.843 \\
\hline$\Delta \mathrm{RPV}\left({ }^{\circ}\right)$ & $-9.9 \pm 3.4$ & $-0.8 \pm 3.8$ & $0.000 *$ \\
\hline$\Delta \mathrm{SS}\left({ }^{\circ}\right)$ & $-10.7 \pm 4$ & $-1 \pm 3.8$ & $0.000 *$ \\
\hline$\Delta \mathrm{PT}\left({ }^{\circ}\right)$ & $9.8 \pm 4.1$ & $0.6 \pm 4.2$ & $0.000 *$ \\
\hline$\Delta \operatorname{LLA}\left({ }^{\circ}\right)$ & $-11 \pm 3.9$ & $-0.6 \pm 4.3$ & $0.000^{*}$ \\
\hline$\Delta$ Lumbar Apex & $-0.72 \pm 1.1$ & $0 \pm 0.9$ & $0.009 *$ \\
\hline$\Delta \mathrm{NVL}$ & $0.4 \pm 0.5$ & $0.5 \pm 0.7$ & 0.645 \\
\hline$\Delta \mathrm{ULA}\left({ }^{\circ}\right)$ & $3 \pm 10.1$ & $-3.4^{\circ} \pm 6.3$ & $0.003 *$ \\
\hline$\Delta$ LTA $\left(^{\circ}\right)$ & $2.8^{\circ} \pm 10$ & $-3.2 \pm 6.5$ & $0.005^{*}$ \\
\hline$\Delta \mathrm{UTA}\left({ }^{\circ}\right)$ & $3.8^{\circ} \pm 9.2$ & $9.6^{\circ} \pm 8.9$ & $0.014 *$ \\
\hline$\Delta \mathrm{PJA}\left(^{\circ}\right)$ & $19.1 \pm 9.3$ & $15.3 \pm 5.5$ & $0.047 *$ \\
\hline
\end{tabular}

$P J K$ proximal junctional kyphosis, $P J F$ proximal junctional failure, $P I$ pelvic incidence, $P T$ pelvic tilt, $L L A$ lower lumbar arch, $F O A$ femoral diaphysis angle, $R P V$ relative pelvic version, $R L L$ relative lumbar lordosis, $L D I$ lordosis distribution index, $R S A$ relative sagittal alignment, $P J A$ proximal junctional angle, $P S O$ pedicle subtraction osteotomy, $S S$ sacral slope, $N V L$ number of vertebrae in the lordosis, $U L A$ upper lumbar arch, LTA lower thoracic arch arco, UTA upper thoracic arch

*Statistical significance

\section{ORAL COMMUNICATION 42}

\section{LATERAL LUMBAR INTERBODY FUSION IN PATIENTS WITH ADULT SCOLIOSIS: PREVIOUS FACET RELEASE OF THE CONCAVITY IMPROVES THE CAPACITY OF CORRECTION}

Authors: Díez Ulloa, Máximo Alberto ${ }^{1}$; Domínguez Esteban, Ignacio $^{2}$; Otero Fernández, María ${ }^{3}$; Pino Minguez, Jesús ${ }^{4} ;$ Díez Sanchidrian, Eva ${ }^{5}$; Puente Sánchez, Luis ${ }^{1}$

Affiliations: ${ }^{1}$ COT. CHU Santiago de Compostela, Santiago de Compostela, Spain; ${ }^{2}$ Unidad de Columna. Hospital Clínico San Carlos, Madrid, Spain; ${ }^{3}$ Complexo Hospitalario Universitario de Santiago, La Coruña, Spain; ${ }^{4}$ Sergas. Xerencia de Xestión Integrada de Santiago XXI. Laboratorio de Investigación Neirid. IDIS (Instituto de Investigación Sanitaria de Santiago), Santiago de Compostela, Spain; ${ }^{5}$ Facultad de Medicina. Universidad de Santiago de Compostela, Santiago de Compostela, Spain

Over the past years, anterior spinal approach has been resumed in deformity surgeries, although the basic principle has changed: it is no longer a release procedure at thoracic level, but rather a reconstruction of the sagittal profile at lumbar level. Lateral approaches are used (lateral lumbar interbody fusion-LLIF), from the concavity, to open disc space and correct the coronal plane, while giving height to the anterior spine to reconstruct the lordosis (sagital plane).

The problem is that lumbar spine in adult scoliosis, (rotated, listhetic or subluxated), develops a facet hypertrophy during the genesis of the lumbar curve, particularly in the concavity of the apex, which limits the reductive capacity of these lateral approaches. To the best of our knowledge, no one has though to act at this level.

Hypothesis: facet release of the concavity may ease the capacity of correction in these lateral approaches.

Materials and methods: Ambispective cohort study of patients who underwent staged double approach surgery for adult scoliosis: Group A $(n=7)$, prospective arm; patients underwent a two-level facetectomy (at the apex concavity); Group B, control $(n=23)$, retrospective arm; patients had NOT undergone facetectomy. Comparison between Group A and B was carried out. The release is performed through a posterior approach with the patient positioned for lateral approach; the concavity upwards.

Variables: age, sex, levels, spinopelvic parameters, and Cobb (preoperative, bending, intermediate - after anterior approach-and final postoperative).

Statistical analysis: IBM SPSS Statistics-Subscription (online) December 2020.

Results: Bending does not provide information on final correction.

Group A: curve $38^{\circ} \pm 11^{\circ}$ corrected to $11^{\circ}$ after anterior approach and to $5^{\circ} \pm 4^{\circ}$ at the end, with a correction of $32^{\circ} \pm 9^{\circ}$; per level: $15.1^{\circ}+3.2^{\circ}$.

Group B: age 68 years, curve $29^{\circ} \pm 10^{\circ}$ corrected to $8^{\circ} \pm 10^{\circ}$ at the end, with a correction of $21^{\circ} \pm 4^{\circ}$; per level: $6.6^{\circ} \pm 3.6^{\circ}$.

Preoperative curves are comparable $(p=0.055)$ and the postoperative ones are also similar.

Number of levels addressed by LLIF: Group A: $2.1 \pm 0.4$ versus Group B: $3.6 \pm 0.7$

Correction: total Group A > Group B (Mann-Whitney U test, $p=0.012$ ); per level: Group A $>$ GroupB (Mann-Whitney U test, $p<0.001$ ).

Conclusions:

(1) Facetectomy of the concavity before lateral approach allows for greater both total and per level correction.

(2) Taking into consideration the order of magnitude of the correction and the added duration of surgery, it is probably advisable mostly on rigid curves.

\section{ORAL COMMUNICATION 43}

\section{GAIN IN HRQL AFTER ADULT SPINAL DEFORMITY SURGERY IS MAINTAINED AFTER 2 AND 5 YEARS' FOLLOW-UP}

Authors: Vila Casademunt, Alba $^{1}$; Núñez Pereira, Susana ${ }^{2}$; Capdevila Bayo, Maria ${ }^{1}$; Haddad, Sleiman ${ }^{3}$; Ruiz De Villa, Aleix ${ }^{1}$; Kleinstück, 
Frank $^{4}$; Pizones Arce, Javier ${ }^{5}$; Obeid, Ibrahim ${ }^{6}$; Alanay, Ahmet ${ }^{7}$; Pellisé Urquiza, Ferran ${ }^{3}$; ESSG. European Spine Study Group ${ }^{8}$

Affiliations: ${ }^{1}$ Vall d'Hebron Institut de Recerca, Barcelona, Spain; ${ }^{2}$ Hospital Universitario Donostia, San Sebastián, Spain; ${ }^{3}$ Hospital Universitari Vall d'Hebron, Barcelona, Spain; ${ }^{4}$ Schulthess Klinik, Zurich, Switzerland; ${ }^{5}$ Hospital Universitario La Paz, Madrid, Spain; ${ }^{6} \mathrm{CHU}$ Bordeaux, Bordeaux, France; ${ }^{7}$ Acibadem Hospital, Istanbul, Turkey; ${ }^{8}$ ESSG. European Spine Study Group, Barcelona, Spain

Background and objectives: Despite the increasing number of surgeries done for Adult Spinal Deformity (ASD), there is a lack of follow-up beyond 2-years after surgery. The aim of this study was to assess differences in clinical outcomes at 2 and 5-years after surgery and to identify predictors for loss to follow-up.

Materials and methods: Patients operated before March 2015 with data available and a minimum follow-up of 2-years, were selected from an international, multicenter, prospective ASD database. We compared complications and reinterventions, radiographic results, and health-related quality of life (HRQL) measures (ODI, SRS22, SF36) between 2 and 5-year (Y) follow-up (FU). An analysis of patients with and without 5-year follow-up data was performed to assess predictors of loss to follow-up using logistic regressions and controlling for confounding variables.

Results: 361 patients underwent surgery before March 2015. 316 patients $(87.5 \%)$ (77.5\% women, mean age 51.9, 9.2 fused levels, $15.8 \%$ with tricolumnar osteotomy, $36.7 \%$ with pelvic fixation, $94.6 \%$ with posterior-only approach) had complete 2 YFU data and 258 (71.5\%), 5YFU data. 2YFU HRQL was maintained at 5YFU $(p>0.05)$. Loss to follow-up at $5 \mathrm{Y}$ was not associated to patient characteristics, having suffered complications between 2 and $5 Y$, degree of deformity correction, or HRQL gain at 2YFU $(p>0.05)$, except for SF36-MCS. Proportion of patients reaching minimal clinically important differences (MCIDs) and Patient Acceptable Symptom State (PASS) was similar $(p>0.05)$ at 2 and 5YFU (Table). Worse baseline HRQL scores and sagittal balance (Global Tilt, LGap) were associated $(p<0.05)$ with a greater gain in $5 \mathrm{YFU}$ HRQL. Worse preoperative HRQL, sagittal balance (lordosis gap, global tilt), and presence of complications or reinterventions were associated to worse HRQL at $5 \mathrm{YFU}$.

Conclusions: Gain in HRQL at $2 \mathrm{Y}$ is maintained at $5 \mathrm{Y}$ after surgery. $5 \mathrm{YFU}$ is not related to patient characteristics, surgical outcome (HRQL, correction of the deformity), or complications at 2YFU.

\section{HRQL}

Proportion of patients reaching MCIDs

ODI

SRS22 Subtotal

SF36 PCS

Proportion of patients reaching PASS (Patient Acceptable Symptom State)
Table $\mathbf{h}$ continued

\begin{tabular}{|c|c|c|}
\hline \multicolumn{3}{|l|}{ HRQL } \\
\hline \multirow[t]{2}{*}{ ODI } & At $2 \mathrm{Y}$ & $39.4 \% \quad p=0.52$ \\
\hline & At $5 \mathrm{Y}$ & $36.6 \%$ \\
\hline \multirow[t]{2}{*}{ SRS22 (subtotal) } & At $2 \mathrm{Y}$ & $43.0 \% \quad p=0.16$ \\
\hline & At $5 \mathrm{Y}$ & $48.8 \%$ \\
\hline \multicolumn{3}{|c|}{ Major complications } \\
\hline \multicolumn{3}{|c|}{$\begin{array}{l}\text { Occurred between surgery and } \\
2 \text { YFU }\end{array}$} \\
\hline Neurological & \multicolumn{2}{|l|}{$17(8.2 \%)$} \\
\hline Mechanical & \multicolumn{2}{|l|}{$109(52.1 \%)$} \\
\hline Infectious & \multicolumn{2}{|l|}{$29(13.9 \%)$} \\
\hline Medical & \multicolumn{2}{|l|}{$54(25.8 \%)$} \\
\hline TOTAL & \multicolumn{2}{|l|}{$193(100 \%)$} \\
\hline \multicolumn{3}{|c|}{ Occurred between 2-5YFU } \\
\hline Neurological & \multicolumn{2}{|l|}{$2(2.8 \%)$} \\
\hline mechanical & \multicolumn{2}{|l|}{$55(78.6 \%)$} \\
\hline Infectious & \multicolumn{2}{|l|}{$4(5.7 \%)$} \\
\hline Medical & \multicolumn{2}{|l|}{$9(12.9 \%)$} \\
\hline TOTAL & \multicolumn{2}{|l|}{$70(100 \%)$} \\
\hline \multicolumn{3}{|l|}{ Reinterventions } \\
\hline Before $2 \mathrm{Y}$ & \multicolumn{2}{|l|}{$\begin{array}{l}95(18.8 \% \text { of } \\
\text { patients })\end{array}$} \\
\hline Between 2-5Y & \multicolumn{2}{|l|}{$\begin{array}{c}56(12.1 \% \text { of } \\
\text { patients })\end{array}$} \\
\hline TOTAL & \multicolumn{2}{|l|}{151} \\
\hline
\end{tabular}

\section{ORAL COMMUNICATION 44}

\section{ANALYSIS OF PROGRESSION OF FRAILTY IN ADULT SPINAL SURGERY PATIENTS AND INFLUENCE OF PERIOPERATIVE COMPLICATIONS}

Authors: Lombao Iglesias, Domingo ${ }^{1}$; Blanco Hortas, Andrés ${ }^{1}$; Salido Villaron, Alejandro ${ }^{1}$; Coto Caramés, Laura ${ }^{1}$; Fernández González, $\mathrm{Manuel}^{2}$; Esteban Blanco, Marta ${ }^{2}$; Betegón Nicolás, Jesús²; Lozano

Table 1

\begin{tabular}{lc}
\hline Variable & Patients $\mathrm{N}=62$ \\
\hline Sex $(\mathrm{M})^{*}$ & $51(82.2)$ \\
Age & $66.7(10.9)$ \\
BMI & $28.4(5.3)$ \\
Follow-up & $31.6(9.7)$ \\
\hline
\end{tabular}

Values are presented as absolute cases and percentages in parenthesis (*categorical variables) or as means and standard deviations (*continuous variables) 
Table 2 .

\begin{tabular}{lc}
\hline Medical complications & $15(24.2)$ \\
ITU & $3(4.8)$ \\
Pleural effusion & $2(3.2)$ \\
Delirium & $4(6.5)$ \\
Syncope & $1(1.6)$ \\
Ileus & $5(8.1)$ \\
Intraoperative complications & $\mathbf{1 0}(\mathbf{1 6 . 1})$ \\
Dural tear & $5(8.1)$ \\
Vascular lesion & $3(4.8)$ \\
Implant misplacement & $2(3.2)$ \\
Infection & $\mathbf{1 4}(\mathbf{2 2 . 6})$ \\
Superficial & $9(14.5)$ \\
Deep & $5(8.1)$ \\
\hline
\end{tabular}

Values are presented as absolute cases and percentages in parenthesis

Table 3

\begin{tabular}{lccc}
\hline Measurement & Total & Frailty index & $p$ value \\
\hline $\begin{array}{l}\text { Medical complications } \\
\text { GROUP WITH COMPLICATIONS }\end{array}$ & 15 & $0.16(0.12)$ & 0.305 \\
GROUP NO COMPLICATIONS & 47 & $0.12(0.12)$ & \\
Infection & & & \\
Yes & 14 & $0.16(0.11)$ & 0.329 \\
No & 48 & $0.13(0.12)$ & \\
Intraoperative complications & & & \\
Yes & 10 & $0.17(0.12)$ & 0.255 \\
No & 52 & $0.13(0.12)$ & \\
\hline
\end{tabular}

Values are presented as means and standard deviations $p$ values were calculated using Student's t-test

Muñoz, Ana $^{2}$; Hernández Encinas, José Ángel²; Villar Pérez, Julioº Gallego Díez, Leticia ${ }^{2}$

Affiliations: 1Hospital Universitario Lucus Augusti, Lugo, Spain; 2Complejo Asistencial Universitario de Leon (CAULE), Leon, Spain

Background and objectives: Surgical treatment of adult spinal deformity often entails significant aggression to the body due to the extension of the approach, bleeding, or duration of the surgery.

On the other hand, frailty, defined as a decrease in the physiological reserve of the body, has been associated to greater risk of morbidity and mortality in aged patients who undergo surgery.

The aim of this study was to assess if adult spinal surgery entails significant change in frailty and possible influence on medical-related complications in the outcome.

Materials and methods: Series of adult patients who underwent spinal deformity surgery a follow-up of more than 2 years. We determined preoperative and at end of follow-up frailty with the aid of the short version of the Frailty Index (mFI).

From the initial series, two cohorts were established based on postoperative occurrence of medical complications.

Collaterally we created two analysis subgroups considering intraoperative complications or development of infections.
Changes in frailty between preoperative and end of follow-up and the relationship with the studied complications were determined using Student's t-test.

Results: Sixty-two patients were included in the study; mean age was 66.7 years, $82.2 \%$ women, BMI 28.4, and mean follow-up of 31.6 months (Table 1).

The medical complications group included 15 cases (incidence of $24.2 \%$ vs. $47(75.8 \%)$ in the group with no complications). Incidence of intraoperative complications and infection was $16.1 \%$ and $22.6 \%$, respectively (Table 2 ).

Significant worsening of frailty was observed at the end of followup in comparison to the preoperative situation, 0.13 versus 0.07 $(p<0.001)$

However, despite the trend of worse frailty values in the group with medical complications, as well as with the occurrence of intraoperative complications or infections, differences were not significant (Table 3).

Conclusions: Deterioration of frailty at the end of follow-up is seen in adult patients who undergo spinal deformity surgery. However, perioperative complications do not seem to have significant effect on the observed worsening.

\section{ORAL COMMUNICATION 45}

\section{INCIDENCE AND RISK FACTORS OF UPPER ADJACENT SEGMENT KYPHOSIS (PJK) IN SPINAL DEFORMITY SURGERY IN THE ELDERLY}

Authors: Gallego Bustos, Jesús ${ }^{1}$; Mengis Palleck, Charles-Louis R. ${ }^{1}$; Peiró García, Alejandro ${ }^{2}$; Tomé Bermejo, Félix ${ }^{3}$; Benito Gallo, Marina $^{1}$; Rodríguez Arguisjuela, María G. ${ }^{1}$; Ismael Coifman, Lucena $^{1}$; Álvarez Galovich, Luis ${ }^{1}$

Affiliations: ${ }^{1}$ Fundación Jiménez Díaz. Unidad de Pathology de Columna, Madrid, Spain; ${ }^{2}$ Hospital Sant Joan de Deu, Barcelona, Spain; ${ }^{3}$ Hospital Universitario Fundación Jiménez Díaz. Hospital General de Villalba, Madrid, Spain

Background and objectives: Advanced age seems to be a predisposing factor for the occurrence of adjacent segment kyphosis (PJK). However, this specific population group has not been studied. The purpose of the present work was to analyze different risk factors for the development of PJK in a group of aged patients.

Materials and methods: Retrospective analysis of prospectively collected data from an adult spinal deformity database. We identified 137 operated patients aged $\geq 70$ years and minimum follow-up of 1 year. Study factor was PJK as described by Glattes. We assessed the following variables: age, sex, DMO, BMI, extension of the instrumentation, instrumentation to the sacrum, duration of the surgery, performance and type of osteotomy, upper segment used instrumentation, open or percutaneous technique of the upper segment. We analyzed pre- and postoperative spinopelvic parameters, as well as percentage of surgery-related variation.

Results: Mean follow-up was 3.9 years; $86.9 \%$ were women and mean age was 76.3 years. The epidemiological factors that most influenced on PJK presence were low DMO and BMI. Higher incidence was seen in patients with fusion to the sacrum and higher percentage of correction of lumbar lordosis (Table 1). Similarly, there was a correlation between preoperative IP and presence of PJK (Table 2). Regarding instrumentation, the element that seems to be more effective for protecting against PJK was percutaneous use in proximal segments. There were no PJK cases in this group, regardless of the rest of factors.

Conclusions: In aged patients, increased BMI and DMO are factors that favor PJK. Factors that affect the most are instrumentation to 
sacrum and overcorrection of the sagittal plane. Use of percutaneous instrumentation in the proximal segment has a protective effect regardless of the rest of analyzed variables.

\section{ORAL COMMUNICATION 46}

\section{QUALITY OF LIFE IN TIME OF PANDEMIC: ADULT SPINAL DEFORMITY SURGERY}

Authors: Suárez Huerta, María Luz ${ }^{1}$; Gómez Rice, Alejandro² Vázquez Vecilla, Iria Carla ${ }^{1}$; Madrid de la Serna, Cristina ${ }^{1}$; Carvajal Álvarez, Miguel $^{3}$; Delfino Carrillo, Renato ${ }^{1}$; Zúñiga Gómez, Lorenzo

Affiliations: ${ }^{1}$ Hospital Universitario de Getafe, Madrid, Spain; ${ }^{2}$ Hospital Universitario Ramón and Cajal, Madrid, Spain; ${ }^{3}$ Hospital Universitario de Cabueñes, Gijón, Spain

Objectives and background: The number of confirmed COVID-19 cases worldwide is 93,194,922 million and 2,336,451 in Spain. It is affecting particularly the older population, who are greater risk of developing more serious processes. There are particularly afraid of getting infected and tend to isolate and develop depression.

The purpose of this study is to determine the incidence of COVID-19 and quality of life in these patients.

Materials and methods: Observational, transversal case-control study, paired by age, sex, and health area.

Patients with adult spinal deformity, aged $>65$ years, and who underwent surgery between 2010 and 2015 were selected.

The following variables were collected (April to May 2020): sociodemographic, personal background, BMI, levels of arthrodesis, number of interventions, visual analogue scale (fear of going out and attending to the health center), and quality of life scorings (EQ5, GDS, Barthel).

Results: One hundred and six patients were included, from which 53 had undergone spinal surgery; $86.8 \%$ were women, mean age was 75.7 years, COVID-19 incidence was $12.3 \%$, without statistically significant intergroup differences $(p=0.5)$. Patients who had had COVID-19 were primarily men $(p=0.004)$ and individuals who were institutionalized $(p=0.005)$.
Mean follow-up for the group of patients who underwent surgery was 8.7 years with eight-level arthrodesis. Patients from this group took more drugs (10.3) $(p=0.007)$ and opium-based medications $(p=0.01)$, had a lower level of education $(p=0.01)$, as well as walking difficulties when not assisted $(p=0.01) ; 49.1 \%$ has high risk of developing depression (GDS $>5$ ) associated to lower Bartel $(p=0.02)$, gait difficulty $(p=0.03)$, and lower scoring in the EQ5 $(p=0.04)$. However, they are less fearful of going out of the house (VAS 4/10 \pm 1 ) and attending the health center (VAS 4.6/10 \pm 3 ).

Patients who were more fearful to attend a health center (VAS $\geq 5 / 10$ ) were usually younger (73.8 years, $p=0.01)$, GDS 7 $(p=0.02)$, and afraid to go out on the street (VAS 6.7/10, $p=0.001)$. No statistically significant differences were observed between the case-control groups $(p=0.1)$.

Conclusions: Our patients are particularly vulnerable, with a tendency to depression and higher incidence of COVID-19 in comparison to the general population.

\section{ORAL COMMUNICATION $47 \bullet$}

\section{SIMPLIFIED PEDICLE SUBTRACTION OSTEOTOMY IN OSTEOPOROTIC VERTEBRAL FRACTURES}

Authors: Plais Cotrel, Nicolas ${ }^{1}$; Mengis Palleck, Charles-Louis R. ${ }^{2}$; Gallego Bustos, Jesús²; Tomé Bermejo, Félix ${ }^{3}$; Peiró García, Alejandro ${ }^{4}$; Álvarez Galovich, Luis ${ }^{2}$

Affiliations: ${ }^{1}$ Hospital Universitario San Cecilio, Granada, Spain; ${ }^{2}$ Fundación Jiménez Díaz, Madrid, Spain; ${ }^{3}$ Hospital Universitario Fundación Jiménez Díaz. Hospital General de Villalba, Madrid, Spain; ${ }^{4}$ Hospital Sant Joan de Deu, Barcelona, Spain

Objectives: Osteoporotic vertebral fractures (OVF) are continuously rising and their management is an extraordinary challenge. Although most can be treated conservatively, $30 \%$ are subsidiary to surgical treatment. In unstable fractures that associate severe local kyphosis, osteotomies may be necessary. Risk of complications is high in these older frail patients. In this study, we present variations to the classical pedicle subtraction osteotomy (PSO) aiming to reduce the risk of complications.

Table 1 Demographic data, postoperative correction, and complications (radiological parameters)

\begin{tabular}{|c|c|c|c|c|c|c|}
\hline & Age & Sex & Preoperative RK & Postoperative RK & RK correction & Complications \\
\hline Patient 1 & 67 & Female & 34 & -3 & 37 & Postoperative spinal epidural hematoma \\
\hline Patient 2 & 76 & Female & 53 & -3 & 56 & \\
\hline Patient 3 & 77 & Female & 47 & 15 & 32 & Superficial infection \\
\hline Patient 4 & 64 & Female & 31 & -5 & 36 & \\
\hline Patient 5 & 82 & Female & 26 & 8 & 18 & \\
\hline Patient 6 & 61 & Female & 45 & 7 & 38 & Kyphosis junctional proximal \\
\hline Patient 7 & 69 & Female & 30 & 3 & 27 & \\
\hline Patient 8 & 55 & Female & 33 & 12 & 21 & \\
\hline Patient 9 & 66 & Male & 47 & 11 & 36 & \\
\hline Patient 10 & 59 & Female & 49 & 3 & 46 & Pulmonary embolism \\
\hline Patient 11 & 75 & Female & 45 & -3 & 48 & Pneumothorax \\
\hline Patient 12 & 54 & Female & 38 & -3 & 41 & Proximal junctional kyphosis \\
\hline Patient 13 & 78 & Female & 17 & -7 & 24 & \\
\hline Patient 14 & 38 & Female & 43 & 4 & 39 & \\
\hline
\end{tabular}

$R K$ regional kyphosis 
Materials and methods: Retrospective study with $>2$ years of follow-up that included 14 patients (mean age of 71.4 years) diagnosed with unstable thoraco-lumbar fractures with severe kyphosis who underwent surgery by posterior instrumentation with cemented screws and modified pedicle subtraction osteotomy to stabilize the spine and correct the kyphosis. The underlying principle is to shorten the spine and correct the kyphosis by exaggerating the collapse of the fracture. The osteotomy involves four steps:

1. Performance of an extensive lamino-foraminotomy.

2. Use of TLIF-type of manual mills inserted within the pedicle and $25^{\circ}$ in the axial plane until reaching complete decancellation.

3. Insertion of the mills in a more medial orientation $\left(45^{\circ}\right)$ to collapse the posterior wall. The dural sac should not be moved at any time.

4. Rupture of the lateral wall.

Pre- and postoperative clinical and radiological data, intraoperative bleeding, and rate of complications were recorded.

Results: Functional outcomes (COMI) improved; the Oswestry Disability Index and Visual Analog Scale (pain) increased in 33 and 3 points, respectively. Patient satisfaction reached 93\%. Regional kyphosis decreased to $3.79^{\circ}$. Mean hospital stay was 9.7 days. No durotomies or neurological lesions were observed. There was low blood loss $(3.1 \mathrm{~g} / \mathrm{dl})$ In comparison to similar studies. Two mechanical complications (proximal junctional kyphosis) were reported (Table 1).

Conclusions: OVF may lead to limiting deformities. The use of manual mills in the osteoporotic bone may simplify the POS technique, allowing to stabilize the spine and reduce the kyphosis without handling the dural sac. There is lower risk of neurological lesion and bleeding.

\section{ORAL COMMUNICATION 48}

\section{FRACTURES OF THE ODONTOID APOPHYSIS IN THE ELDERLY}

Authors: Blasco Smaranda, Iris Elena ${ }^{1}$; Zarcos Paredes, Irene ${ }^{2}$; Álvarez Villar, Salvador ${ }^{2}$; Gómez Rice, Alejandro²; Cobo Soriano, Javier $^{3}$; Castrillo Amores, Ángel ${ }^{4}$; Martínez Ureña, Paloma ${ }^{2}$; Gutiérrez Gómez, Juan Carlos ${ }^{2}$

Affiliations: ${ }^{1}$ Hospital Universitario La Paz, Madrid, Spain; ${ }^{2}$ Hospital Universitario Ramón and Cajal, Madrid, Spain; ${ }^{3}$ Hospital Ramón and Cajal. Hospital Ruber Internacional, Madrid, Spain; ${ }^{4}$ Hospital Central de la Defensa Gómez-Ulla, Madrid, Spain

Background and objectives: Odontoid fractures are the most common traumatic cervical spine fracture in individuals $>65$ years and the most frequent in people over 80 .

The aim of this study was to assess clinical and radiological outcomes of surgical and conservative treatment of this type of fractures in patients $>60$ years of age.

Materials and methods: Observational retrospective study that included patients $>60$ years with odontoid fracture attended in our center between January 2000 and December 2020.

The characteristics of study patients are summarized in the accompanying table.

We assessed the degree of comorbidity, type of treatment, and complications.

Based on their clinical evaluation, patients were classified as asymptomatic, and satisfactory or not satisfactory outcome.

Consolidation was assessed with X-rays and CT scans.

The ethics committee of the institution approved the study.
Results: In the group of patients who underwent conservative treatment, consolidation was achieved in $52 \%$ in comparison to $37 \%$ of individuals who underwent surgery. All non-consolidated fractures were Anderson D'Alonzo type II.

Sixty-six per cent of operated patients achieved satisfactory results and $33 \%$ not satisfactory. From the group of patients who followed conservative treatment, $4 \%$ were asymptomatic, $72 \%$ achieved satisfactory results, and $14 \%$ not satisfactory.

Of the 20 patients $>80$ years, 17 were managed conservatively (eight with radiological consolidation) and three surgically. In this age group, only one showed a clinically non-satisfactory result (with consolidated of the fracture).

Complications. In the conservative group, eight patients developed complications and five died over the first 6 months following the fracture. In the surgery group, one patient developed a complication. Conclusions: Conservative treatment seems the best option for type I and III fractures.

For type II fractures, surgery seems a good alternative for patients $>65$ years with good baseline status.

In patients with bad baseline status and $>80$ years, conservative treatment may be a good option.

\begin{tabular}{|c|c|c|}
\hline & $\begin{array}{l}\text { Conservative } \\
\text { treatment }\end{array}$ & $\begin{array}{l}\text { Surgical } \\
\text { treatment }\end{array}$ \\
\hline No patients & 29 & 8 \\
\hline \multicolumn{3}{|l|}{ Sex n $(\%)$} \\
\hline Man & $10(34.48)$ & $2(25)$ \\
\hline Woman & $19(65.52)$ & $6(75)$ \\
\hline Median age (range) & $82(62-95)$ & $\begin{array}{r}77.5 \text { years } \\
(66-90)\end{array}$ \\
\hline \multicolumn{3}{|l|}{ ASA n $(\%)$} \\
\hline II & $15(51.72)$ & $4(50)$ \\
\hline III & $12(41.38)$ & $3(37.5)$ \\
\hline IV & $2(6.9)$ & $1(12.5)$ \\
\hline Median mFI (range) & $0.18(0-0.55)$ & $0.18(0-018)$ \\
\hline$\geq 0.27 \mathrm{n}(\%)$ & $13(44.8)$ & 0 \\
\hline Median CCI (range) & $3(0-10)$ & $2.5(0-6)$ \\
\hline \multicolumn{3}{|c|}{$\begin{array}{l}\text { Mechanism of fracture } n \\
(\%)\end{array}$} \\
\hline Non-violent fall & $24(82.7)$ & $4(50)$ \\
\hline Violent fall & $2(6.9)$ & $1(12.5)$ \\
\hline Traffic accident & $2(6.9)$ & $1(12.5)$ \\
\hline Precipitation & $1(3.4 \%)$ & $1(12.5)$ \\
\hline Unknown & 0 & $1(12.5)$ \\
\hline \multicolumn{3}{|l|}{$\begin{array}{l}\text { Clinical presentation } \mathrm{n} \\
(\%)\end{array}$} \\
\hline Cervical pain & $25(86.21)$ & $7(87.5)$ \\
\hline Quadriparesis & $2(6.9)$ & $1(12.5)$ \\
\hline Asymptomatic & $2(6.9)$ & 0 \\
\hline \multicolumn{3}{|c|}{ Type of fracture $n(\%)$} \\
\hline Type I & $1(3.4)$ & 0 \\
\hline Type II & $16(55.17)$ & $7(87.5)$ \\
\hline Type III & $12(41.38)$ & $1(12.5)$ \\
\hline
\end{tabular}




\section{ORAL COMMUNICATION 49}

\section{BENEFITS OF ENHANCED RECOVERY AFTER SURGERY CARE PATHWAY IN SPINAL SURGERY}

Authors: Benito Gallo, Marina ${ }^{1}$; Cano García, Sonia ${ }^{1}$; Garzón Márquez, Francisco M. ${ }^{1}$; Rodríguez Arguisjuela, María G. ${ }^{1}$; Díaz Morfa, Margarita ${ }^{1}$; Mengis Palleck, Charles-Louis R. ${ }^{1}$; Gallego Bustos, Jesús ${ }^{1}$; Peiró García, Alejandro ${ }^{2}$; Álvarez Galovich, Luis ${ }^{1}$

Affiliations: ${ }^{1}$ Fundación Jiménez Díaz, Madrid, Spain; ${ }^{2}$ Hospital Sant Joan de Deu, Barcelona, Spain

Background and objectives: Enhanced Recovery After Surgery (ERAS) is a multimodal approach to improve patient perioperative care based on scientific evidence. Here, we report the results obtained from the introduction of the ERAS care pathway in a spine unit.

Materials and methods: Patients who underwent treatment at two different periods were selected for the study. The first treatment was before the introduction of ERAS (2015-2016) (pre-ERAS Group 1) and in the second treatment the complete ERAS program was applied (mid 2018 to mid 2020) (post-ERAS Group). Comparison of data was performed retrospectively in three subgroups: anterior cervical interbody fusion (ACIF), posterior lumbar interbody fusion (PLIF), and deformity.

Results: The pre-ERAS Group included 859 patients. It included 119 ACIFs, 663 PLIFs, and 96 deformity cases, while in the post-ERAS group there were 115 ACIFs, 549 PLIFs, and 42 deformities. No statistically significant intergroup differences were observed regarding demographic variables, comorbidities, or ASA. Mean hospital stay was significantly shorter for post-ERAS in comparison to preERAS for all subgroups. It decreased from $3.08 \pm 0.9$ a $1.6 \pm 0.6$ days in the ACDF subgroup $(p<0.01)$, from $6.9 \pm 4.8$ to $3.8 \pm 2.3$ days in the posterior fusion posterior cases $(p<0.001)$ and from $11.06 \pm 3.29$ to $8.29 \pm 3.81$ days $(p<0.001)$ in the deformity subgroup. No significant differences were found in general complications between the two study periods for ACIF (5.3\% versus $6.8 \%$, $p=0.12$ ) cases, but significantly reduced for the lumbar fusion $(15.2 \%$ versus $7.9 \%, p<0.001)$ and deformities $(23.2 \%$ versus $13.4 \%, p<0.001)$ subgroups. No differences were seen in $<30$ days readmission rates. Regarding satisfaction (COMI scale) with received medical care, it improved from $83.4 \%$ of pre-ERAS satisfied or very satisfied patients to $87.2 \%$ post-ERAS.

Conclusions: Introduction of the ERAS protocol in our center led to significant decrease of hospital stay in most patients who underwent surgical treatment and without major postoperative complications.

\section{ORAL COMMUNICATION 50}

\section{ANALYSIS REFERRAL TO A SPINE UNIT FROM PRIMARY CARE}

Authors: Blanco Blanco, Juan Francisco ${ }^{1}$; Da Casa Pérez, Carmen² Pescador Hernández, David ${ }^{1}$; Gómez Ruiz, Victoria ${ }^{1}$; Martín Moreno, Víctor Manuel ${ }^{1}$; Vega Suárez, Ángel ${ }^{3}$

Affiliations: ${ }^{1}$ Hospital Universitario de Salamanca, Salamanca; ${ }^{2}$ Instituto de Investigación Biomédica de Salamanca (IBSAL), Salamanca, Spain; ${ }^{3}$ Gerencia de Atención Primaria del Área de Salud de Salamanca, Spain

Objectives: To assess the range of referral of patients from primary care to a spinal surgery unit and assess the quality of such referrals. Background: There are two levels of care in the Spanish healthcare system: primary care and specialized care. Referral of patients to the second healthcare level depends essentially on the judgement of the primary care physician. One of the most demanded services from primary care is traumatology and orthopedic surgery.

Materials and methods: Observational, longitudinal study that included all referrals from primary care to traumatology and orthopedic surgery in a healthcare area during the first half of 2019 . We thoroughly analyzed 6,225 referrals, from which 1,494 were to the spine unit. For each referral, we collected the following data: sex, age, origin, clinical priority, reason for the referral. Quality of the referrals was assessed based on the inclusion of the following parameters: physical examination, imaging studies, pharmacological and physiotherapeutic treatment.

Results: The most frequent reasons for referral were lumbago $(26.4 \%)$, sciatica $(19.5 \%)$, cervicalgy $(6.3 \%)$, displacement of lumbar intervertebral disc without myelopathy (44\%), and scoliosis and/or idiopathic kyphoscoliosis (3.9\%); when grouped per type of pathology, $8.9 \%$ were consultations due to deformity, $85.1 \%$ degenerative, $1.3 \%$ inflammatory, and $4.8 \%$ traumatic; $0.3 \%$ were referred as urgent priority and $37.3 \%$ as preferential priority. It was possible to validate the adequacy of the priority in $63.0 \%$ of the cases. Furthermore, $6.9 \%$ of the referrals were done at the request of the patient; $48.7 \%$ of the referrals were classified as of very bad quality; $81.4 \%$ of the referrals to the spine unit did not specify physical examination signs, and in $61.1 \%$ of the cases there were no imaging tests.

Conclusions: Spinal pathology is one of the most frequent reasons for referral. Quality of the referrals can be significantly improved and may indicate a lack of training regarding spinal problems in primary care.

\section{ORAL COMMUNICATION 51}

\section{SURGICAL TREATMENT OF CERVICAL SPINE METASTASIS. FACTORS ASSOCIATED TO SURVIVAL.}

Authors: Ramírez Valencia, Manuel ${ }^{1}$; García Martínez, Cristina ${ }^{1}$; Reyes Ugalde, Juan Cristobal ${ }^{2}$; Pons Carreto, Alba $^{1}$; García de Frutos, $\mathrm{Ana}^{3}$

Affiliations: ${ }^{1}$ Hospital Vall d'Hebron, Barcelona, Spain; ${ }^{2}$ Hospital San Borja Arriarán, Santiago de Chile, Chile; ${ }^{3}$ Hospital Vall d'Hebron. Institut Universitari Dexeus, Barcelona, Spain

Background and objectives: Among spinal metastasis, the cervical type is the less frequent ( $8-20 \%$ of all cases). The aim of this work was to review our experience on surgical treatment and factors associated to survival.

Materials and methods: Retrospective study of patients who had undergone surgery for cervical metastasis between 2010 and 2018 .

Inclusion criteria: patients operated for cervical spine metastasis and follow-up to current date or death. Exclusion criteria: loss to followup.

We collected epidemiological data, Tomita and Tokuhashi scorings, ECOG, SINS, surgical technique, complications, and survival, among other information.

The SPSS package was used for statistical analysis.

Results: Thirty-two initial patients, one excluded. Mean age was 59.13 (range 15-79); women 18/31. Survival was 21.13 months (range $3-62$ ) and $77.4 \%$ of the patients died (24 cases).

The Tomita scoring adjusted to the planned values in $32.3 \%$ (10 cases) and survival was lower in $45.2 \%$ (14); the Tokuhashi scoring adjusted to $48.4 \%$ of the cases (15) and was higher in $25 \%$ (8).

Pain was the initial clinical sign in 26 cases $(83.9 \%)$; neurological signs were seen in seven cases $(22.6 \%)$.

Posterior approach was used in 15 cases $(48.4 \%)$, double in 10 $(32.3 \%)$, and posterior in five. 
Eight cases had some type of complication (25.8\%) and adjuvant treatment delivered to 17 cases $(54.8 \%)$.

In the univariate study only ECOG $(\mathrm{r}=-0.436 p=0.008)$, KPS $(\mathrm{r}=0.426$ and $p=0.009)$, received adjuvant treatment (27.06 months SD 14.6 vs. 14.08 SD $20.57 p=0.007$ ) and tumor aggressiveness (as per the growth rate) (3.3 months SD 0.5 vs. 22.27 SD 17 and $p=0.079$ ) was significantly associated with survival. The regression study showed that ECOG, KPS, and tumor growth rate had an $\mathrm{r} 2=0.327, p=0.021$.

Conclusions: Surgery in cervical spine metastasis is safe, with low rate of complications and mean survival close to one. The Tomita score tends to overestimate survival; the Tokuhashi score adjusts better with a trend to underestimate.

In our series, factors associated to survival are primary tumor aggressiveness and overall status of the patient (assessed with ECOG and KPS).

\section{ORAL COMMUNICATION 52}

\section{RISK FACTORS FOR SURGICAL SITE INFECTION AFTER INSTRUMENTED SPINAL SURGERY}

Authors: Núñez Pereira, Susana; Hernández Fernández, Alberto; Iribarren Loyarte, José Antonio; Bustinduy Odriozola, María Jesús; Larraza Maiza, Irati; Gesalaga Argote, María

Affiliation: Hospital Universitario Donostia, San Sebastián, Spain

Background: Diabetes mellitus (DM) is one of the most relevant risk factors for surgical site infections (SSI) after instrumented spinal surgery. The high weight of DM when analysing risk factors for SSI may prevent detailed study of other potentially relevant factors. The aim of this work was to assess SSI risk factors in a sample paired by DM.

Materials and methods: Retrospective case and control study. Population: patients who underwent instrumented spinal fusion in a single center between 2010 and 2019. Cases: patients with deep surgical site infection during the first year postoperative. One control per case was selected with the following matching criteria: DM, age, sex, number of instrumented segments, operated region (thoracic, lumbar...). Statistical analyses was performed with a non-parametric test (the Mann-Whitney U test), as variables did not follow a normal distribution.

Results: One thousand one hundred and seventy-eight patients, 44 deep infections (infection rate $3.7 \%$ ); five excluded due to insufficient data; 17 (43.6\%) gram positive cocci, nine (23.1\%) Cutibacterium acnes; $7 / 39(17.9 \%)$ had DM. There were no differences in matching criteria between cases and controls (Table 1). Statistically significant relationships were found between use of multiple medication, defined as the treatment with seven or more drugs of different families, penicillin allergy, and corticoid treatment (oral or inhaled) and SSI. An association trend was seen between history of previous surgeries, use of immunosuppressants (antirheumatic drugs), and having received antibiotic treatment in the 2 years before surgery, although without statistical significance. Other factors such as history of neoplasia, ASA index, tobacco use, body mass index, or hospital admissions in the 2 years before surgery were not statistically significant.

Discussion: Despite being a relatively small sample size, pairing by type of intervention (area, number of segments, and approach) and DM allows deepening in the study of other variables characteristic of the patient. Further studies are needed with a larger sample size to confirm the findings of this study.

Baseline characteristics/matching criteria

\begin{tabular}{|c|c|c|}
\hline & INFECTION & CONTROL \\
\hline Diabetes mellitus & $7(17.9 \%)$ & $7(17.9 \%)$ \\
\hline Female & $19(48.7 \%)$ & $19(48.7 \%)$ \\
\hline $\begin{array}{l}\text { Number of instrumented } \\
\text { segments }\end{array}$ & 4.1 (SD 3.8) & 3.62 (SD 3.62) \\
\hline Age & 60.28 (SD 19.8) & 60.75 (SD 19.6) \\
\hline Deformity & $8(20.5 \%)$ & $9(10.3 \%)$ \\
\hline Degenerative & $20(51.3 \%)$ & $23(59.0 \%)$ \\
\hline Fracture & $8(20.5 \%)$ & $6(15.4 \%)$ \\
\hline Tumor & $3(7.7 \%)$ & $1(2.6 \%)$ \\
\hline $\begin{array}{l}\text { Lumbar or lumbosacral } \\
\text { region }\end{array}$ & $21(53.8 \%)$ & $24(61.6 \%)$ \\
\hline $\begin{array}{l}\text { Thoracic or thoracolumbar } \\
\text { region }\end{array}$ & $14(38.5 \%)$ & $12(30.7 \%)$ \\
\hline Fixation to pelvis & $3(7.7 \%)$ & $3(7.7 \%)$ \\
\hline Posterior approach & $39(100 \%)$ & $39(100 \%)$ \\
\hline
\end{tabular}

\section{ORAL COMMUNICATION 53}

\section{EN BLOC VERTEBRECTOMY AS TREATMENT OF THORACIC AND LUMBAR SPINE TUMORS: RESULTS AFTER 9 YEARS OF EXPERIENCE.}

Authors: García-Mauriño Peñin César ${ }^{1}$; Fernández Maza, Beatriz ${ }^{2}$; Pizones Arce, Javier ${ }^{1}$; Talavera, Gloria ${ }^{1}$; Sánchez Márquez, José Miguel $^{1}$; Fernández-Baillo Gallego-Sacristana, Nicomedes ${ }^{1}$

Affiliations: ${ }^{1}$ Hospital La Paz, Madrid, Spain; ${ }^{2}$ Hospital Puerta de Hierro, Madrid, Spain

Background and objectives: Over the past years, en bloc vertebrectomy has gained popularity within the management of spine tumors.

The purpose of this study was to describe the experience of two hospitals in the treatment of thoracolumbar spine aggressive benign and malignant tumors (primary and secondary) using en bloc vertebrectomy.

Materials and methods: Retrospective study of a series of cases. We included patients with spinal primary tumors and metastasis who underwent en bloc surgery between 2011 and 2020 in two hospitals in Madrid.

We collected the following information: demographic data, tumor histological type and location, use of adjuvant therapies, data on the surgical intervention, pre- and postoperative hemoglobin levels, and achieved margins.

The Weinstein-Boriani-Biagini classification, the Tomita classification, and the modified Tokuhashi scoring were used. Follow-up data were collected.

Results: Twenty-two patients were included in the study. Two patients had aggressive benign tumors (hemangiomas), six primary malignant tumors (most frequently Ewing sarcoma), and 13 patients had metastasis (primarily breast cancer as the primary tumor). 
Patients underwent surgery by en bloc vertebrectomy following the Tomita et al. technique by posterior approach $(62 \%)$ or double approach $(38 \%)$ plus anterior approach, posterolateral or bilateral videothoracoscopy. Surgical complications occurred in $16 \%$ of the cases (intraoperative durotomy, muscle weakness, and postoperative infection). There was no implant failure in any of the cases. Mean postoperative anemization was $2.08 \mathrm{mg} / \mathrm{dl}$ of $\mathrm{Hb}$, with no intraoperative transfusion specifications in $75 \%$ of the cases. R0 margin was achieved in $60 \%$ of the cases. Mean follow-up was 30.5 months. Local recurrence was seen in one patient, and disease progression in five. Fifteen patients were still alive by the end of follow-up.

Conclusions: En bloc vertebrectomy, performed by an experienced consolidated surgical team, is an adequate treatment, despite being technically complex, for benign aggressive and malignant spine lesions in terms of local control, vital prognosis, and postoperative functioning.

\section{ORAL COMMUNICATION 54}

\section{RETROSPECTIVE ANALYSIS OF PATIENTS WITH MULTIPLE MYELOMA IN THE SPINE OPERATED FOR INSTABILITY}

Authors: Álvarez Villar, Salvador ${ }^{1}$; Zarcos Paredes, Irene ${ }^{1}$; Gómez Rice, Alejandro ${ }^{1}$; Zúñiga Gómez, Lorenzo ${ }^{2}$; Cobo Soriano, Javier ${ }^{3}$; Martínez Ureña, Paloma ${ }^{1}$; Castrillo Amores, Ángel ${ }^{4}$; Gutiérrez Gómez, Juan Carlos ${ }^{1}$

Affiliations: ${ }^{1}$ Hospital Universitario Ramón and Cajal, Madrid, Spain; ${ }^{2}$ Hospital Universitario de Getafe, Madrid, Spain; ${ }^{3}$ Hospital Ramón and Cajal. Hospital Ruber Internacional, Madrid, Spain; ${ }^{4}$ Hospital Central de la Defensa Gómez-Ulla, Madrid, Spain

Background and objectives: Multiple myeloma is a primary malignant tumor increasingly affecting the adult spine. Although myeloma of the spine is a radiosensitive lesion, it may sometimes require surgery.

The aim of this work was to assess the clinical presentation, type of surgery, complications, and survival after surgical treatment in patients with multiple myeloma who underwent surgery for instability.

Materials and methods: Retrospective study. We identified 37 patients who were operated for multiple myeloma (16 patients for instability and 21 kyphoplasties, the latter excluded from the study). The following were assessed: stability using Spinal Instability Neoplastic Score (SINS), comorbidity with the Charlson Comorbidity Index (CCI); International Staging System (ISS) for multiple myeloma and the Frankel scale.

The Kaplan-Meier method was used to estimate survival. Results: Nine women; seven men. Anatomical location: six in the cervical spine, seven in the dorsal spine, three in the lumbar spine. Quantitative variables are expressed as medians (interquartile range).

Age 63 (51-73). Follow-up period 38 months (17.8-82.8).

SINS: 11 (9.75-15.25). CCI: 5 (3-10); ISS: 2 (2-3). Five (3.25-6) instrumented levels.

Four out of 16 patients showed associated neurological symptoms (two Frankel D, one Frankel C, and one Frankel B). Three of them showed improvement in the Frankel scale after surgery.

Fifteen primary surgeries. One patient had undergone prior decompression surgery at the same level.

Anterior, posterior, and double approach were used in five, nine, and two patients, respectively. Eight patients required corpectomy of the affected level.

Complications: incidental durotomy in one patient. None of the patients required unplanned reinterventions due to complications.
Median survival was 61 months.

Conclusions: Our series of patients with multiple myeloma who underwent surgery for imbalance shows low rate of complications with a median survival of 61 months. Most patients presenting neurological symptoms improved after surgery.

\section{E-POSTER PRESENTATION 1}

\section{C1-C2 FUSION WITH ANTERIOR TRANSARTICULAR SCREWS IN ELDERLY PATIENTS WITH ODONTOID FRACTURE: A SERIES OF THREE CASES}

Authors: Tortosa Sipán, Esteban ${ }^{1}$; Domenech Fernández, Julio ${ }^{2}$; Álvarez Llanas, Alejandro ${ }^{2}$

Affiliations: ${ }^{1}$ Hospital Arnau de Vilanova-Llíria, Valencia, Spain; ${ }^{2}$ Hospital Arnau de Vilanova. Universidad Cardenal Herrera CEU, Valencia, Spain

Background: To date there are few case series reporting anterior C1$\mathrm{C} 2$ arthrodesis with transarticular screws in elderly patients with odontoid fracture.

Objectives: We present three cases of odontoid fracture (two type II and one type III) in aged patients with good functionality before the fracture. Patients, an 82-year-old woman and two 85-year-old men, fell at their home. Initial radiographic diagnosis was odontoid fracture, later confirmed by computed tomography. None showed neurological symptoms, only pain at cervical level at palpation and with movement.

Materials and methods: After initial immobilization with a Philadelphia-type collar at the emergency door and subsequent reduction and traction with halo under sedation and radiographic control, surgical stabilization of the fractures was decided.

In all cases, left Smith-Robinson approach at C4 level and intraoperative radiographic control with two $\mathrm{C}$-arm fluoroscopy, transarticular fixation following the technique described by Milan K. Sen et al. (2005) using Herbert type screws to lateral C1-C2 lateral masses and partial thread screw by compression in odontoid were used. A Philadelphia-type collar was applied immediately after surgery and patients were discharged early.

Results: During follow-up visits in our service, patients showed good clinical progression regarding pain, without neurological symptoms. Conclusions: In our experience, this is a simple, minimally invasive technique associated to few complications in comparison to Magerl's posterior arthrodesis technique, easily reproducible, and does not require particularly expensive material. Furthermore, older patients can sit up and walk promptly, facilitating the recovery process and avoiding problems such as tolerance to brace and halo use, extended bed stay, and/or potential related complications.

\section{E-POSTER PRESENTATION 2}

PATIENT WITH SEVERE DIFFUSE IDIOPATHIC SKELETAL HYPEROSTOSIS AND INFREQUENT SIMULTANEOUS OSSIFICATION OF THE POSTERIOR COMMON LONGITUDINAL LIGAMENT AND FORMATION OF ANTERIOR CERVICAL OSTEOPHYTES CAUSING DISTORTION OF THE OESOPHAGUS, DYSPHAGIA, AND COMPRESSIVE CERVICAL MYELOPATHY 
Authors: Tomé Bermejo, Félix ${ }^{1}$; Cervera Irimia, Javier ${ }^{2}$; Moreno Mateo, Fernando ${ }^{2}$; Álvarez Galovich, Luis ${ }^{3}$; Mengis Palleck, CharlesLouis R. ${ }^{3}$; Gallego Bustos, Jesús ${ }^{3}$; De la Rosa Zabala, Kelman ${ }^{2}$; Rodríguez Arguisjuela, María G. ${ }^{3}$; Garzón Márquez, Francisco M. ${ }^{3}$; Sanz Aguilera, Sylvia ${ }^{3}$; Peiró García, Alejandro ${ }^{4}$; Piñera Parrilla, Ángel R. ${ }^{5}$

Affiliations: ${ }^{1}$ Hospital Universitario Fundación Jiménez Díaz. Hospital General de Villalba, Madrid; ${ }^{2}$ Hospital General de Villalba, Madrid, Spain; ${ }^{3}$ Fundación Jiménez Díaz, Unidad de Pathology de Columna, Madrid, Spain; ${ }^{4}$ Hospital Sant Joan de Deu, Barcelona, Spain; ${ }^{5}$ Hospital Universitario de Cabueñes, Gijón, Spain

Objectives and background: Diffuse idiopathic skeletal hyperostosis (DISH) Forestier's disease is considered a non-primary underdiagnosed and mainly asymptomatic spondyloarthritis. The aetiology of DISH remains unknown and is often incidentally detected on radiographs of patients with spinal rigidity and movement restrictions. Development of anterior cervical osteophytes large enough to lead to impingement, distortion of the oesophagus, and dysphagia, accompanied by ossification of the posterior common longitudinal ligament (PCLL) leading to symptomatic cervical myelopathy rarely occur simultaneously.

Materials and methods: We present a rare case of a 58-year-old man with cervical pain, dysphagia to solids and liquids with food impaction, progressive weight loss, and bilateral hypertonia and hyperreflexia of upper extremities secondary to compressive myelopathy caused by the development of exuberant ectopic calcifications anterior and posterior to the spine secondary to DISH. Diagnosis was based on imaging studies and surgical and histopathological findings. Because cervical compression presented at levels that were still mobile, above and below the ankylosis of the cervical spine, the pathological mechanism may be considered chronic stress in the junction between the subaxial cervical and lower cervical spine, both ankylosed.

Results: The patient underwent total excision of anterior osteophytes in C3-C4-C5, C4 corpectomy, complex decompression and arthrodesis with corpectomy metal implant and bolted anterior plaque. Because of difficult airway mobility due to compromised space between the airway and anterior osteophytes, the patient suffered intraoperative esophageal rupture, and despite its immediate suture, the patient presented cervical emphysema, temporary paresis of hemilarynx, and required percutaneous endoscopic gastrostomy feeding for 1 year, until completely resolved. The Neck Disability Index improved from 32 preoperatively to 15 at the end of the followup.

Conclusions: This case illustrates that DISH, anterior osteophytes, and PCLL ossification can coexist in the same patient, causing dysphagia and cervical myelopathy. Anterior surgical decompression is effective but technically demanding and with potential complications that the surgeon must anticipate.

\section{E-POSTER PRESENTATION 3}

\section{ARACHNOIDITIS OSSIFICANS: A RARE DIAGNOSIS}

Authors: Molina Márquez, José Miguel ${ }^{1}$; Nogales López, Julio ${ }^{1}$; Tena Roig, Miguel ${ }^{2}$; Subirats Rodríguez, Laura ${ }^{1}$

Affiliations: ${ }^{1}$ Hospital Verge de la Cinta de Tortosa, Tortosa, Spain; ${ }^{2}$ Hospital San Juan de Dios, Barcelona, Spain

Objectives and background: We describe a new case of arachnoiditis ossificans, a rare entity.

Materials and methods: Fifty-four-year-old woman with no relevant medical history presented to the emergency department complaining of few days' lumbosciatalgia and bad pain control; the patient was admitted to hospital and treatment with intravenous analgesics initiated. Few days later, the patient showed symptoms of phlebitis at intravenous site, altered inflammatory and infectious analytical parameters, and increased low back pain.

Lumbar MR confirmed L4-L5 spondylodiscitis and empiric antibiotic therapy was started until the antibiogram was available.

One week after admission, there was worsening of analytical parameters and clinical symptoms with signs of cauda equina syndrome and an emergency surgery was performed: release of L4-L5 lumbar canal and posterior instrumented arthrodesis. There were no incidents over the postoperative period and the patient was discharged 2 weeks later and prescribed antibiotic therapy at home; the patient achieved complete neurological recovery with intermittent low-back discomfort.

Results: Two years after surgery, the patient returned to consultation complaining of dysesthesia and paraesthesia in legs. MR indicated signs of postsurgical arachnoiditis; lumbar CT confirmed the presence of epineural-like calcifications wrapping cauda equina roots caudally to the L4-L5 segment with a diagnosis of aracnoiditis ossificans.

Conclusions: This is an uncommon aetiology with chronic proliferative changes consisting of adhesive intrathecal osseous metaplasia accompanied in many cases by neurological alterations. Forty-seven cases have been described in the literature since 1957; however, it was only in 1971 when Kaufman and Dunsmore suggested a definition.

In most cases, the event responsible for this condition occurs years before being diagnosed. Some of the described causes are prior surgery, traumatisms, myelogram, subarachnoid haemorrhage, anaesthesia and infection, as in the case we present here.

Prognosis is variable and indication for surgery depends on the symptoms and affected segment, being more indicated at dorsal level and controversial at lumbar level.

Patients with progressive neurological symptoms require surgery to remove calcified plaques and decompress the spinal cord and nerve roots.

\section{E-POSTER PRESENTATION 4}

\section{WE HAD NOT SEEN IT BEFORE: A RETROPERITONEAL HERNIA}

Authors: García Cañas, Rafael; Rodríguez Moro, Carlos; Bernácer López, José Luis; Cobo Soriano, Javier; Areta Jiménez, Fco. Javier; Álvarez-Sala Walther, Fernando

Affiliation: Unidad de Patología Vertebral. Hospital Ruber Internacional, Madrid, Spain

Background and objectives: Retroperitoneal hernias are extremely rare lumbar wall defects. Secondary hernias can occur after previous flank surgeries, infection or trauma. There is a paucity of literature regarding lumbar incisional hernias, most of them related to lateral approaches to the spine.

Here we report a case of herniation of the retroperitoneal content into the paravertebral space following several posterior lumbar spine approaches.

Materials and methods: Presentation of a clinical case and review of the literature.

Results: Case of a 47-year-old woman, with a history of multiple low back surgeries, assessed for presenting lumbar disabling pain when at rest, refractory to conservative treatment and third step analgesic medication. Nuclear magnetic resonance revealed herniation of retroperitoneal fat towards the left paravertebral space at L3 level, associated to significant fluid collection. The patient underwent 
elective open drainage of fluid collection and the repair of transversalis fascia and the middle layer of the thoracolumbar fascia using a biological mesh derived from human extracellular matrix. There were no incidents in the postoperative period and patient showed satisfactory clinical and radiological progression.

Conclusions: Lumbar hernias can be categorized as congenital and acquired, which make up $20 \%$ and $80 \%$ of lumbar hernias, respectively. Acquired lumbar hernias can be primary or secondary. Primary acquired lumbar hernias are more common, comprising 55\% of all lumbar hernias. Risk factors for developing a primary hernia are obesity, connective tissue disease, poor nutritional status, and conditions that increase intra-abdominal pressure, as the persistent cough. Secondary lumbar hernias are either iatrogenic, traumatic, or following recurrent infection or inflammation process, and account for $25 \%$ of acquired lumbar hernias.

Most of the iatrogenic retroperitoneal hernias described in the literature have been related to injury to the retroperitoneal fascia in renal transplant surgery, retroperitoneal nephrectomies, radical cystectomy, or obtaining bone graft from the iliac crest, among others. However, hardly any cases of retroperitoneal hernias have been reported in the context of spinal surgery, and most of them are incisional hernias associated with lateral approaches to the thoracolumbar spine. Although some authors suggest that its true incidence may be underestimated, only twenty three cases of incisional hernias have been described as a consequence of a lateral approach to the spine.

Based on our findings and to our knowledge, this is the only case report of a retroperitoneal hernia as a complication of a direct posterior lumbar spinal exposure. Although the complication in this patient was extremely rare, we must emphasize the importance of an adequate surgical exposure in order to preserve the retroperitoneal and thoracolumbar fasciae as biological barriers during surgical approaches to the spine.

\section{E-POSTER PRESENTATION 5}

\section{ISCHEMIC STROKE FOLLOWING IDIOPATHIC SCOLIOSIS SURGERY IN PEDIATRIC PATIENTS}

Authors: Galán-Olleros, María ${ }^{1}$; Egea-Gámez, Rosa María²; González-Díaz, Rafael ${ }^{2}$

Affiliations: ${ }^{1}$ Hospital Clínico San Carlos, Madrid, Spain; ${ }^{2}$ Hospital Universitario Niño Jesús, Madrid, Spain

Background and objectives: Stroke in pediatric patients during idiopathic scoliosis surgery is a rare complication, but may lead to serious consequences. The aim of the present work is to present a case of cerebral ischemia of unknown etiology in a pediatric patient after idiopathic scoliosis surgery.

Materials and methods: A 12-year-old female with early onset scoliosis that had been treated with a brace since the age of six, underwent surgery to correct a $65.6^{\circ}$ Lenke $1 \mathrm{~B}$-scoliosis after a normal preoperative study with pneumological, cardiological, analytical and anesthetic assessment (ASA II). T4-L4 posterior instrumentation was performed without significant complications under total intravenous anesthesia with propofol and remifentanil. Tranexamic acid was administered, the patient remained hemodynamically stable, and was extubated to the recovery unit. Intraoperative neurophysiological monitoring showed alterations.

Results: Twelve hours after surgery she developed central left facial paresis, diplopia, and gait instability. An urgent MRI revealed an acute ischemic lesion in the right parasagittal subthalamic-mesencephalic region, for which she received anticoagulant therapy. The results of hematologic and cardiologic studies were normal and the diagnosis of "stroke of undetermined etiology" was made according 
to the CASCADE (Childhood AIS Standardized Classification and Diagnostic Evaluation) criteria. Therefore, prophylaxis was changed to antiplatelet therapy for 3 months. The patient evolved satisfactorily, with symptoms resolving after 1 week, except for occasional diplopia that subsided after 2 months and persistence of a small focus of encephalomalacia in the subthalamic-mesencephalic region on MRI. Clinical and radiological follow-up of the spine was favorable, with correction of the curve to $17.2^{\circ}$ and good coronal and sagittal balance.

Conclusions: Ischemic stroke after scoliosis surgery may occur in adult patients; however, to the best of our knowledge, there are only two other published cases involving pediatric patients (Table 1 ) associated with longer procedures and underlying pathology. Despite its low frequency, it is important to consider this potential perioperative complications after spinal surgery, due to the importance of early detection and adequate management for prognosis.

Publisher's Note Springer Nature remains neutral with regard to jurisdictional claims in published maps and institutional affiliations. 